University of Louisville

ThinkIR: The University of Louisville's Institutional Repository

$5-2012$

\title{
Building a dynamic model linking potential mercury regulations to risk to susceptible populations.
}

Caroline Biagi Chan

University of Louisville

Follow this and additional works at: https://ir.library.louisville.edu/etd

\section{Recommended Citation}

Chan, Caroline Biagi, "Building a dynamic model linking potential mercury regulations to risk to susceptible populations." (2012). Electronic Theses and Dissertations. Paper 231.

https://doi.org/10.18297/etd/231

This Doctoral Dissertation is brought to you for free and open access by ThinkIR: The University of Louisville's Institutional Repository. It has been accepted for inclusion in Electronic Theses and Dissertations by an authorized administrator of ThinkIR: The University of Louisville's Institutional Repository. This title appears here courtesy of the author, who has retained all other copyrights. For more information, please contact thinkir@louisville.edu. 


\title{
BUILDING A DYNAMIC MODEL LINKING POTENTIAL MERCURY REGULATIONS TO RISK TO SUSCEPTIBLE POPULATIONS
}

\author{
By \\ Caroline Biagi Chan \\ B.S., University of Notre Dame, 1984 \\ M.P.H., University of Louisville, 2007

\begin{abstract}
A Dissertation
Submitted to the Faculty of the

School of Public Health and Information Sciences

in Partial Fulfillment of the Requirements

for the Degree of

Doctor of Philosophy

Department of Environmental and Occupational Health Sciences

University of Louisville

Louisville, Kentucky
\end{abstract}

May 2012 


\section{BUILDING A DYNAMIC MODEL LINKING POTENTIAL MERCURY REGULATIONS TO RISK TO SUSCEPTIBLE POPULATIONS}

by

Caroline Biagi Chan

B.S., University of Notre Dame, 1984

M.P.H., University of Louisville, 2007

A Dissertation Approved on

April 3, 2012

by the following Dissertation Committee:

David Tollerud, Dissertation Director

John Myers

Robert Jacobs

Nageshwar Bhaskar

Russell Prough

John Heinbokel 


\section{ACKNOWLEDGEMENTS}

The journey to this dissertation was a long road that contained the usual detours and potholes. But it has been a thoroughly enriching and fascinating trip. Without the help of so many people, I would certainly have ended in a ditch.

First and foremost, I would like to thank Dr. Robert Jacobs, my mentor. He knew I liked to be challenged and did so constructively. His critiques and questions always pointed me in the right direction. I especially appreciate his understanding that one can succeed at academic pursuits even if it is not always the first priority in life. I would also like to thank Dr. David Tollerud, my Committee Chair. The opportunities that Dr. Tollerud has put before me have greatly expanded the breadth of my experiences. I particularly appreciate learning from his ability to bring disparate voices to an agreement. I would like to thank Dr. John Heinbokel and Dr. Jeff Potash for introducing me to systems thinking. It has given me a new and exciting way of thinking about problems. They taught me that the questions are sometimes more important than the answers. Thanks also to my other Committee Members, Drs. John Myers, Nageshwar Bhaskar, and Russell Prough, for offering their diverse perspectives. Barbara Parker has earned my utmost gratitude. Her ability to navigate the nuts and bolts has made this process so much easier and more enjoyable. Finally, I would like to thank my husband Joe and my children. Joe understood that I needed to do this more than I. His encouragement while in 
has been invaluable. My children, as always, required that I be a good role model. I could not pull off the road while they were in the car. 


\section{ABSTRACT \\ BUILDING A DYNAMIC MODEL LINKING POTENTIAL MERCURY REGULATIONS TO RISK TO SUSCEPTIBLE POPULATIONS \\ Caroline Biagi Chan}

April 3, 2012

Human exposure to mercury has been shown to cause a number of adverse health outcomes, predominantly neurological effects. The developing fetus is most susceptible, and even low levels of exposure have been shown to produce nervous system deficits. A systems approach was used to address the problem of human exposure to mercury from the consumption of contaminated fish from local waterways. Two models were developed in order to link environmental levels of mercury with human exposure. The human exposure model characterizes the disposition of mercury in the human body and fetus. The bioaccumulation model tracks the movement of mercury from water column to fish tissue. The two models were combined in order to evaluate the outcome of potential policy scenarios.

The human disposition model projects mercury concentrations in common biomarkers of exposure in response to mercury concentrations in fish. The model predicts biomarkers for fish consumption rates representing the mean, $90^{\text {th }}, 95^{\text {th }}$, and $99^{\text {th }}$ percentiles of populations of interest. 
Water quality and basin characteristics were inputs into the bioaccumulation model and fish tissue mercury the output. Mean average prediction error for calibration sites was $26 \%$ and $51 \%$ for evaluation sites. Sensitive parameters influenced the system at several points and included forested and wetlands coverage, and nutrient levels. Less sensitive parameters modified the system at only one point and included the total mercury input and the portion of the basin that is developed.

The two models were combined and the impacts of potential policies were analyzed. Evaluated policy scenarios included fish consumption advisories, emissions reductions, and watershed management strategies. Simulations indicated the characteristics of a basin combined with the unique pattern of intake rates of susceptible populations determine the risk associated with fish consumption from a given waterway. Each population had a unique pattern of biomarker response to changes in fish tissue mercury. Bioaccumulation efficiency, a result of basin characteristics, determined the responsiveness of a basin to reductions in loading. Management strategies that lowered bioaccumulation rates lessened ecosystem services to an unacceptable degree. Targeting systems with greater bioaccumulation efficiency for reductions in loading would provide the benefit of reduced contamination and greater services. 


\section{TABLE OF CONTENTS}

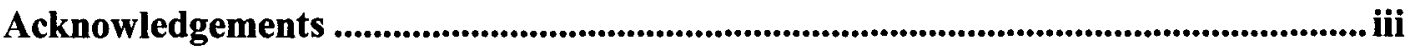

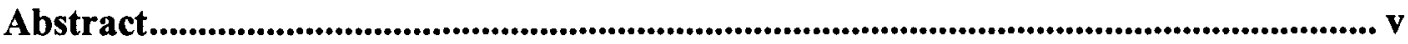

Index of Figures............................................................................................................................ ix

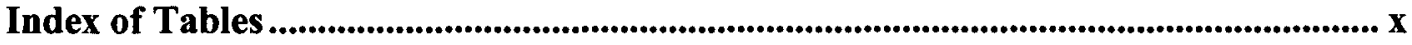

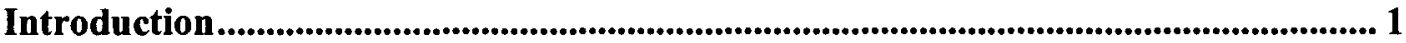

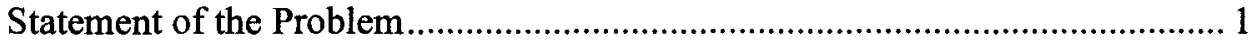

Sources of $\mathrm{Hg}$ contamination..................................................................... 2

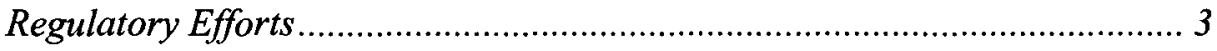

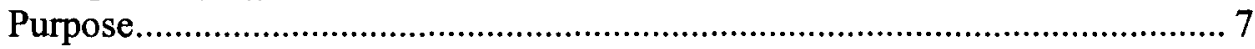

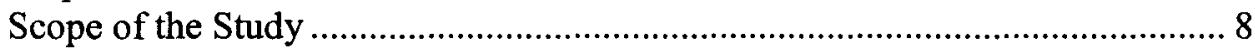

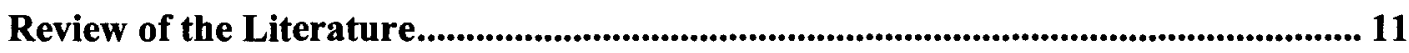

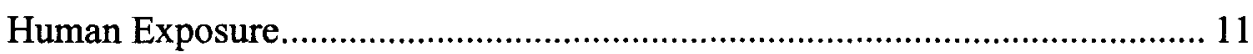

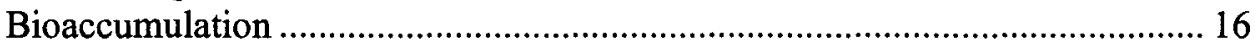

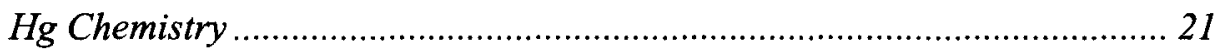

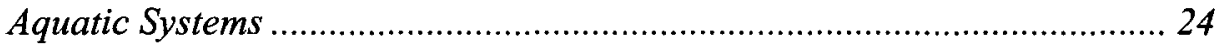

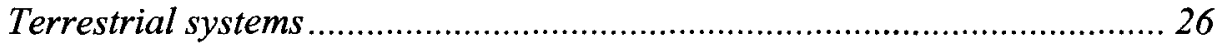

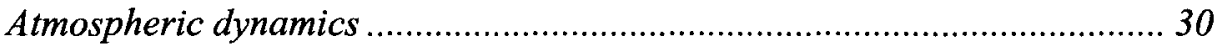

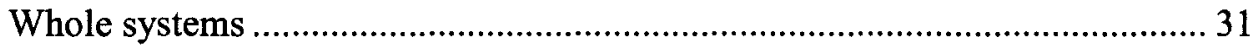

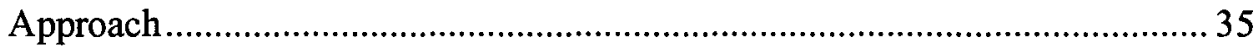

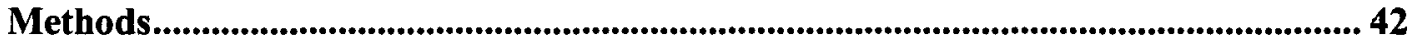

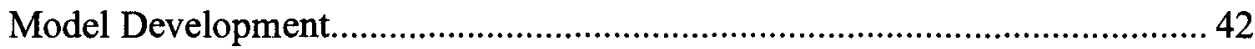

Population Biomarkers of Exposure model ........................................... 44

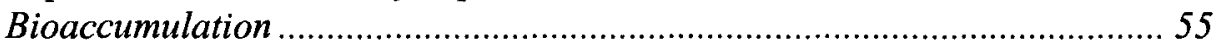

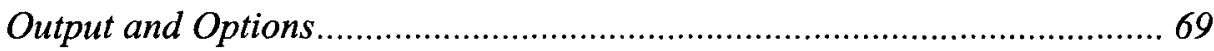

Policy and Climate Change Analyses ...................................................... 70

Fish Consumption Advisories and Population Choice ............................. 70

Emissions Reductions................................................................................ 71

Watershed Management Strategies........................................................ 71

Climate Change ................................................................................... 72

Data requirements needed for atmospheric model........................................ 72

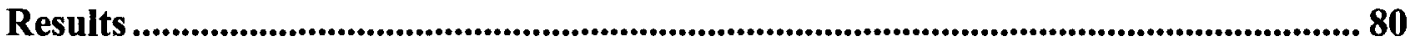

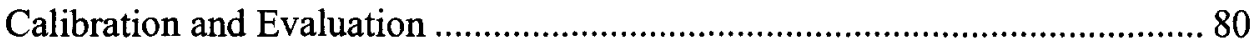




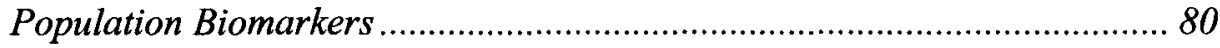

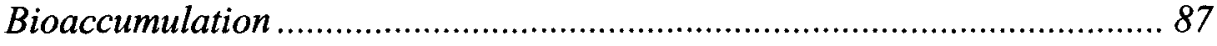

Policy and Climate Change Analyses ........................................................ 96

Fish Consumption Advisories and Population Choices............................. 96

Emissions Reductions............................................................................... 99

Watershed Management Strategies...................................................... 101

Climate Change Scenarios.................................................................. 104

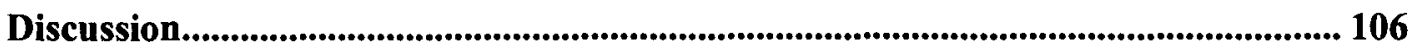

Human disposition model .................................................................... 107

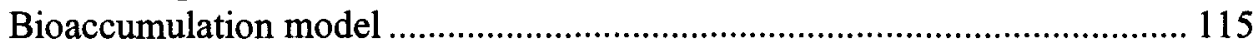

Projecting policy and climate change scenarios ......................................... 128

Fish Consumption Advisories ......................................................... 128

Emissions Reductions........................................................................ 130

Watershed Management Strategies.................................................... 132

Climate Change ..................................................................................... 134

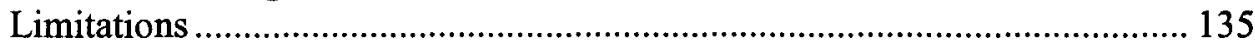

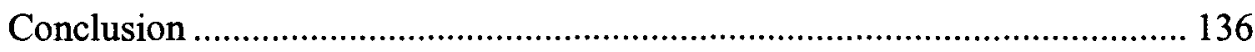

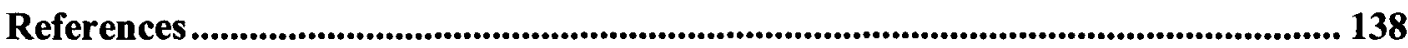

Appendix A Model Equations........................................................................................ 156

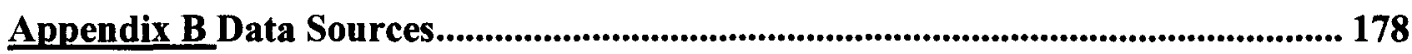

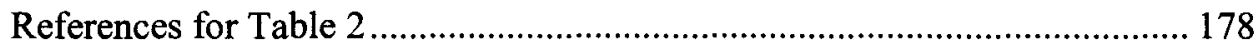

Fish Tissue Data............................................................................ 180

Appendix C Land cover maps for calibration and evaluation basins...................... 184

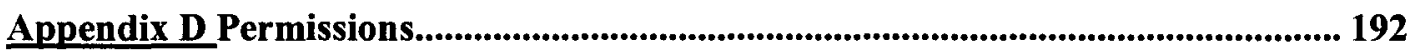

Curriculum Vitae ............................................................................................................................ 193 


\section{INDEX OF FIGURES}

Figure 1. The human disposition model. ................................................................ 46

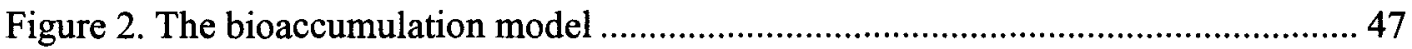

Figure 3. User interface page of combined model ....................................................... 48

Figure 4. Subroutines for the bioaccumulation model.................................................. 61

Figure 5. Simplified structure of system showing $\mathrm{Hg}$ movement from atmosphere to

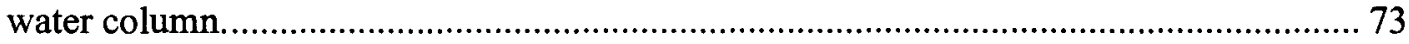

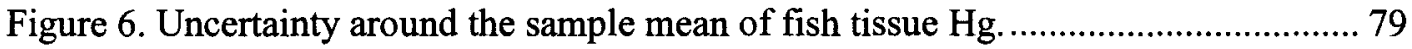

Figure 7. Comparison of model output to predicted values based on calibration sources. 84 Figure 8. Comparison of output to evaluation sources for human disposition model. ..... 85

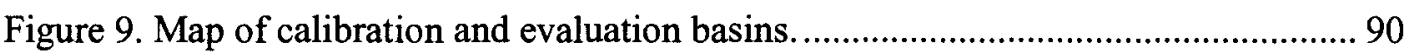

Figure 10. Sensitivity of model output to reductions in total and dissolved $\mathrm{Hg}$..............93

Figure 11. Response of the blood MeHg biomarker to changes in fish tissue

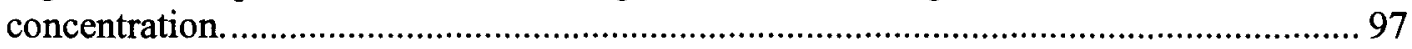

Figure 12. Impact of reduction in THg on blood MeHg biomarker. .......................... 100

Figure 13. Impact of changes in sensitive basin parameters on populations. ................ 103 


\section{INDEX OF TABLES}

Table 1. Distribution of intake rates of freshwater fish for populations......................... 50

Table 2. Data sources for bioaccumulation model.................................................67

Table 3. Model biomarker outcomes compared to predicted for various populations. .... 83

Table 4. Chi-squared analysis p-values of predicted versus observed biomarkers........... 86

Table 5. Literature sources for evaluation of human disposition model.......................... 86

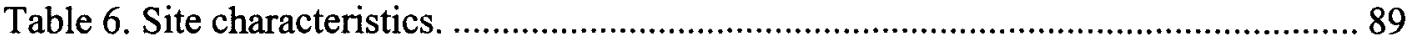

Table 7. Fish tissue $\mathrm{Hg}$ of sample mean compared to model output and calculated



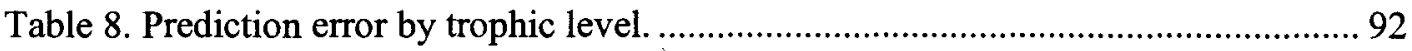

Table 9. Sensitivity analysis for bioaccumulation model........................................... 95

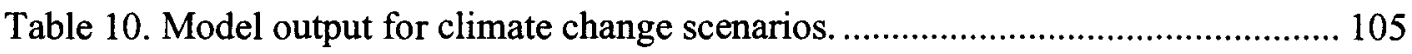




\section{CHAPTER 1}

\section{INTRODUCTION}

\section{Statement of the Problem}

Mercury $(\mathrm{Hg})$ exposure is an ongoing public health concern. Low levels of exposure can result in nervous system deficits, with developing fetuses and infants at greatest risk. The USEPA designated a reference dose of $0.1 \mu \mathrm{g} / \mathrm{kg}$-day of $\mathrm{MeHg}$ to protect the developing fetus from adverse effects from exposure. The reference dose was based on human epidemiologic studies with developmental and neuropsychological impairments in offspring of exposed mothers being the outcome of interest (USEPA 2010a). The 1999-2002 National Health and Nutrition Examination Study (NHANES) found that $6 \%$ of women of childbearing age had blood $\mathrm{Hg}$ levels indicative of exposure at or above the USEPA reference dose (CDC 2004). These results indicate that a significant portion of babies born in the US are exposed to $\mathrm{Hg}$ at levels that could potentially cause adverse effects. The largest source of exposure is through consumption of contaminated fish (USEPA 1997a, 2010b). As of 2010, 1.2 million miles, roughly $30 \%$, of the nation's rivers were out of compliance with water quality standards for fish consumption because of $\mathrm{Hg}$ contamination (USEPA 2009, 2011a). The problem is both national and global in perspective and without a clear understanding of the relationship between the environmental and physiological disposition of $\mathrm{Hg}$, effective strategies to reduce contamination have not been forthcoming. 
In order to devise a strategy to reduce risk to populations from $\mathrm{Hg}$ exposure, an understanding of the factors that influence fetal exposure and how local emissions relate to those factors is necessary.

\section{Sources of Hg contamination}

In order to reduce human exposure to $\mathrm{Hg}$, reducing $\mathrm{MeHg}$ levels in fish tissue is essential. Understanding the source of $\mathrm{Hg}$ in fish tissue, however, is complicated. $\mathrm{MeHg}$ in fish tissue begins with inorganic $\mathrm{Hg}(\mathrm{IHg})$ in the atmosphere. $\mathrm{IHg}$ is emitted by a number of processes. Natural sources of $\mathrm{IHg}$ include volcanic activity and erosion. This accounts for about one third of atmospheric $\mathrm{Hg}$. The remaining two thirds comes from anthropogenic sources (USEPA 2010c). Approximately half of this is from reemission of previously deposited $\mathrm{Hg}$, and half from new sources. Coal burning power plants are the largest source of anthropogenic emissions in the United States. Previously, medical waste and municipal waste incinerators contributed substantial amounts of $\mathrm{Hg}$ to the atmospheric pool, but regulatory controls have been placed on these sources and $\mathrm{Hg}$ emissions from incinerators have been reduced by over $90 \%$ (USEPA 2006). While some reductions in emissions from coal-fired power plants have occurred as an ancillary benefit from $\mathrm{SO}_{\mathrm{x}}$ controls, $\mathrm{Hg}$ emissions from this industry remain unregulated and are the largest source of emissions in the United States.

One form of atmospheric $\mathrm{Hg}$, divalent $\mathrm{Hg}$, associates with particulates and settles on land and waterways through dry or wet deposition. Once it reaches waterways through direct deposition or being washed into a waterway from a rain event, it settles in the sediment. Microbes then convert the $\mathrm{IHg}$ into $\mathrm{MeHg}$; a form that bioaccumulates and 
magnifies in the food chain, and can be highest in predatory fish (USEPA 2010b). In order to reduce $\mathrm{MeHg}$ concentrations in fish, lower atmospheric $\mathrm{Hg}$ levels are required.

Regulatory Efforts

The Clean Water Act (CWA) requires states to set water quality standards in order to protect specific uses of our nation's waterways. One such use is the consumption of fish. In Kentucky and many other states, fish tissue levels of $\mathrm{Hg}$ are out of compliance with standards that have been set to protect children and developing fetuses from nervous system damage. Fish consumption advisories are in effect for all of Kentucky's waterways. Statewide, women of childbearing age and children under the age of six are advised to limit consumption to one meal per week. Certain waterways with higher contamination levels have more restrictive advisories, limiting consumption, depending on fish species, to one meal per month, six meals per year, or no consumption at all (Kentucky Department of Fish and Wildlife Resources, 2010).

Waters that do not meet the designated water quality standards must have Total Maximum Daily Loads (TMDL) developed for the targeted pollutants. The purpose of the TMDL is to cap point and nonpoint source pollutants at levels that will bring the waterway into compliance for the given water quality standards. The TMDL is achieved by allocating a portion of the total allowable loading to various point and nonpoint sources, the former through a permitting system (USEPA 2008a). Nonpoint source pollutants are addressed through watershed management programs. Atmospheric deposition to aquatic systems is one form of nonpoint source pollution. Because atmospheric deposition is ubiquitous, watershed management programs cannot effectively reduce $\mathrm{Hg}$ loading in waterways. The CWA is inadequate in addressing the 
problem of $\mathrm{Hg}$ contamination in the nation's waters, but addressing $\mathrm{Hg}$ emissions through the Clean Air Act (CAA) would result in reductions in contamination of waterways.

In 1990, Congress designated $\mathrm{Hg}$ as a Hazardous Air Pollutant (HAP) as part of the 1990 amendments to the CAA. The amendment mandates that standards be promulgated for designated HAPs within ten years, and that compliance with those standards be achieved within three years of the standard being set. $\mathrm{Hg}$ compounds are one of the pollutants named as a HAP (Clean Air Act: Section 112, 1990). The outcome of this designation is that major sources of $\mathrm{Hg}$ emissions were required to be regulated with the maximum achievable control technology (MACT). The administrator dictates which form of technology is used to control emissions.

In 2000, under the Clinton administration, the USEPA was ready to begin regulating $\mathrm{Hg}$ in power plants with MACT (USEPA 2010d). It was believed that existing technology would be able to reduce $\mathrm{Hg}$ emissions from coal and gas burning power plants by $90 \%$, from 48 tons to about 5 tons per year (Shore 2003). Under the Bush administration, the regulation of $\mathrm{Hg}$ emissions by MACT was put on hold. Industries challenged the regulation of $\mathrm{Hg}$ under Section 112 of the Clean Air Act. Subsequently, the USEPA, with the backing of the president and energy industry, reconsidered the December 2000 ruling that it was "appropriate and necessary" to regulate $\mathrm{Hg}$ emissions under Section 112. Instead, the USEPA recommended that $\mathrm{Hg}$ be regulated under Section 111 which regulates pollutants by establishing "standards of performance." Unlike MACT, the technology to achieve that standard is not mandated (Clean Air Act: Section 111,1970 ). A standard of performance requires that emissions of a particular pollutant 
not exceed a certain "standard", or level, but it is up to the industry to determine how to comply with the given standard. In March of 2005, the USEPA issued the Clean Air $\mathrm{Hg}$ Rule (CAMR), a cap and trade program, to regulate Hg emissions (USEPA 2011b).

On February 8, 2008 the United States Court of Appeals for the District of Columbia vacated the rule that delisted coal-fired electric utilities from Section 112 of the CAA. The delisting was found unlawful because, under Section 112(c)(9), specific findings must be given in order to delist a source. The USEPA delisted coal-fired electric utilities without presenting any specific findings (Federal District Court of Appeals for the District of Columbia, 2008). Because the removal from Section 112 was unlawful, regulation under Section 111 was prohibited, effectively invalidating the cap and trade regulatory approach of the CAMR.

With the approach of another election in 2008, developing regulations to address $\mathrm{Hg}$ emissions from electric utilities was put on hold, resulting in 20 years of no progress on the issue at the federal level. This stalemate led several states to consider implementing their own regulations to reduce $\mathrm{Hg}$ emissions (USEPA 2012). Because $\mathrm{Hg}$ emissions into the atmosphere can travel great distances, industries have contended that regulations to limit $\mathrm{Hg}$ emissions need to also occur at the international level to benefit local waterways. Research, however, has demonstrated that local hotspots do occur near emission sources (Volz et al., 2007). Subsistence fishers and their families who live near these emission sources may be disproportionately affected. Individuals with low socioeconomic status may rely on fishing as an affordable source of protein and consequently bear a greater burden of exposure from this food source than less disadvantaged populations. Regulations at the state level would play a role in mitigating 
these hotspots, but because government entities cannot regulate outside their own borders, this piecemeal approach would still allow hotspots to occur from emissions from neighboring states.

As some states have taken action in regulating $\mathrm{Hg}$ emissions, the USEPA has again issued a rule regulating $\mathrm{Hg}$ emissions. The $\mathrm{Hg}$ and Air Toxics Standards (MATS) were promulgated in December of 2011, with utilities having until 2016 to comply. MATS set emission standards for $\mathrm{Hg}$, particulate matter as a surrogate for other toxics, and $\mathrm{HCl}$ as a surrogate for acid gases (USEPA $2011 \mathrm{c}$ ). The standard applies to existing and new sources of coal and gas fired electric utilities. While the cost of implementing these standards is estimated to be $\$ 9.6$ billion per year, health benefits are estimated at between $\$ 37$ billion and $\$ 90$ billion per year and will result in a $90 \%$ reduction in $\mathrm{Hg}$ emissions from electric utilities.

Regulation of $\mathrm{Hg}$ emissions from electric utilities at the national level is an important step in addressing the problem of human exposure to $\mathrm{Hg}$. Electric utilities account for $50 \%$ of US Hg emissions (USEPA 2011c) and will certainly reduce the problem of $\mathrm{Hg}$ hotspots. However, Seigneur et al. (2004) estimated that only $25 \%$ to $32 \%$ of total $\mathrm{Hg}$ ( $\mathrm{THg}$ ) deposition in the United States was from North American sources. Selin and Jacob (2008) reported that $20 \%$ of THg deposition in the United States was from North American sources, but also reported considerable regional variability with $60 \%$ of $\mathrm{Hg}$ wet deposition in the northeast from regional sources. While reducing $\mathrm{Hg}$ emissions from the United States' largest source will help, it will not solve the problem.

This project focuses on the problem from the perspective of a state agency seeking to address the problem of mercury exposure. The project was initially developed 
in cooperation with the Kentucky Department of Environmental Protection. The Environmental Quality Commission for the state formed a Mercury Task Force to address the problem of $\mathrm{Hg}$ contamination in fish (EPPC et al. 2006). The recommendations put forth by the Task Force included strengthened testing and analysis for $\mathrm{Hg}$ and working to correlate sampling in air, precipitation, and fish tissue. The availability of data in the various media and cooperation and interest from Kentucky Department of Environmental Protection employees made Kentucky an ideal state to focus on for model development.

\section{Purpose}

The problem to be addressed by this research was human exposure to $\mathrm{Hg}$ through the consumption of fish from local waterways. The purpose was to gain understanding in the system that moves $\mathrm{Hg}$ from emission sources, through environmental compartments, to exposure to susceptible populations. This understanding could be used to assist decision makers in the process of assessing possible policy choices in order to minimize risk to vulnerable populations. The goal of this project was to model the reduction in human risk that could be obtained by the implementation of various policy choices.

A dynamic model was constructed that evaluated the behavior of the complex system of $\mathrm{Hg}$ dynamics in the environment as well as its relationship to human exposure. Complex systems are non-linear and characterized by feedback loops (Meadows and Robinson, 1985). Because of this complexity, attempts to address these problems often lead to unexpected results. System dynamics require breaking the system down into its component parts and carefully analyzing the relationships between those parts and the factors that influence those relationships (CIESD 2006). The goal of this process is to provide new insights into the behavior of the system. In addition, dynamic models can 
identify parameters that have the greatest influence on the behavior of the system. "What if?" scenarios can be postulated to translate management decisions into human health impacts. STELLA (isee systems, Inc., Lebanon, $\mathrm{NH}$ ) was the system dynamics modeling software tool used for this project. STELLA simulates complex systems, tracks changes within the system and subsystems, and simulates the effects of interventions.

Dynamic modeling was used to predict changes in $\mathrm{Hg}$ concentration in environmental compartments and biomarkers of exposure in response to reductions in loading and manipulation of environmental variables. A systems approach allowed the assessment of "what if?" scenarios including reductions in Hg loads, changes in basin characteristics, and climate change scenarios. The model allows users to evaluate potential policy options and pose better questions to decision makers seeking to protect susceptible populations.

\section{Scope of the Study}

The complete problem of $\mathrm{Hg}$ exposure encompasses following $\mathrm{Hg}$ from emission source, through atmospheric, terrestrial, and aquatic compartments, its conversion to $\mathrm{MeHg}$ and incorporation in the aquatic food web where it bioaccumulates. Finally, human exposure occurs with the consumption of contaminated fish. This study examines the system from the point of $\mathrm{Hg}$ in the water column through population exposure. The dynamics of $\mathrm{Hg}$ in aquatic systems varies based on watershed characteristics. Simulations are defined by stream basin and population. Model output is given as fish tissue concentration of $\mathrm{Hg}$ and the distribution of biomarkers for the defined population.

The project was broken into three steps:

1. Predict the reduction in risk to susceptible populations by relating fish consumption to $\mathrm{Hg}$ levels in maternal and fetal blood based on a dynamic 
whole-body physiologically based pharmacokinetic model of hypothetical individuals with intake rates representing the $50^{\text {th }}, 90^{\text {th }}, 95^{\text {th }}$ and $99^{\text {th }}$ percentiles of the population of interest.

2. Develop a model to predict fish tissue $\mathrm{Hg}$ levels based on site-specific parameters that influence bioaccumulation.

3. Join the two models and use the complete model to investigate the impact of potential regulatory policies on the reduction in risk to identified populations.

The complex problem of human exposure to $\mathrm{Hg}$ through fish consumption was examined through a systems approach. Two parts of the problem, population exposure and bioaccumulation in fish, were examined separately. As described in step 1, the dynamics of population exposure was simulated with a dynamic model that projected biomarkers of exposure for the distribution of intake rates of specified populations given a fish tissue $\mathrm{Hg}$ concentration. The second dynamic model, as delineated by step 2 , projected fish tissue $\mathrm{Hg}$ levels for defined stream basins given water quality and watershed variables from available regulatory data. To examine the complete problem of $\mathrm{Hg}$ in the environment, a third model would be necessary to simulate the movement of $\mathrm{Hg}$ through atmospheric and terrestrial compartments and its subsequent movement to the stream. This third model was not developed due to the lack of emissions and wet deposition data, particularly at the basin level. As a tool for regulators, model usage is dependent on the availability of input data. Regulatory agencies monitor $\mathrm{Hg}$ in water more frequently than wet deposition or ambient air data, making the water column a good starting point for modeling the system.

Step threes specifies the models be combined and the impact of potential regulatory strategies be investigated. The two models were combined and output analyzed from the perspective of a regulatory decision maker charged with protecting 
populations from the adverse impacts of $\mathrm{Hg}$ exposure. Potential policy scenarios were projected with the combined model in order to examine what could be learned from a systems approach to the problem of $\mathrm{Hg}$ exposure as well as to determine what better questions should be asked in the search for solutions to this problem.

Three types of policy scenarios were considered in this evaluation: emission reduction regulations, watershed management strategies, and fish consumption advisories. Emission reduction regulations result in lower contamination levels in the environment and subsequently lowered exposure for populations that consume those fish. However, the timeframe from the implementation of the regulation to a sufficient reduction in fish tissue levels of $\mathrm{Hg}$ to protect populations may take decades (Knightes et al. 2009). The long timeframe for remediation of contamination requires that regulators look at other options to protect populations. Watershed characteristics can influence the efficiency of bioaccumulation in a basin. While regulating land cover or land use would not be a likely policy strategy for mitigating $\mathrm{Hg}$ exposure, forecasting the outcome of proposed changes in a basin may be a factor in approving or disapproving land use activities. Because mitigation of $\mathrm{Hg}$ contamination has been difficult to achieve, the combination of fish consumption advisories and educational outreach is the current policy used to protect the public from possible adverse effects from $\mathrm{Hg}$ exposure. 


\section{CHAPTER II}

\section{REVIEW OF THE LITERATURE}

\section{Human Exposure}

In order to predict the reduction in risk to susceptible populations, the disposition of $\mathrm{MeHg}$ in the human from fish consumption was modeled. Early human studies measured the disposition of $\mathrm{Hg}$ in various compartments of the body. Additionally, some studies measured the half-life of $\mathrm{Hg}$ in the blood and tissue. These studies provided the basis for the development of the physiologically based pharmacokinetic model.

A study by Miettinen, Rahola, Hattula, Rissanen, and Tillander (1971), measured the elimination of $\mathrm{MeHg}$ after volunteers consumed fish that had been fed ${ }^{203} \mathrm{Hg}$ labeled MeHg. Radioactivity was measured in feces, urine, and blood, as well as the whole body through scans to determine the disposition of MeHg. Results indicated that about $6 \%$ of the $\mathrm{Hg}$ was eliminated in the feces during the three to four days following the meal, representing about $1.9 \%$ per day, but this rate decreased thereafter. Elimination in urine was $0.01 \%$ per day. When examining whole blood, $90 \%$ of $\mathrm{MeHg}$ was found in the red blood cell component. The half life in red blood cells was $50 \pm 7$ days. The half life for the whole body was found to be $76 \pm 3$ days. This study provided important information about the absorption of $\mathrm{Hg}$ into the bloodstream and eliminated in feces.

Khershaw, Clarkson, and Dhahir (1980) built on the work of Miettinen et al. by measuring the elimination of $\mathrm{MeHg}$ from blood after volunteers ate a meal of fish with a known concentration of $\mathrm{MeHg}$. The dose of $\mathrm{MeHg}$ the volunteers received was calculated 
known concentration of $\mathrm{MeHg}$. The dose of $\mathrm{MeHg}$ the volunteers received was calculated not to exceed $20 \mu \mathrm{g} / \mathrm{kg}$ body weight, a dose expected below the maximum safety level set by the Swedish Expert Group. Frequent blood sampling occurred for the first 12 to 15 hours after the meal, with less frequent sampling as time after the meal progressed. Hair samples were taken at the start of the study and several months later. The ratio of red blood cell to plasma $\mathrm{MeHg}$ was found to be 20-22. Peak concentrations were found at about 14 hours after the meal. During the initial 20 to 30 hours after the meal, $\mathrm{MeHg}$ concentrations in blood rose rapidly, and then declined. A slower decline ensued over the next 5 months of follow-up for what was characterized as a biphasic decline. The halftime in whole blood was $52 \pm 4$ days. The study found that $5.9 \%$ of the dose remained in the blood after the initial rise and decline. For hair samples a growth rate of $1.1 \mathrm{~cm} / \mathrm{month}$ was assumed. Because $1 / 2 \mathrm{~cm}$ lengths were analyzed at a time, blood levels for each 2 week period were averaged. A limitation of this approach is that the initial high blood concentrations cannot be reflected in measuring a segment of hair. The average hair-toblood ratio was 292 . This study adds information about excretion of $\mathrm{Hg}$ into hair, a commonly used biomarker of $\mathrm{Hg}$ exposure.

To understand the effects of $\mathrm{MeHg}$ exposure to populations, a calculation of steady-state Hg levels in blood is necessary. The studies of Miettinen et al. (1971) and Khershaw et al. (1980) determined the half-lives of $\mathrm{MeHg}$ in blood and the whole body at roughly 50 days for blood and 76 days for the whole body. These values can be used to calculate a proportionality constant, $k$, which relates daily intake with blood concentration at steady state by the formula: $\mathrm{C}_{\infty}=k \mathrm{I}$, where $\mathrm{C}_{\infty}$ is blood concentration at steady state in units of $\mu \mathrm{g} / \mathrm{kg}$, I is daily intake in $\mu \mathrm{g} / \mathrm{kg}$, and $k$ is in day $/ \mathrm{kg}$ (Sherlock, 
Hislop, Newton, Topping, and Whittle, 1984). These single intake studies resulted in a proportionality constant of 0.9 day $/ \mathrm{kg}$ (Kershaw et al., 1980) and 1.0 day $/ \mathrm{kg}$ (Miettinen et al., 1971). However, several chronic exposure studies found values of $k$ that were close to 0.2 day $/ \mathrm{kg}$ (Sherlock et al., 1984). A study was designed to determine the proportionality constant based on consumption of fish with known levels of MeHg over a three month period, with blood monitoring for a further three months. Subjects were assigned to one of four groups that had varying intake rates of the fish meals, and therefore varying exposures to Hg. Exposure levels were expected to create significant increases in the blood levels of the subjects over background. Because of the 50 day half-life of $\mathrm{Hg}$ in blood, the three month exposure period was expected to bring blood $\mathrm{Hg}$ concentrations to $70 \%$ of steady state for the assigned intake rates. $\mathrm{Hg}$ levels in blood were measured before the start of exposure and at regular intervals during exposure. After adjustment for body weight, the values obtained for $k$ were found to be 0.8 days $/ \mathrm{kg}$ for all four exposure groups (Sherlock et al., 1984). These findings agree well with the single intake findings, giving confidence to the values found for clearance of $\mathrm{MeHg}$ from the blood and body, which becomes important when examining exposure to the developing fetus.

The developing fetus is most at risk for adverse effects from $\mathrm{Hg}$ exposure, with the brain being the organ of interest. Measurement of fetal exposure has most frequently been through $\mathrm{Hg}$ concentrations in cord blood. Maternal blood concentrations and measurement of $\mathrm{Hg}$ in maternal hair have also been used as surrogates (Cernichiari et al., 2007). Maternal blood and hair concentrations of $\mathrm{Hg}$ have both been shown to be highly correlated to fetal cord blood concentrations. How this relates to fetal brain exposure is unknown, especially since brain size and growth rate during fetal development changes 
with time. However, autopsies of the brains of infants who died shortly after birth have found that $\mathrm{MeHg}$ levels in maternal blood, maternal hair, infant blood, and infant brain do correlate. The authors contend that any of these biological measures give an accurate estimate of exposure to the fetal brain, and that maternal hair has the advantage that it can be used to determine past exposure levels. Because all of these biomarkers correlate with the exposure of interest, $\mathrm{Hg}$ exposure to the fetal brain, all of the markers were included in the model.

Several studies examined the ratio between maternal and cord blood and provided information for developing the model to predict fetal blood $\mathrm{Hg}$ levels. A longitudinal study examining $\mathrm{MeHg}$ in cord blood and the blood of pregnant and lactating women found cord blood correlated well with maternal blood at an average of 1.8 times maternal blood concentrations, with the $5^{\text {th }}$ and $95^{\text {th }}$ percentiles being 0.88 and 3.1 times maternal Hg concentration (Vahter et al., 2000). Maternal blood concentrations were lower at gestational week 36 and three months postpartum compared to gestational week 11. At 15 months postpartum, blood concentrations were higher than gestational week 11 . Questionnaires indicated that most women indicated a decrease in fish consumption with the pregnancy. The authors suggest that because the half-life of $\mathrm{MeHg}$ in blood is roughly two months, fetal exposures can occur from exposures prior to pregnancy. The higher cord blood $\mathrm{Hg}$ concentrations were explained partly by the comparatively higher levels of fetal hemoglobin than maternal hemoglobin resulting in the one-way transport of $\mathrm{MeHg}$ to the fetus.

Cord blood levels of $\mathrm{Hg}$ were the basis for the calculation of the USEPA reference dose, with the response of interest being neuropsychological effects in children. The dose 
was calculated by relating maternal blood $\mathrm{Hg}$ levels to intake rates of $\mathrm{Hg}$ contaminated fish, with the assumption of a 1:1 ratio between cord blood and maternal blood levels. Studies have consistently shown that cord blood levels of $\mathrm{Hg}$ are close to two times the maternal blood concentration (Bjornberg et al., 2005a; Vahter et al., 2000), so small changes in maternal blood levels may have larger effects on fetal exposure. Instead of addressing the variability between maternal and cord blood in the dose conversion, the USEPA chose to address this difference in the application of uncertainty factors (USEPA 2010a). Stern and Smith (2003) examined the cord blood: maternal blood ratio in order to determine if uncertainty from this factor can be reduced when addressing risk assessment. A meta-analysis of published studies was used to generate a central tendency estimate for this ratio as well as a coefficient of variation. Monte Carlo analysis was used to generate a distribution. Ten studies were included in the analysis with widely varying population characteristics. Weighted, based on sample size, and un-weighted Monte Carlo analyses were compared. The best fit was found for the weighted log-normal distribution for the ratio, with a mean of 1.7 and standard deviation of 0.9 (Stern and Smith, 2003).

Stern (2005) went further to do a reassessment of the USEPA's dose reconstruction by using the central tendency estimate and variability from the earlier study for the cord blood: maternal blood concentrations of $\mathrm{Hg}$. Stern was able to reduce the need to use an uncertainty factor to account for pharmacokinetic variability between maternal and cord blood, but found that his analysis resulted in a maternal ingested dose half the USEPA's value. Stern's analysis reduced the uncertainty in the conversion of cord blood $\mathrm{Hg}$ level to maternal ingested dose. The reduction in ingested dose combined with the elimination 
of one uncertainty factor suggests a reference dose that is more certain, but is essentially unchanged.

The literature provided ample information relating ingestion of contaminated fish to disposition throughout the body and to the fetus. The absorption fraction, half life in blood and tissue, and the ratio of the concentration in maternal blood to fetal blood were essential elements in developing the model. These factors were critical in predicting exposure across the distribution of intake rates.

\section{Bioaccumulation}

The exposure of interest for this study was $\mathrm{MeHg}$ from consumption of locally caught fish. In order to relate this exposure to policy choices regulating emissions, the simulation of $\mathrm{Hg}$ movement through the environment was necessary. A first step in understanding this process was to examine the movement of $\mathrm{Hg}$ through the food web to the point of human exposure. An examination of parameters that influence bioaccumulation of a food web model was undertaken to better understand the relevant issues that impact the degree of contamination in fish for a given watershed.

Hope (2003) constructed a food web model in order to relate predatory fish tissue $\mathrm{Hg}$ levels to water column $\mathrm{Hg}$ levels. The author noted that the USEPA provides a national default value for biomagnification, but local conditions influence this process, and therefore local data should be used to predict accumulation in a given food web. The Willamette River was the system of concern, and the model was constructed by detailing the species in this system and their feeding preferences. Intake for each species was calculated by noting the components of the diet, and calculating intake based on the fraction of the diet for each component. This was repeated for each trophic level. Intake 
rates, assimilation efficiency, and elimination rates were used to determine $\mathrm{Hg}$ concentrations for each organism. Hg concentrations for each species in the food web were calculated, with predatory fish tissue concentrations being the outcome of interest (Hope, 2003). The model predicted water column values that would result in the fish tissue criterion set by the USEPA being surpassed by a given percentage of predatory fish $(5 \%, 50 \%$ or $95 \%$ levels). These modeled water column values were lower than the national default value which is provided by the USEPA, confirming the value of using local data to predict biomagnification.

As primary producers at the base of food webs, the accumulation of $\mathrm{MeHg}$ in algae is a key step in the biomagnification of $\mathrm{MeHg}$ in the food web. Research into the uptake mechanism of $\mathrm{MeHg}$ into algae has produced conflicting evidence as to whether the mechanism is active or passive facilitated transport (Moye et al. 2002). A study was designed to characterize the transport of $\mathrm{MeHg}$ into algal cells. Four species of algae were chosen representing both prokaryotic and eukaryotic cells, with each species having differing cell membrane characteristics. To distinguish between active and passive transport, tests were undertaken that varied temperature, altered light regimes, introduced metabolic inhibitors, and exposed cells to radiation. Radiation treatment was used to kill cells, and has been found to affect cell membrane permeability. Decreasing exposure to light reduces photophosphorylation and would be expected to decrease active transport. Phosphorylation uncouplers decrease the production of ATP needed for active transport, and temperature changes affect enzyme activity.

Results suggested that both active transport and passive diffusion play a role in $\mathrm{MeHg}$ accumulation in algae. Uptake showed a bimodal character, exhibiting two distinct 
slopes depending on $\mathrm{MeHg}$ concentration. The authors suggest that the higher slope at lower $\mathrm{MeHg}$ concentrations represented a form of active transport. Results from the inhibitor tests showed that $\mathrm{MeHg}$ uptake is sensitive to inhibition of photophosphorylation. Differences in cells with varying surface area to volume ratios did showed that passive diffusion was not a major mechanism of $\mathrm{MeHg}$ uptake. The radiation test showed reduced uptake after exposure, suggesting an active transport mechanism. The temperature sensitivity test resulted in a linear uptake relationship, suggesting passive uptake. Another finding was that the prokaryotic species, Schizothrix, showed significantly lower $\mathrm{MeHg}$ accumulation. A eukaryotic species, Thalassiosira, also exhibited lower $\mathrm{MeHg}$ accumulation than the remaining two eukaryotic species. The lower accumulation rates found with these two species may involve the nature of their chloroplasts. Schizothrix does not contain chloroplasts and the chloroplasts in Thalassiosira are surrounded by two additional membranes. The authors suggest that chloroplast membranes may be the site of active transport. Taking into consideration the results of all tests, both active and passive transport may be involved in $\mathrm{MeHg}$ uptake by algae and further research is needed to elucidate transport mechanisms. However, the results suggest that the composition of the algal community may be a factor in determining the degree of biomagnification in a particular waterway.

Bloom dilution has been studied as a mechanism for lowered fish tissue $\mathrm{MeHg}$ levels in eutrophic systems. Bloom dilution is the concept that in eutrophic systems, a fixed amount of $\mathrm{MeHg}$ molecules is divided between greater numbers of cells than in oligotrophic or mesotrophic system. Consequently, a lower concentration per algal cell is found in eutrophic systems than in nutrient dilute systems. Pickhardt et al. (2002) 
designed a study to test this hypothesis using stable isotopes of $\mathrm{MeHg}$ and divalent $\mathrm{Hg}$. Algae were incubated in tanks with varying concentrations of nutrients. After two weeks, the stable isotopes were added. Daphnia were added 48 hours later.

As expected, algal biomass responded positively to increasing nutrient supplies. At the time of Daphnia introduction to the tanks, samples were taken and divalent and $\mathrm{MeHg}$ levels were measured in the algae. Decreasing concentrations of both forms of $\mathrm{Hg}$ were found with increasing phosphorus levels. The result of higher algal biomass and lower $\mathrm{Hg}$ per gram of algae validates the bloom dilution hypothesis.

Zooplankton $\mathrm{Hg}$ levels were measured at two and three weeks after introduction into the tanks. As expected, $\mathrm{MeHg}$ accumulation in zooplankton from the high nutrient tanks was significantly lower than in the low nutrient tanks. Divalent $\mathrm{Hg}$, however did not show a linear trend, and was found at lower concentrations than the $\mathrm{MeHg}$. The authors explain that $\mathrm{MeHg}$ is found within the algal cell cytoplasm and is readily assimilated. The divalent $\mathrm{Hg}$ is most frequently surface-bound and is not likely to be assimilated with feeding. These results strongly support the hypothesis that eutrophic status leads to lower levels of $\mathrm{Hg}$ in fish tissue through bloom dilution.

The concept of somatic growth dilution (SGD) was examined by Karimi et al. (2007). The trophic transfer of MeHg from algae to Daphnia pulex was examined in relation to the nutritive quality of the algae, Ankistrodesmus falcatus. The study hypothesized that the consumption of high quality algae would induce disproportionate growth in biomass relative to $\mathrm{MeHg}$ accumulation. Past work has shown that zooplankton grow more efficiently at higher concentrations of phosphorus relative to nitrogen or carbon. Daphnia were fed with either high quality (low C:P) or low quality (high C:P) 
algae containing radiolabeled MeHg. Results indicated that growth of Daphnia on the high quality diet was approximately 3.5 times greater than those fed the low quality algae. Conversely, the rate of ingestion was lower for those fed the high quality algae. This greater growth was a result of more mass gained per unit uptake along with a decrease in the amount of food consumed. Measurements of the $\mathrm{MeHg}$ in both groups of Daphnia found that those fed the lower quality algae had MeHg levels that were 1.3 times higher than the high quality group. The effect of SGD may be an important function of $\mathrm{MeHg}$ accumulation in food webs. The author's postulate that this difference in accumulation based on waters with higher phosphorus content may be one factor in the variation found in fish tissue levels.

In stream systems, periphyton predominate over free-floating algae. A study by Cleckner et al. (1999) showed high rates of methylation of IHg in periphyton mats. The study reported evidence that periphyton mats have active communities of sulfate reducing bacteria. Periphyton mats have redox microstructures that can enhance microbial sulfate reduction. Methylation within the periphyton mat is important because these mats form the lowest trophic level for these aquatic communities. Uptake of $\mathrm{MeHg}$ by the periphyton or bacteria within the biofilm serves as a direct path into the food web.

The literature shows that $\mathrm{THg}$ in waterways does not predict predatory fish tissue levels (Ward et al. 2010a). A number of parameters influence the degree of bioaccumulation. These include food web complexity and (Riva-Murray et al. 2011), nutrient levels (Karimi et al. 2007, Pickhardt et al. 2002, Ward et al. 2010b), and the presence of humic substances (Miskimmin et al. 1992, Ward et al. 2010a). These factors were included in the development of the food web sector of the model. 
$\mathrm{Hg}$ readily moves between compartments, and is present as three chemical species in the environment: elemental $\mathrm{Hg}$, divalent $\mathrm{Hg}$ and $\mathrm{MeHg}$. Each species behaves differently. Toxicity and fate are determined by environmental conditions and the species present. A number of physical, chemical, and biological factors influence the fate and transport of $\mathrm{Hg}$ in a given system. Ultimately, the dynamics of divalent $\mathrm{Hg}$ control the amount of $\mathrm{Hg}$ entering and concentrating in the food web (Orihel et al. 2007, Selin and Jacob 2008). An understanding of these factors was necessary in order to develop the physical environmental compartments of the model.

\section{Hg Chemistry}

Characteristics of two streams in Minnesota were compared to determine water chemistry parameters associated with $\mathrm{MeHg}$ discharge. Weekly samples were taken from April through October of 2003. A heavy rain in June resulted in a discrete episode of increased $\mathrm{MeHg}$ discharge. Dissolved oxygen (DO), temperature, $\mathrm{pH}$, total suspended solids (TSS), dissolved organic carbon (DOC), sulfate, nitrate, iron, manganese, orthophosphate, and potassium levels were measured (Balogh et al. 2004). Discharge was inversely related to alkalinity and alkalinity was used as a surrogate for discharge. A heavy rainfall event $(12 \mathrm{~cm})$ resulted in elevated concentrations of both total and $\mathrm{MeHg}$. It was postulated that higher temperatures and moist conditions prior to the rain event contributed to $\mathrm{MeHg}$ production. These peaks indicated that runoff contributed to $\mathrm{Hg}$ loading by transporting $\mathrm{MeHg}$ from areas of production, possibly wetlands, in the watershed. Minor runoff events in August and September did not result in increases in $\mathrm{Hg}$ loading. 
Other chemical parameters changed during the major runoff event in conjunction with increases of total and $\mathrm{MeHg}$. Corresponding to the peak in $\mathrm{MeHg}$, DO was found to be at a minimum and orthophosphate and manganese concentrations reached a maximum. Concentrations of DOC and $\mathrm{pH}$ also peaked, while nitrate and sulfate concentrations were at a minimum. Iron concentrations peaked a few days later. These chemical conditions indicate that $\mathrm{MeHg}$ peaked when stream water exhibited reducing conditions. The MeHg was found almost entirely in the filtered portion, indicating that it was associated with DOC. Wetlands are a major source of DOC. This suggests that the rain event washed $\mathrm{MeHg}$ into the streams from wetlands. These wetlands have been characterized as having high peat content which has been shown to result in elevated $\mathrm{MeHg}$ in porewater.

Balogh et al. (2003) monitored $\mathrm{Hg}$ levels in three rivers in Minnesota by weekly sampling over a year. THg levels were measured for all weeks. $\mathrm{MeHg}$ was recorded sporadically for the first portion of the study and then weekly. Additional measurements were taken of total suspended solids (TSS), volatile suspended solids, chlorophyll $a$ and total Kjeldahl (organic) nitrogen. THg levels were associated with TSS, and both increased after a rain event. The suspended sediments in these rivers were associated with erosion from the watershed. $\mathrm{MeHg}$ showed a statistically significant relationship with TSS although with more variability than was found with THg. MeHg levels varied over time. One episode of elevated $\mathrm{MeHg}$ corresponded with leaf fall and may have been related to this allochthonous input. When comparing levels between the three rivers, $\mathrm{MeHg}$ levels were lower in the river with less organic matter. 
Studies have consistently shown that dissolved organic matter (DOM) plays a role in lowering the bioavailability of $\mathrm{Hg}$ (II) in food webs (Ravichandran 2004). However, the composition of DOM varies from ecosystem to ecosystem making it difficult to ascertain the stoichiometric relationship between $\mathrm{Hg}(\mathrm{II})$ and DOM. A study by Haitzer, et al. (2003) examined the composition and binding of DOM from several environments and the effect of $\mathrm{pH}$ on $\mathrm{Hg}$-DOM binding, and presented a model of bidentate binding to describe the findings. The authors hypothesized that $\mathrm{Hg}(\mathrm{II})$ would bind to reactive thiol sites with the second functional binding group varying. They further hypothesized that a decrease in $\mathrm{pH}$ would decrease DOM binding.

DOM was isolated and characterized from seven sites. The conditional binding constant of the DOM, $\mathrm{K}_{\mathrm{DOM}}$, was determined for each isolate and for a range of $\mathrm{pHs}$ (from 4-7). The binding of $\mathrm{Hg}(\mathrm{II})$ to DOM was then modeled using simulated distribution ratios (the distribution between inside and outside the bag). The results found that the distribution coefficients varied for the sites by approximately one order of magnitude. The influence of $\mathrm{pH}$ showed a clear trend of decreased binding with decreasing $\mathrm{pH}$. Based on structural information from X-ray absorption fine structure spectroscopy, the authors hypothesized that $\mathrm{Hg}$ binds to a thiol and a second functional group that may be nitrogen, oxygen, or sulfur. The model predicted pKa values in the range of $8-12$ for the thiol group, and less than 10 for the second site. The expected $\mathrm{pKa}$ value for fully deprotonated binding sites was $25-35$. The model had a good fit with the experimental data. The slope of the line for the model was close to two, indicating bidentate binding. The authors conclude that the strength of binding of $\mathrm{Hg}$ (II) to DOM is consistent for different isolates, that one binding site is a thiol, and that a bidentate model fits the 
data. Interaction of $\mathrm{Hg}(\mathrm{II})$ with $\mathrm{DOM}$ is dependent on $\mathrm{pH}$, with greater binding at higher $\mathrm{pH}$.

Aquatic Systems

Two lakes with similar morphometric characteristics, Sargent and Richie, were studied in order to determine factors that contributed to higher levels of $\mathrm{MeHg}$ in northern pike in Sargent Lake (Gorski et al. 2003). Samples of water, zooplankton, benthic invertebrates from the littoral zone, and fish (yellow perch and pike) were collected. Water was analyzed for total and $\mathrm{MeHg}, \mathrm{DOC}$, pigments, and suspended particulate matter. Pigments were used to calculate abundance of algal groups. Biotic samples were analyzed for total and $\mathrm{MeHg}$. In addition, trophic level was determined by measuring $\delta^{15} \mathrm{~N}$ and $\delta^{13} \mathrm{C}$ for the various organisms. The lighter isotopes are preferentially excreted resulting in a $0.34 \%$ enrichment of $\delta^{15} \mathrm{~N}$ per trophic level and 0.1 $-0.2 \%$ increase for $\delta^{13} \mathrm{C}$. Bioaccumulation (BAF) and biomagnification factors (BMF) were calculated for the two lakes. The BAF was calculated as the concentration of $\mathrm{MeHg}$ in biota divided by the concentration in water. The BMF was the concentration in predator divided by the concentration in prey.

Sargent Lake was found to have lower levels of total and MeHg, DOC, suspended particulate matter and chlorophyll $a$. Algal abundance was not determined, but pigment analysis indicated that Sargent Lake had a greater percentage of green algae and less blue-green algae than Richie Lake. While MeHg levels were less in Sargent Lake, partitioning to particulate matter was almost twice that of Richie Lake. In addition, bioaccumulation factors for zooplankton, insects, and age-1 and adult perch were also 
about twice that of Richie Lake. Biomagnification factors were also higher for Sargent Lake for each trophic level, although the difference in BMFs was small.

The trophic structure and levels were similar in both lakes. Zooplankton in Sargent Lake accumulated higher levels of MeHg than Richie Lake. The authors suggested that better food quality (fewer blue-green algae) may have enhanced accumulation. The authors also suggested that higher levels of DOC in Richie Lake may have reduced bioavailability in that lake. Levels of $\mathrm{MeHg}$ in insects were also higher in Sargent Lake, although the differences were not significant. Differences in perch populations were only found with larger adults. Perch in Sargent Lake accumulated $66 \%$ more $\mathrm{Hg}$ after $40 \mathrm{~mm}$ of growth. This increased accumulation may account for the greater $\mathrm{Hg}$ concentration in pike for that lake. The carbon isotope has been used to determine if food sources are benthic or pelagic in nature. Both perch and pike in Richie Lake exhibited a $\delta^{13} \mathrm{C}$ signature that suggested a diet with benthic origins. The $\delta^{13} \mathrm{C}$ profile suggested that fish in Sargent Lake fed primarily on pelagic food sources. This difference in food webs may have contributed to the difference in $\mathrm{Hg}$ levels in predatory fish. The authors conclude that the factors that contributed to higher $\mathrm{Hg}$ concentrations in pike were higher bioavailability and bioaccumulation due to lower levels of DOC, higher rates of bioaccumulation and magnification in zooplankton, and higher biomagnification in perch. Differences in food origin (benthic or pelagic) may have also contributed to differences in accumulation. The authors acknowledge that more research is needed to validate their conclusions.

A similar study comparing $\mathrm{Hg}$ bioaccumulation and trophic dynamics in geographically diverse stream systems was undertaken by Chasar et al. (2009). The 
objective was to determine if bioaccumulation in predatory fish in stream systems behaved similarly to lake systems. Eight streams, both urban and non-urban, were sampled. Aquatic biota and stream water were sampled over three years. Biota were placed in three categories: invertebrates, forage fish, and predatory fish. A strong correlation was found between water column total and $\mathrm{MeHg}, \mathrm{DOC}$ and tissue concentrations in all categories of biota. The correlation was strongest for predatory fish, with $\mathrm{MeHg}$ concentration in water being the strongest predictor of predatory fish tissue levels. In comparing the $\mathrm{Hg}$ contamination in predatory fish across the range of environmental conditions, the supply of $\mathrm{MeHg}$ at the base of the food web was a stronger determinant of contamination levels than trophic position or trophic transfer efficiency. This finding is affirmed with the positive correlation found for percent wetland in the watershed, a factor that has been identified by other studies as being associated with higher levels of $\mathrm{MeHg}$ contamination.

\section{Terrestrial systems}

Several studies have examined the dynamics of $\mathrm{Hg}$ fluxes between the atmosphere and soil. An observational study by Fleck et al. (1999) examined Hg concentrations from three separate sites in surface mineral soil, forest floor, woody tissue, and 1994 and 1995 needles. The objective of the study was to determine if foliar and woody $\mathrm{Hg}$ represented internal cycling of $\mathrm{Hg}$ from soil or if it originated from atmospheric sources, signifying an additional input into the watershed. Measurements indicated that woody tissue levels differed by area, but did not differ by soil $\mathrm{Hg}$ levels. For needles, the 1994 needles had twice the concentration of the 1995 needles. Needle concentrations were not related to soil or forest floor concentrations. The authors 
concluded that $\mathrm{Hg}$ in foliage and trees comes from atmospheric sources, and should be considered inputs into the system.

Litterfall is thought to contribute to the flux of $\mathrm{Hg}$ to soils. Other sources of inputs to soil include precipitation and throughfall. Rea et al. (2002) collected foliage, soil, ambient air, and litterfall samples at two mixed hardwoods watersheds over a growing season. They found a ten-fold increase in foliar $\mathrm{Hg}$ over the growing season for all species. Soil concentrations were 5-18 times higher at one watershed; however foliar concentrations did not reflect this difference supporting the concept that foliar $\mathrm{Hg}$ is atmospheric in source. Steady accumulation in $\mathrm{Hg}$ over the growing season also suggested that leaves continuously accumulated gaseous elemental $\mathrm{Hg}$. A model of the dry depositional flux based on meteorological data and canopy characteristics found that dry depositional flux was greater than the estimated accumulation rate of $\mathrm{Hg}$. Differences in $\mathrm{Hg}$ concentrations were found between species in litterfall, possibly reflecting differing biochemical processes during nutrient reabsorption prior to leaf drop. Based on measurements, the authors conclude that litterfall acounts for about $40 \%$ of the THg flux in the watersheds studied, and that this flux represented an input of $\mathrm{Hg}$ into the system.

In addition to litterfall and precipitation, throughfall can be a source of $\mathrm{Hg}$ into terrestrial systems. Throughfall occurs when precipitation falls through a canopy and washes off dry deposited material. Rea et al. (2001) designed a study to examine the significance of dry deposition and foliar leaching of $\mathrm{Hg}$ in throughfall of hardwood forests. Measurement of net throughfall $\mathrm{Hg}$ (total throughfall $\mathrm{Hg}$ minus the concentration in precipitation) varied with the antecedent dry period. Foliar leaching of $\mathrm{Hg}$ was not supported because leaching increases with increased precipitation amount, which was not 
found in this study. The results suggest that throughfall $\mathrm{Hg}$ represented wash off of dry deposited $\mathrm{Hg}$ on leaf surfaces.

A study to quantify and determine the relative importance of litterfall to $\mathrm{Hg}$ flux, as well as to determine the influence of plant community composition on litter was undertaken by Sheehan et al. (2006). Two watersheds in Acadia National Park were examined, and vegetation communities were categorized as hardwood, softwood, mixed, or scrub. $\mathrm{Hg}$ in litterfall, throughfall, and precipitation were measured and $\mathrm{THg}$ flux was calculated for the vegetation types. The concentration of $\mathrm{Hg}$ in hardwood litterfall was lower than all other vegetation categories. Softwood litterfall had the highest mean $\mathrm{Hg}$ concentration. However, in calculating $\mathrm{Hg}$ flux, the larger mass of hardwood litterfall in the fall balanced the lower concentration resulting in similar annual estimates of $\mathrm{Hg}$ deposition in litter. The authors note that hardwood forests deposit litterfall at the end of the growing season, whereas softwood forests deposit litterfall at lower rates throughout the year. In comparing sources of $\mathrm{Hg}$ deposition, the authors found a ratio of $1: 1.5: 1.5$ for $\mathrm{Hg}$ flux, comparing precipitation to throughfall to litterfall. They note that studies that report $\mathrm{Hg}$ deposition only by measures of precipitation may be inadequate because total flux may be much greater.

Movement of $\mathrm{Hg}$ from terrestrial compartments to aquatic compartments depends on the dynamics of $\mathrm{Hg}$ in soil. Demers et al. (2007) studied the dynamics of $\mathrm{Hg}$ in decomposing litterfall and soil in deciduous and coniferous forests. Litterfall in two forest plots, one deciduous and one coniferous, was collected, and leaves were partially dried, weighed, and placed in mesh bags and subsequently redeployed, with 10 replicate bags per plot. Individual bags were removed over time, and mass, nitrogen, and $\mathrm{Hg}$ content 
were measured. Decomposition rates were determined, and net $\mathrm{Hg}$ and nitrogen flux into the decaying litter was calculated for each interval between bag collections. Throughfall was measured for a portion of the experimental period, and throughfall amount estimates were then used for the entire period, related to total precipitation. $\mathrm{Hg}$ in precipitation was estimated from a nearby MDN site. A soil core was taken and $\mathrm{Hg}$ measured in the organic horizons. Soil leachate flux was estimated from measurements of water flux. After two years of decomposition, litter mass decreased while both concentration and mass of $\mathrm{Hg}$ in the litterfall increased for both types of leaf litter, with $141 \%$ increase in deciduous litter and $128 \%$ increase in coniferous litter. However, these concentrations were still less than that of the uppermost organic horizon. The highest concentrations of $\mathrm{Hg}$ in soil were found in the horizon with intermediate decomposition of organic matter. Throughfall inputs could not account for the increase of $\mathrm{Hg}$ in the deciduous litter, although this could account for the increase in the coniferous stand. A biotic mechanism was suggested for the increasing $\mathrm{Hg}$ because of the similarity in the pattern of flux of nitrogen in the litter. A significant correlation between nitrogen and $\mathrm{Hg}$ was found for the deciduous stand, and near significance was reached for the coniferous stand. The authors suggest that fungal translocation from the organic horizons of soil may explain this increase because sequestration of metals has been attributed to fungal translocation by other studies. The soil profile showed that the $\mathrm{Hg}$ pool in the deciduous forest floor was more than twice that of the coniferous soil pool. Factors that may explain this difference are slower decomposition rates, less litterfall mass, less capture of throughfall inputs by litter, and possibly greater volatilization of throughfall inputs. The authors conclude that incorporation of $\mathrm{Hg}$ into decaying leaf litter will increase its residence time on the forest 
floor rather than allowing the movement of it through the soil profile. Retention in the top layers may slow the response of aquatic systems to decreases in atmospheric inputs by making it continually available for washout to waterways.

\section{Atmospheric dynamics}

$\mathrm{Hg}$ emissions from coal-fired power plants are the largest source of emissions in the United States (USEPA 2010e). The stack emissions from these facilities contain elemental $\mathrm{Hg}$, reactive gaseous $\mathrm{Hg}$, and particulate-bound divalent $\mathrm{Hg}$. The species composition is largely controlled by the type of coal, the operating conditions of the plant, and the presence of particulate control devices (Kellie et al., 2004). Galbreath and Zygarlicke (1996) reported that greater than $50 \%$ of $\mathrm{Hg}$ emissions in coal combustion are in the form of divalent $\mathrm{Hg}$. While this form of $\mathrm{Hg}$ is soluble and can more easily be removed by scrubbers than elemental $\mathrm{Hg}$, when emitted, it is more likely to be deposited locally or regionally.

In the atmosphere, the largest portion of $\mathrm{Hg}$ is present as elemental $\mathrm{Hg}$. This form is stable and tends to be transported great distances, as its atmospheric residence time is estimated to be $1 / 2$ to 2 years (USEPA 1997b). Oxidation of elemental $\mathrm{Hg}$ to divalent $\mathrm{Hg}$ has been shown to slowly occur in cloud water droplets. Divalent $\mathrm{Hg}$ tends to quickly associate with particulates and is hydrophilic. Divalent $\mathrm{Hg}$ deposits to land in precipitation, or may settle directly to earth through dry deposition. The atmospheric residence time for divalent $\mathrm{Hg}$ is comparatively short, hours to months, depending on the size of particle to which the divalent $\mathrm{Hg}$ is bound (USEPA 1997b). Lindberg and Stratton (1998) found that concentrations of reactive gaseous $\mathrm{Hg}$ had seasonal and daily trends, correlating with temperature and solar radiation. 


\section{Whole systems}

An inherent difficulty in designing a study that examines how $\mathrm{Hg}$ moves from the atmosphere through a catchment and eventually into a waterbody where it concentrates in the food web is the nature of how the $\mathrm{Hg}$ moves and is stored in different compartments. A whole-ecosystem study was conducted in the Experimental Lakes Area of northwestern Ontario. Two experimental approaches were undertaken in order to better understand the movement of $\mathrm{Hg}$ through different compartments and the relative importance of newly deposited $\mathrm{Hg}$ in the bioaccumulation process. An entire catchment was manipulated by the application of $\mathrm{Hg}$. The applied $\mathrm{Hg}$ consisted of different isotopes for three compartments that were expected to differ in the fate and transport of $\mathrm{Hg}$. These isotopes allowed the researchers to monitor the movement of newly deposited $\mathrm{Hg}$ and to ascertain its importance relative to ambient concentrations of $\mathrm{Hg}$ in the process of methylation and bioaccumulation in fish (Harris et al., 2007). Separate isotopes were added annually to three components of the watershed: the lake, wetland, and upland. The paper reported the results after three years of applications.

The upland and wetland spikes were applied by airplane to vegetation while the lake spike was applied by boat to the surface water. After three years of applications, the results showed that the $\mathrm{Hg}$ was still moving from the points of application to the soil or sediment where large amounts of $\mathrm{Hg}$ are stored. None of the wetland $\mathrm{Hg}$ was detected in the lake, and only a small amount of upland spike was exported to the lake, although the amount increased each year $(0.1 \%, 0.3 \%$, and $0.6 \%)$. Methylated lake $\mathrm{Hg}$ spike was found within days in the anoxic sediment. Over the three year period, increasing amounts of methylated lake spike was found in the water, sediment, and biota-including young 
of the year yellow perch. The upland spike was not found in the biota until the third year, and wetland spike was not detected during the study. The slow movement of $\mathrm{Hg}$ spike from the terrestrial zones of the catchment reflects the soil acting as a sink for $\mathrm{Hg}$. The wetland exported fairly large amounts of ambient $\mathrm{MeHg}$ to the lake, but after three years, the spike was still largely tied up in the vegetation above the water table. Wetlands with higher water tables may see more rapid movement of $\mathrm{Hg}$ from wetland to lake. The authors conclude that changes in atmospheric loading may lead to an initial rapid decline in $\mathrm{Hg}$ levels in fish from reductions in $\mathrm{Hg}$ directly deposited to the lake surface. This would be followed by a long, slow decline, perhaps over centuries, as upland and wetland soils slowly reach steady state with the atmosphere while releasing small amounts of $\mathrm{Hg}$ to waterways. This suggests that for stream systems with little direct atmospheric loading to the water surface, the time frame for declines in $\mathrm{Hg}$ levels in fish tissue from atmospheric loading will be long.

A closer look at the dynamics of newly deposited $\mathrm{Hg}$ versus older ambient $\mathrm{Hg}$ in aquatic systems was undertaken with the use of mesocosms set up in the littoral zone of a lake. Hg was applied for two years in the mesocosms, with each year using a different isotope. Monitoring of the water column, sediment, periphyton, and various biota allowed the comparison of the newly deposited $\mathrm{Hg}$ versus older $\mathrm{Hg}$ in the system. The objective was to examine how the distribution, methylation, and bioaccumulation of $\mathrm{Hg}$ changed over time (Orihel et al., 2008). The results showed the spikes moving from the water column to the sediment over time in agreement with other studies that indicate the sediments act as a sink for $\mathrm{Hg}$. Methylation of the first year $\mathrm{Hg}$ increased over time, and remained at higher concentrations in the second year than the methylation of the second 
year spike. Concentrations of $\mathrm{Hg}$ in the biota showed mixed results. In the second year, some organisms showed higher concentrations of the first year spike, some showed higher concentrations of the second year spike, and some had roughly equal concentrations. The authors grouped the organisms according to these results, and found that organisms associated with the water column with short life spans had higher concentrations of newer $\mathrm{Hg}$. Biota associated with the benthic food chain and with longer life spans had higher concentrations of the older $\mathrm{Hg}$ spike. The organisms that had roughly equal amounts of the two spikes were found to be omnivores that fed both in the water column and on benthic organisms. The authors conclude that continuing methylation of older $\mathrm{Hg}$ in the sediments will result in a slow recovery after reduction in atmospheric loading, but that $\mathrm{Hg}$ concentrations in organisms associated with short-lived pelagic organisms in the food web will decline more quickly than concentrations in organisms supported by benthic food webs. The results suggest that the rate of reduction in fish tissue concentrations of $\mathrm{Hg}$ after reductions in atmospheric loading may depend on the particular feeding preferences of the species of interest.

A number of models addressing the fate and transport of $\mathrm{Hg}$ in the environment have been described in the literature. The task of representing the movement of $\mathrm{Hg}$ in the environment is complicated by the number of environmental compartments in which $\mathrm{Hg}$ is found, and the three species of $\mathrm{Hg}$ with differing chemical characteristics. Macleod et al. (2005) addressed this complexity by constructing a mass balance model that addressed the movement of each species through the defined compartments of air, water, soil, sediment and vegetation. The model did not include a food web compartment. The model depicted transformation processes from one species and compartment into another 
species in the same compartment, as well as movement of the same species from one environmental compartment to another. The model was a regional model of the San Francisco Bay Area and included the San Francisco Bay Estuary and the Central Valley catchment. Input and concentration data were obtained from regulatory sources to estimate $\mathrm{Hg}$ species concentrations in each compartment. Confidence factors were $95 \%$ confidence intervals around a median. For parameters with a single measure, a confidence factor was estimated depending on the degree of uncertainty. Fluxes were determined by partitioning between species and compartments.

The study determined that the dynamics of $\mathrm{Hg}$ cycling in that region were controlled by divalent $\mathrm{Hg}$. This species was the most prevalent in all compartments except the atmosphere. In addition, it was found that sediment dynamics controlled $\mathrm{Hg}$ concentrations in the aquatic system. $\mathrm{Hg}$ concentrations in sediment were controlled by sediment layer mixing, depth, and sediment burial rate relative to resuspension and advection to the ocean. In this particular system, historic gold mining, a point source, resulted in substantial erosion of contaminated sediments from upstream sources. Systems with only atmospheric loading may have different drivers controlling the dynamics of mercury cycling. The mass balance approach allowed the identification of the components of the system that controlled the movement of $\mathrm{Hg}$ through the system.

A study examining the response time of fish tissue $\mathrm{Hg}$ to changes in atmospheric deposition was undertaken using ecosystem-scale fate and bioaccumulation models available from the USEPA (Knightes et al., 2009). Five separate water bodies with differing watershed and flow characteristics were modeled using appropriate available models, including Watershed Characterization System Hg Loading Model (WCS-MLM), 
Spreadsheet-based Ecological Risk Assessment for the Fate of Hg (SERAFM), Water Quality Analysis Simulation Program (WASP), and Bioaccumulation and Aquatic System Simulator (BASS). For atmospheric deposition, baseline wet and dry deposition rates were estimated using the Community Multi-scale Air Quality Model (CMAQ). To investigate temporal changes in fish tissue concentrations, a $50 \%$ reduction in atmospheric loading was input into the simulations. Results indicated that larger watersheds and longer food chains lead to a slower decline in fish tissue $\mathrm{Hg}$ levels. The results were in agreement with the study by Harris et al. (2007) that found an initial rapid decline followed by a longer slow reduction that may take from decades to centuries to reach steady state with the new loading scenario.

The literature describes many factors that influence the movement and transformation processes of $\mathrm{Hg}$ through environmental compartments. These factors were included in the model to more accurately simulate the processes that occur at the chosen sites. In addition, whole system studies and descriptions of modeled systems give information about the expected behavior of the ecosystem when an emission reduction scenario is postulated. This understanding was used during the calibration and evaluation of the model.

\section{Approach}

STELLA models are often used to simulate the interaction of various types of systems, such as interactions between population growth, economic systems, and other outcomes (e.g. health). Because STELLA allows the interactions of these different systems, it is often chosen as a tool to assess possible policy choices (Sterman, 1991). 
A model to demonstrate the effectiveness of a dynamic model in simulating the interaction of physical, chemical, and biological systems was developed by Wood and Shelley (1999). Constructed wetlands are an efficient and cost-effective treatment option for municipal wastewater. A concern is the accumulation of toxic metals in the sediments of these systems. A dynamic model was constructed to better understand the factors that control the bioavailability of metals in constructed wetlands. The model was constructed with STELLA software. The model was effective in integrating the physical, biological, and chemical processes that influence the bioavailability of metals in constructed wetlands, and identifying which factors had the greatest influence on pore water concentrations. In addition, analysis of individual metals predicted which metals would exhibit toxicity first. The model output also suggested that when constructing the wetlands, addition of sulfide may be a strategy for reducing initial toxicity and seeding with organic soils may reduce toxicity later. The study demonstrated the utility of dynamic models in understanding the factors that influence the processes of complex ecosystems.

Often, management or policy decisions about complex problems need to be made with the involvement of stakeholders with varying levels of understanding. STELLA, as a system dynamics tool, has been shown to be helpful in involving stakeholders in the process of exploring various policy options and aiding in the understanding of sometimes unexpected results. Water managers in Las Vegas, NV were faced with the complex problem of a decreasing water supply and an increasing population (Stave, 2003). Only two basic strategies, or a combination of the two, could be applied to address the problem: decrease consumption (conserve) or increase supply (find more). Because 
finding new sources of water was not a likely solution, the involvement of the community and its support of a chosen strategy was seen as essential to the success of implementing any management plan.

A STELLA model was built that simulated the movement of water from Lake Mead through distribution and consumption in Las Vegas, through the wastewater treatment system, and back into Lake Mead. Losses to the system were through outdoor use and evapotranspiration. Parameters that influenced the system were population size, hotel use, per capita demand, and total water supply. Because treated wastewater is returned to Lake Mead upstream from the water intake, this flow represents a credit to the system. For community involvement, resource managers conducted workshops with stakeholders using the constructed model. The model was explained and the pathway from Lake Mead through distribution and use to treatment and back to Lake Mead was shown. Participants were told the goal was to increase the time before demand became greater than supply. Workshop attendees suggested various parameters to represent policy decisions. Suggested plans included increasing supply, making hotels conserve more, reducing indoor residential water use, reducing outdoor residential water use, slowing population growth, and combining strategies. The strategy that stimulated the most discussion was that increasing indoor water use increased supply because it returned water to the system. Participants found that despite the lavishness of some of the hotel water features, conservation by hotels had a minimal effect on supply, but reduction of residential outdoor water use was an effective conservation strategy. The study demonstrated the effectiveness of dynamic modeling as a tool for communication and stakeholder involvement when devising strategies to address complex problems. 
Literature examples show the effectiveness of using dynamic models to simulate the interaction between various types of systems. In addition, STELLA models have been shown to be effective in determining policy choices. As a software modeling tool, STELLA has shown the ability to facilitate communication between the decision makers and stakeholders. The purpose of this study was to test the ability of the model to effectively simulate the complex problem that links $\mathrm{Hg}$ in stream systems to risk to susceptible populations in order to assess possible policy choices.

The literature contains many examples of addressing the individual parts of $\mathrm{Hg}$ movement from emissions to human exposure. Models of the disposition of $\mathrm{Hg}$ in humans, biomagnification through food webs, fate and transport through environmental compartments, and atmospheric transport from emissions to deposition are well represented. However, models that connect human exposure to global, regional, and local sources of emissions or translate the impact of policy decisions to changes in health outcomes to human populations are lacking. In addition, models in the literature are predominantly mass balance, steady state models. While these models may be able to predict final concentrations of $\mathrm{Hg}$ in a given environmental compartment, they cannot predict the time frame for reaching steady state. Dynamic models can quantify changes that occur and give the time frame for those changes.

A model is constructed to simulate the behavior of real systems as a means to better understand or predict possible outcomes of various scenarios. Because real systems are complex and contain a multitude of variations, each model is a simplification and can never be completely accurate. George E. P. Box expressed this judgment succinctly by 
stating, "Essentially, all models are wrong, but some are useful" (Box and Draper, 1987).

In order to determine the usefulness of a model, a careful examination of its purpose and its ability to adequately meet that purpose are necessary. In determining if a model is adequate, it is necessary to examine the uncertainty associated with the model and make a judgment about whether the uncertainty associated with the model renders the information the model provides unreliable for the purpose for which the model is employed.

Sterman (1991) discussed the importance of a clear purpose in model construction. A useful model addresses a specific problem. The purpose of the model provides the criterion to simplify and set boundaries for the exercise. If an entire system is modeled without any simplification, it would not provide any more clarity than the real system itself. While not the only type of model, simulation models, like the model in this project, attempt to mimic real systems. If the structure of the system is adequately represented, conditions can be imposed upon the system and the resulting behavior in the system can be used for foresight and policy decisions. Sterman pointed out that foresight differs from point predictions in that foresight anticipates the behavior of the system. For the purpose of making policy decisions, point predictions have no advantage over broad, qualitative knowledge, making the effort expended to make precise predictions wasted.

Both uncertainty and variability affect the range of the confidence interval around model output (McColl et al. 2000). Variability refers to the natural randomness that is inherent in a system. For example, in environmental systems, temperature varies throughout each day, throughout the year, and from year to year. Variability cannot be substantially reduced with more or better data. The ability to accurately represent 
temperature in a model is limited by the random variability of the parameter. Uncertainty, however, refers to inaccuracies due to a lack of knowledge. Uncertainty can be reduced by collection of more or better data, but frequently at substantial cost. It can be further characterized as model uncertainty or parameter uncertainty. Model uncertainty is the lack of knowledge within the structure and representations in a model. This could be reflected in an oversimplification of model structure or the use of an inaccurate equation to represent a relationship between two parts of the model. Parameter uncertainty is lack of knowledge about the numerical values that represent variables in the model. Some variables are difficult to measure, while some may be measured with bias.

The purpose of a model establishes the boundaries or precision needed. Precise simulation of complex environmental problems would require an enormous effort in data collection that would still result in a wide range of possible outcomes because of natural variability. However, regulatory decisions to address these problems can reasonably be made with a comprehensive understanding of how the system in question behaves in response to imposed changes. The purpose of this project was to gain understanding in the system that moves $\mathrm{Hg}$ from emission sources, through environmental compartments, to exposure to susceptible populations. This understanding can be used to assist decision makers in the process of evaluating possible policy choices in order to minimize risk to the most vulnerable. The usefulness of this project is not in how precisely it can predict fish tissue $\mathrm{Hg}$ levels or the decrease in risk to susceptible populations at some time in the future; its usefulness comes from the foresight gained by better understanding how the system responds to various regulatory scenarios. 
The finished model can make the connection between policy choices and human health outcomes related to global, regional, and local sources of $\mathrm{Hg}$ emissions. The dynamic model quantifies changes that occur and gives the time frame for those changes. By using a systems thinking approach and constructing a dynamic model, the project can assist regulatory decision makers in the process of assessing possible policy choices in order to minimize risk to the most vulnerable, giving decision makers the foresight needed to make informed policy choices. 


\section{CHAPTER III}

\section{METHODS}

\section{Model Development}

The Hg model was completed in three steps. The first step, shown in Figure 1, was the development of a model to simulate the disposition of $\mathrm{Hg}$ in the human body to project common biomarkers of exposure. The distribution of intake rates for defined populations was simulated in order to forecast the pattern of biomarkers for that population. The second step, shown in Figure 2, was the development of model to depict the movement of $\mathrm{Hg}$ from the water column to bioaccumulation in fish for a user-defined stream system. For the third step, the two models were joined and the impact of locally caught fish on susceptible populations was simulated. A discussion of the data that would be needed to develop the third portion of the system-from atmosphere through terrestrial compartments to the stream--is found at the end of this chapter.

The model was developed using STELLA version 9.0 .3 (isee systems, Lebanon, $\mathrm{NH})$. STELLA is an icon-based modeling program that graphically represents components of systems and how they interact (isee systems 2010). In the model, stocks, shown as rectangles, represent compartments in which $\mathrm{Hg}$ accumulates, and flows, the arrows, show the movement of $\mathrm{Hg}$ from one compartment to another or into or out of the system. Each flow is controlled by an equation that can be impacted by multiple variables. Equations can be found in Appendix A. These variables are represented by 
circles in the model and are called converters. The model uses a monthly time scale with a 100-year run and a time step of 0.25 . Euler's method was used for integration.

Calibration involves refinement of model parameters to effectively simulate actual measured environments. Evaluation of the model occurs when the calibrated model effectively predicts measurements from another data set (Cowan et al. 1995). According to Forrester and Senge (1980), evaluation is the process of building confidence in the usefulness of the model. They also assert that models that respond to extreme conditions in an expected manner typically have improved outcomes when using more typical values. Calibration and evaluation data sets for the human disposition model were taken from literature sources. For the environmental compartments, seven calibration and seven evaluation sites with available regulatory data were chosen. The model was developed and calibrated using stream basins from the state of Kentucky. To evaluate the model and to test its general utility for other regions, stream basins from outside of Kentucky but within the greater Ohio River Valley were used. Seven evaluation sites from the surrounding region were chosen based on availability of data.

The structure of the modeled system controls the dynamics of storage and movement through the human system. Initial values for all stocks, equations for the flows, and values or equations for converters are given in Appendix A.

The final step was projection, or testing the impact of mitigation policies. Options to perturb certain parameters were added in order to project the effects of possible regulatory or watershed management strategies. Sensitivity analysis of the bioaccumulation model found the most sensitive input parameters were nutrient loads and the fraction of the watershed that were forested or in wetlands. These three variables were 
modified within their plausible range to examine potential watershed management strategies. Total Hg input was perturbed for potential regulatory strategies. In order to modify a variable, the user selects the "perturb variable" input and then adjusts the corresponding slider to the desired value. For the variables that are input into the model as monthly means (THg input and nutrients), the value that is set on the slider is input for each month, eliminating any seasonal variations that may naturally occur. This final step asks what impact a change in policy will have on human exposure. Relevant questions to be answered were: what reduction in loading is necessary to reduce fish tissue concentrations to levels that reduce the risk to susceptible populations? How do watershed characteristics impact bioaccumulation efficiency? How responsive will a defined basin be to reductions in $\mathrm{Hg}$ loading?

\section{Population Biomarkers of Exposure model}

The user chooses the population to be modeled on the interface page of the model (Figure 3). The distribution of intake rates is represented as an array in the model, so that biomarker values are calculated for the mean, $90^{\text {th }}, 95^{\text {th }}$, and $99^{\text {th }}$ percentiles for the chosen population. These percentiles were chosen to give decision makers some flexibility in choosing a level of protection for populations. Intake rates and population descriptions are given in Table 1. During a model run, graphical output is produced on the interface page for the three biomarkers: blood $\mathrm{MeHg}$, hair THg, and fetal blood $\mathrm{MeHg}$.

Intake rates for populations of interest were taken from the literature. The Exposure Factors Handbook provided the intake rates for all but two of the populations modeled, and gave ingestion of freshwater fish in g/day (USEPA and NCEA 1997). The 
two exceptions were the Anglers 2 population and the Subsistence Fishers 1 population. The Anglers 2 intake rates were taken from Connelly et al. (1996) and describe the consumption patterns of Lake Ontario sports fishers. The Subsistence Fishers 1 intake rates were calculated from summary statistics given in Burger et al. (1999) and represent a rural southern subsistence population. While several populations were described in the paper, the distribution of intake rates used in this study was calculated for the population with income under $\$ 20,000$. The standard error was used as the variance parameter instead of the standard deviation in the calculation of the lognormal distribution to give a more accurate estimate of fish ingestion. 


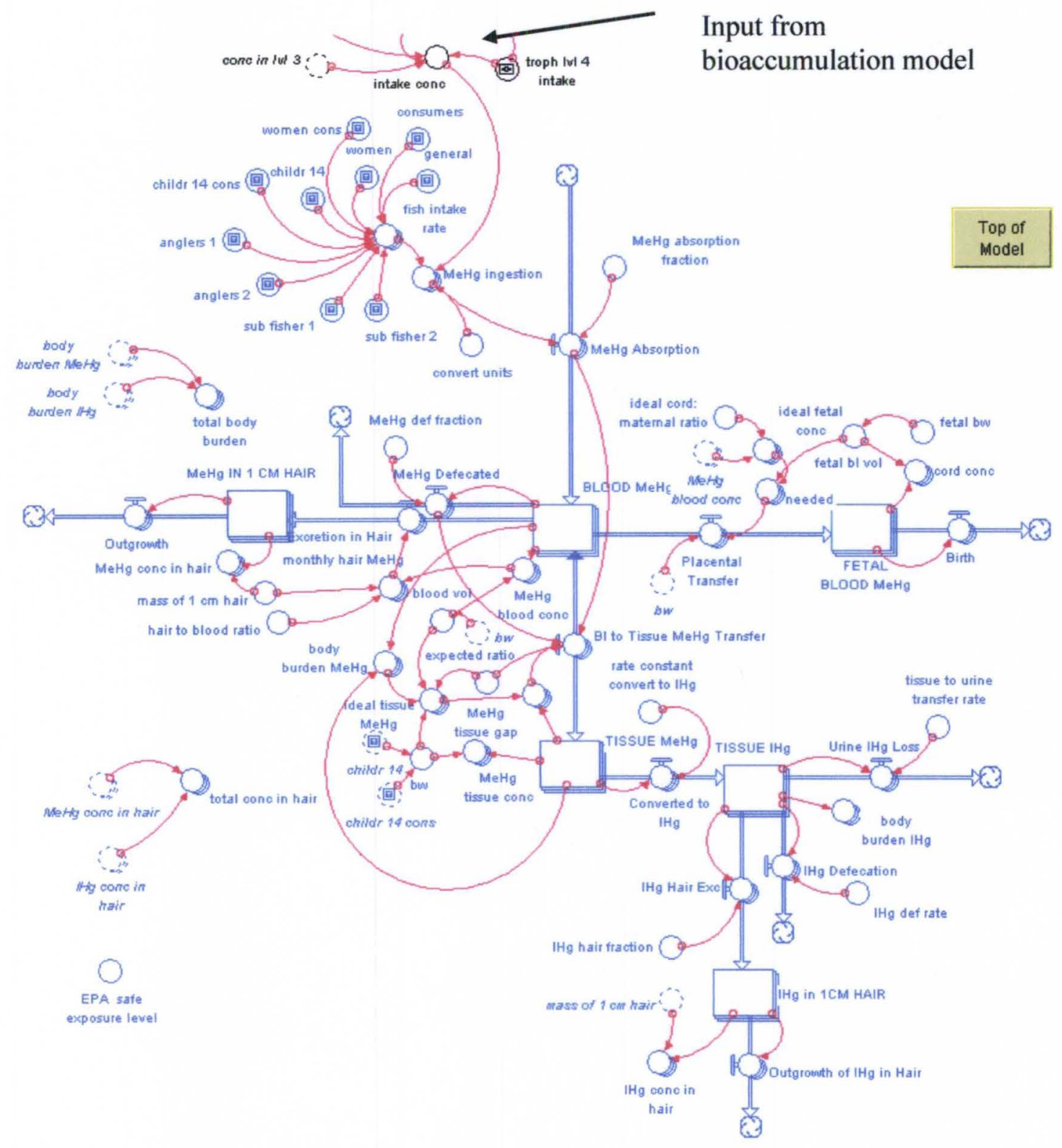

Figure 1. The human disposition model determines the distribution of biomarkers of exposure of selected populations. 
Figure 2. The bioaccumulation model directly links to the human disposition model through the intake concentration converter.

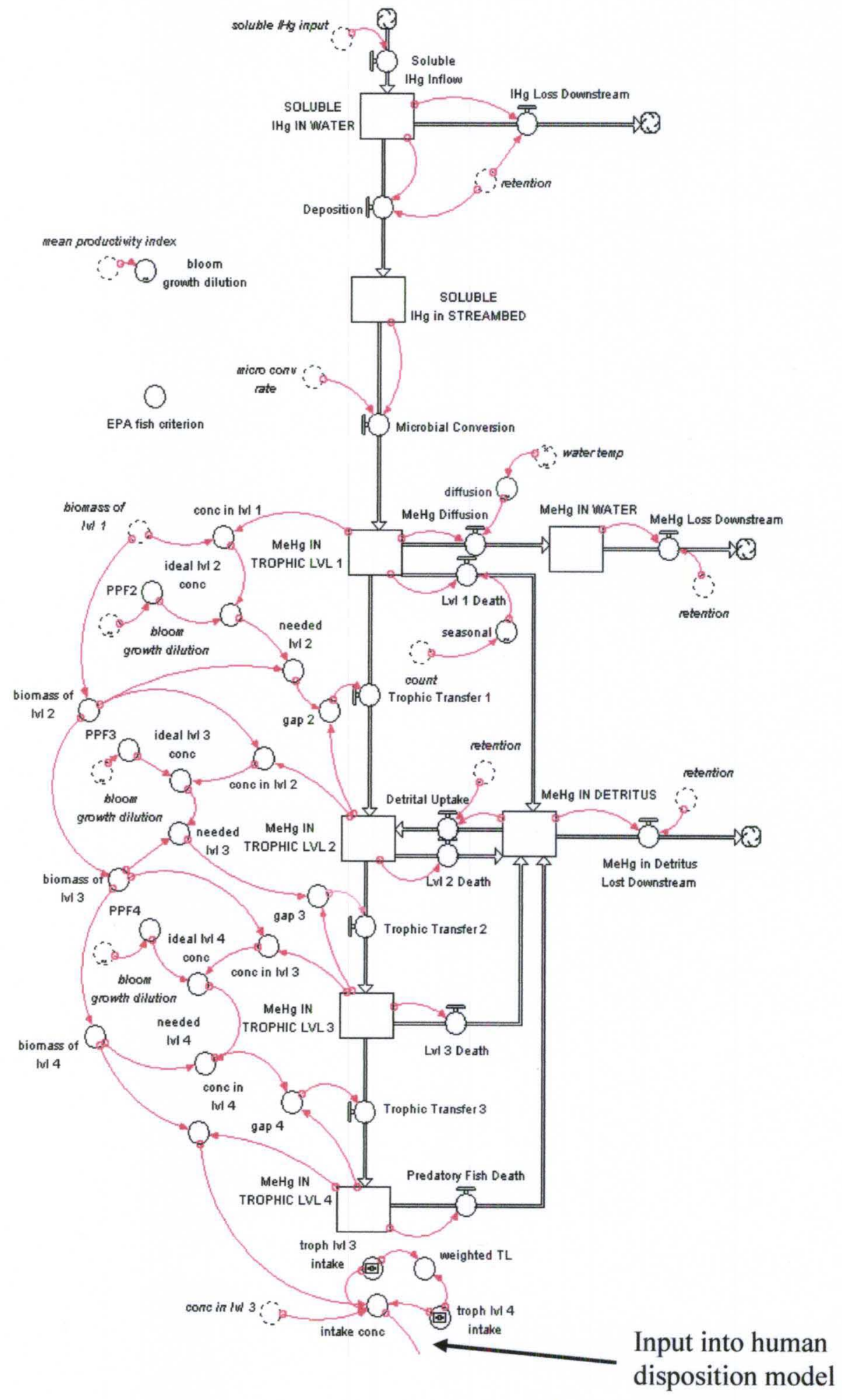


Figure 3. User input and model output are given on the interface page. User inputs include population choice, the mean trophic level the population consumes, and the option to perturb basin characteristics. Output includes fish tissue Hg level for the chosen trophic level and the distribution of biomarkers of exposure for the chosen population.

Perturb basin characteristics

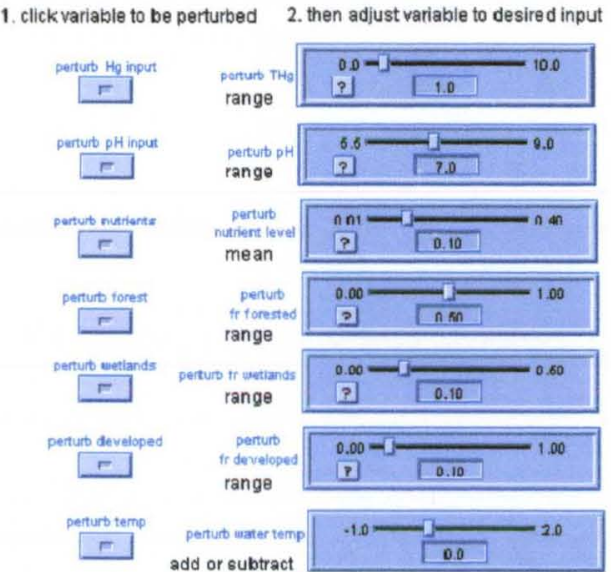

$-1.0-\frac{10}{0.0}$

\section{Trophic Level Intake for} chosen population

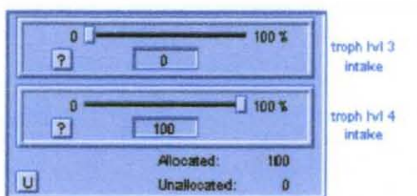

Adjust the Intake raction to simulate the variety of fish a population cons umes.

determine the mean trop

the silders accordingly. Defautt is trophic

the silders accordingly. Defaut is trophic
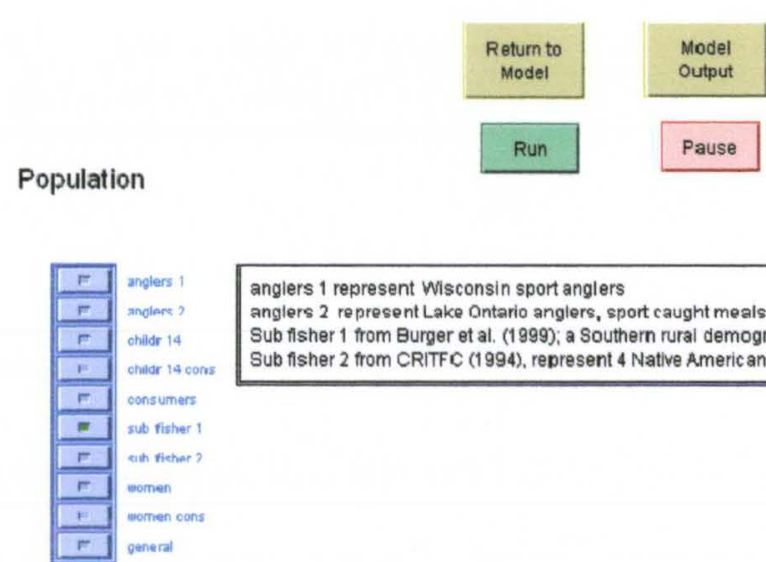

anglers 1 represent Wisconsin sport anglers

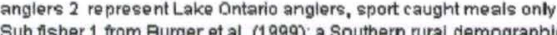
Sub fisher 2 from CRITFC (1994), represent 4 Native Americ an tribes in Washington

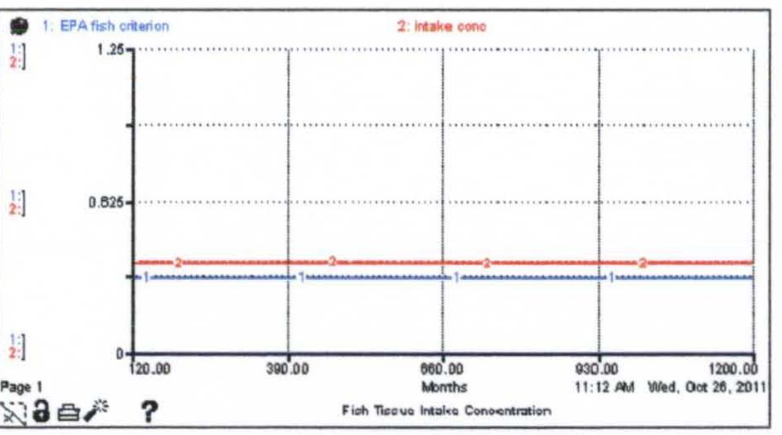

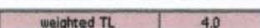


Figure 3, continued.

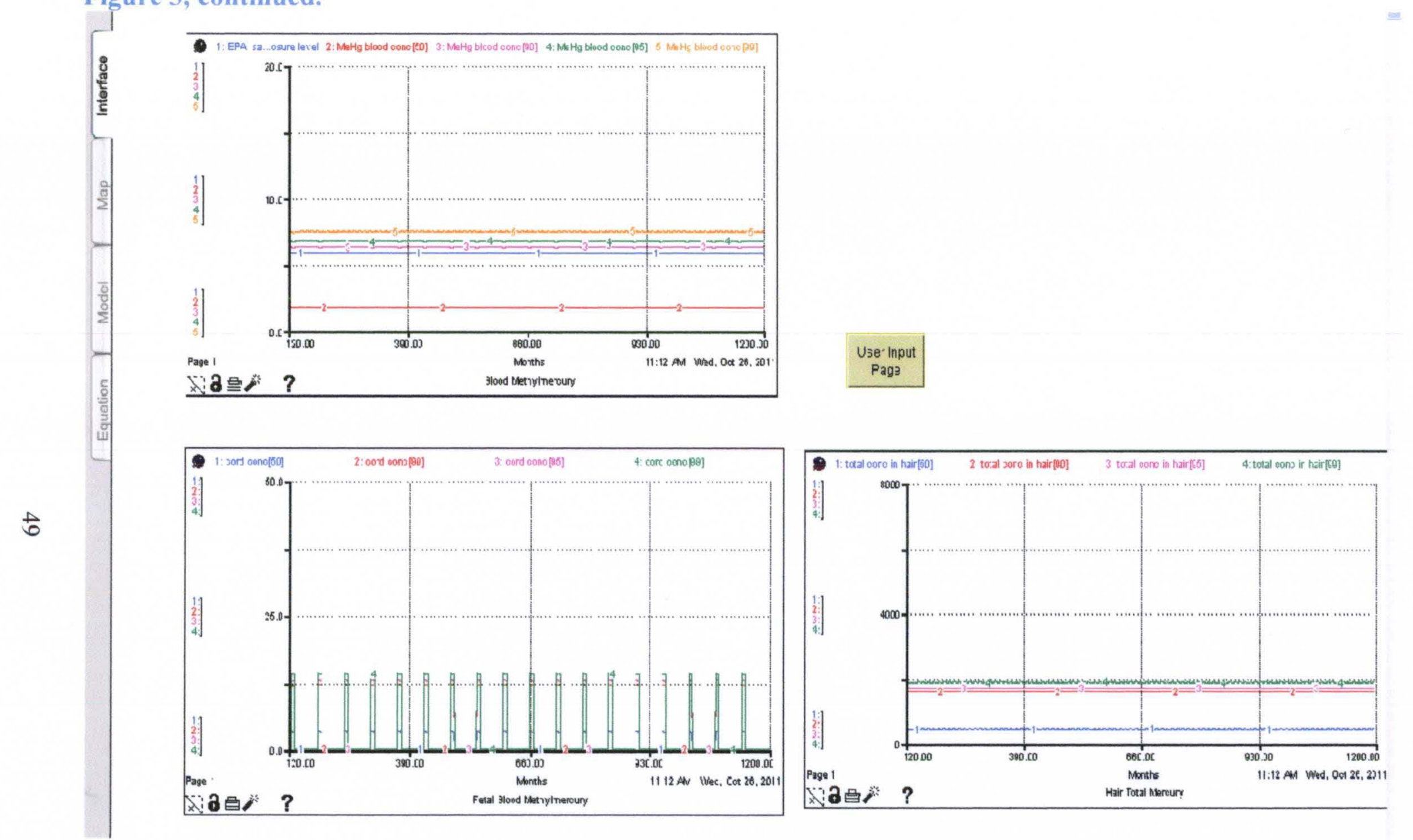


Table 1. Distribution of intake rates of freshwater fish for populations in $\mathrm{g} / \mathrm{day}$.

\begin{tabular}{|l|r|r|r|r|r|l|}
\hline \multirow{2}{*}{ Population } & \multicolumn{4}{|c|}{ Percentile } & \multirow{2}{*}{ Source* } & \multicolumn{1}{c|}{ Description } \\
\cline { 2 - 6 } & Mean & \multicolumn{1}{|c|}{90} & \multicolumn{1}{|c|}{95} & \multicolumn{1}{|c|}{99} & & \\
\hline General & 4.7 & 12.6 & 32.2 & 82.5 & 1 & US population \\
Consumers only & 68 & 170.8 & 224.8 & 374.7 & 1 & US population that consumes fish \\
Women (15-44) & 5.3 & 10.9 & 28.8 & 70.9 & 1 & All women of childbearing age \\
Women (15-44) Consumers & 61.4 & 148.8 & 185.4 & 363.6 & 1 & Women of childbearing age who consume fish \\
Children (0-14) & 1.9 & 1.3 & 13.9 & 40.8 & 1 & Children ages 0 to 14 \\
Children (0-14) Consumers & 45.7 & 108.4 & 136.2 & 214.6 & 1 & Children ages 0 to 14 who consume fish \\
Anglers 1 & 7.4 & 20.6 & 24.6 & 41.1 & 1 & Wisconsin sport anglers \\
Anglers 2 & 17.9 & 13.2 & 17.9 & 39.8 & 2 & Lake Ontario sport fishers \\
Subsistence Fishers 1 & 55.5 & 150 & 200 & 338 & 3 & Subsistence fishers on Savannah River \\
Subsistence Fishers 2 & 58.7 & 110 & 170 & 389 & 1 & 4 Native American tribes in Washington State \\
\hline
\end{tabular}

* Source

1. NCEA (1997) Exposure Factors Handbook

2. Connelly et al. (1996)

3. Burger et al. (1998) 
$\mathrm{MeHg}$ ingestion is calculated from the fish tissue concentration and the distribution of intake rates of the population selected by the user. Miettinen et al. (1971) reported that about $95 \%$ of ingested $\mathrm{MeHg}$ is absorbed into the bloodstream. The model flow "MeHg Absorption" calculates the amount of $\mathrm{MeHg}$ that is absorbed into the bloodstream. "BLOOD MeHg" is both a clearinghouse for the disposition of $\mathrm{MeHg}$ throughout the body, and the stock from which the biomarker, $\mathrm{MeHg}$ blood concentration, is calculated. Pathways leading from "BLOOD MeHg" include removal by defecation, transfer to tissue, excretion in hair, and the fetal pathway.

The MeHg defecation pathway includes the "MeHg defecated" flow which is calculated as a fraction of "BLOOD MeHg". Defecation is thought to account for about $80-90 \%$ of $\mathrm{Hg}$ loss (Smith et al. 1994). However, it is unclear what portion is lost through demethylation by gut fauna (Clarkson et al. 2007) or through transformation to IHg in the tissues and subsequent transport to gut for defecation (Farris et al. 1993). Since no consensus was found in the literature, both processes are simulated. The relative portion that is converted to $\mathrm{IHg}$ in the tissue versus converted in the gut does not impact the purpose of the model: to accurately forecast biomarkers based on intake rates. Therefore, the rate of conversion to IHg in the tissue was adjusted on the basis of accurately predicting biomarkers and matching literature values for reaching steady state and halflife of ingested $\mathrm{MeHg}$.

The MeHg in hair pathway includes the "Excretion in Hair" and "Outgrowth" flows, and the "MeHg in 1 CM HAIR" stock. THg in hair is a commonly used biomarker of exposure. The converters "hair to blood ratio", "mass of $1 \mathrm{~cm}$ hair", and "MeHg blood conc" are used to calculate the mass of $\mathrm{MeHg}$ that moves through the "Excretion in Hair" 
flow. The "monthly hair MeHg" converter calculates the amount of $\mathrm{Hg}$ in $1 \mathrm{~cm}$ of hair (from the entire scalp) based on the ratio of hair concentration to blood concentration. This is multiplied by 0.8 because only a portion of hair $\mathrm{Hg}$ is organic. The inorganic portion is excreted separately through the inorganic pathway (Bakir et al. 1973, Phelps et al. 1980).

The stock "MeHg IN 1 CM HAIR" is used to calculate MeHg concentration in hair, the organic fraction of the biomarker of interest. The "Outgrowth" flow moves the MeHg out of the stock at a monthly rate, simulating the constant growth of hair, and with it, the $\mathrm{MeHg}$ that is excreted in hair. Total hair $\mathrm{Hg}$ is calculated by adding the organic and inorganic fractions in hair.

The fetal pathway includes the stock "FETAL MeHg" and the flows "Placental Transfer" and "Birth". This pathway simulates fetal exposure, and the biomarker of interest is cord blood concentration. For this model a pregnancy is generated at 5 year intervals. When a population of children is selected, the fetal pathway is switched off. The mass of $\mathrm{Hg}$ needed in the fetus is calculated from the maternal $\mathrm{MeHg}$ blood concentration ("MeHg blood conc") and the ideal fetal blood concentration ("ideal fetal conc"). The ideal fetal blood concentration is determined by the literature-derived ratio and the maternal MeHg blood concentration. This concentration is then converted to mass by the "fetal bl vol" converter. The $\mathrm{Hg}$ is transferred to the fetus over a 9 month interval. Literature values are not available for cord blood throughout the course of pregnancy; so as a biomarker, cord blood concentration represents exposure for the fullterm neonate. Fetal bodyweight ("fetal bw") is set at $3.25 \mathrm{~kg}$, and is divided by 9 for linear growth to the full term neonate. Fetal blood volume is also divided by 9 for linear 
growth to full term. The "Birth" flow empties the "FETAL BLOOD MeHg" stock after 9 months. A limitation of this flow is that emptying occurs over a one month time period when it is instantaneous in vivo. Over the time scale modeled, this slowing of $\mathrm{Hg}$ loss through this pathway does not affect the accuracy of the modeled biomarkers.

The primary pathway MeHg follows out of "BLOOD MeHg" is to "TISSUE MeHg" ("Bl to Tissue MeHg Transfer" flow). A set of converters is used to calculate the amount of $\mathrm{MeHg}$ that needs to move from "BLOOD MeHg" to "TISSUE MeHg", or vice versa, in order to maintain or attain the expected steady state ratio between blood and tissue published in the literature. The literature reports that the ratio between tissue and blood ranges from 5:1 to 10:1 (Cernichiari et al. 2007), so an expected ratio of 7.5:1 was applied. Ingested MeHg moves from absorption into blood and then to tissue in less than a month. The monthly time scale of the model requires that each movement from one stock to another take a minimum of one month. In order to circumvent this limitation and more closely model the rapid movement of $\mathrm{MeHg}$ from ingestion into tissue, a fraction of the "MeHg Absorption" flow is added to the fraction taken from the "BLOOD MeHg" stock in the calculation for the flow "Bl to Tissue MeHg Transfer". The fraction was determined by adjusting to reach the literature reported ratio between blood and tissue in the shortest time. This streamlining of movement enabled attainment of steady state ratios in a more realistic time frame.

Two converters, "MeHg blood conc" and "MeHg tissue conc", are tools for the user. Stocks give the mass of $\mathrm{MeHg}$, but the literature primarily reports concentrations in various compartments. "MeHg blood conc" reports the biomarker maternal blood concentration. It is the mass of $\mathrm{MeHg}$ in the "BLOOD MeHg" compartment divided by 
the volume of blood. The "MeHg tissue conc" is not a biomarker. However, calculating this value facilitated the calibration process by determining whether the model was giving the expected ratio in the disposition of $\mathrm{MeHg}$ between tissue and blood.

Conversion to IHg occurs through the "Converted to IHg" flow. This process moves $\mathrm{Hg}$ from the "TISSUE MeHg" stock into the "TISSUE IHg" stock. The "TISSUE IHg" stock represents $\mathrm{IHg}$ in all compartments of the body. It should be noted that some tissues, such as kidney, concentrate $\mathrm{IHg}$ whereas other tissues may have lower concentrations. The converter, "rate constant convert to $\mathrm{IHg}$ ", determines the fraction of tissue $\mathrm{MeHg}$ that is converted to $\mathrm{IHg}$. This conversion rate was not determined by literature values, but by adjusting the rate so that the half-time in the body and the ratio between blood $\mathrm{MeHg}$ and tissue $\mathrm{MeHg}$ came closest to matching literature values. Three pathways flow out of "TISSUE IHg" and represent losses to the system. These are the flows "fecal loss of IHg", "IHg loss in urine", and "IHg in hair".

The biomarkers of interest do not specifically look at $\mathrm{IHg}$. However, the hair $\mathrm{Hg}$ biomarker typically measures $\mathrm{THg}$ which is approximately $80 \% \mathrm{MeHg}$ and $20 \% \mathrm{IHg}$ (Phelps et al. 1980). Therefore, the IHg in hair pathway is simulated and used in the calculation of THg concentration in hair. Similar to the MeHg excretion in hair pathway, this pathway consists of the flows "Inorganic Hair Exc" and "Outgrowth of IHg in Hair", and the stock "IHg in 1 CM HAIR". Monthly hair IHg is calibrated to be a fraction of "TISSUE IHg". This fraction, 0.0296 in the "IHg hair fraction" converter, was determined by back calculating the portion of "TISSUE IHg" that would be required to make the $20 \%$ of $\mathrm{IHg}$ in hair necessary to attain the desired ratio of hair $\mathrm{THg}$ to blood MeHg. The remainder of this pathway replicates the $\mathrm{MeHg}$ in hair pathway. Total 
concentration in hair ("total conc in hair") is calculated by adding "IHg conc in hair" and "MeHg conc in hair".

The flow "IHg Defecation" simulates the loss of IHg through the feces. It helps balance the loss of $\mathrm{MeHg}$ through defecation to achieve the percent of $\mathrm{THg}$ lost through this pathway found in the literature. "IHg defecation rate" sets the fraction of "TISSUE IHg" that is lost due to defecation.

The loss of IHg in the urine pathway is simulated by the flow "Urine IHg loss". The kidneys tend to accumulate $\mathrm{IHg}$ and slowly release the $\mathrm{Hg}$ into the urine (Passos et al. 2007, Young et al. 2001). Because the rate of mercury excretion through urine is not well documented in the literature, the loss through this pathway balances the loss through the hair and fetal pathways along with the $80-90 \%$ loss through the feces (Clarkson and Magos 2006).

\section{Bioaccumulation}

The bioaccumulation model examines the movement of $\mathrm{Hg}$ in stream systems from water column to fish tissue. The purpose of this model was to assist regulatory decision makers in the process of determining where and how resources can be used to protect populations from adverse $\mathrm{Hg}$ exposures. Because the intended users are regulators, existing data from readily available regulatory sources were used as inputs. The objective was to gain insight into how the unique characteristics of basins in this region interact to impact the bioaccumulation process. This insight can then be used to determine which basins are likely to have elevated fish tissue levels or shed light on the impact of proposed changes in land cover or other watershed characteristics, or the responsiveness of a basin to reductions in $\mathrm{Hg}$ loading. 
Land cover and water chemistry data were inputs into the model and were assumed to be at steady state. Output was fish tissue MeHg levels. The user sets the trophic level of the fish to simulate the mean intake of a population of interest. The user chosen fish tissue $\mathrm{Hg}$ concentration is used as an input into the human disposition model. Model output was compared to actual fish tissue data to determine model accuracy.

Basins used to calibrate and evaluate the model were primarily from the Ohio River Valley, a region that has not been well represented in the literature examining $\mathrm{Hg}$ bioaccumulation. These sites exhibit considerable variation in land use and land cover and span several physiographic regions, from mountainous, heavily forested basins in the Appalachian Highlands to basins in the Interior Plains that are highly cultivated. While increased bioaccumulation has been associated with wetlands coverage and has been a focus of research, wetlands coverage is minimal in the Ohio River Valley (Emery and Spaeth 2011, White et al. 2005). This region offers the unique opportunity to examine the relationships between other drivers of $\mathrm{Hg}$ bioaccumulation.

\section{Basic Structure}

The basic structure of the bioaccumulation model is shown in Figure 2. $\mathrm{Hg}$ enters the system through the flow "IHg Inflow". IHg moves into the INORGANIC Hg IN WATER stock. From this stock, the Hg can move out of the system by flowing downstream, or be deposited through sedimentation to the streambed, represented by the IHg IN STREAMBED stock. This stock also represents any IHg that may be moved to the floodplain or retained by woody debris or held within the system by any other means. Basins with extensive wetlands have been associated with high $\mathrm{MeHg}$ concentrations. 
However, for basins with little or no wetlands, the location of microbial conversion of $\mathrm{IHg}$ to $\mathrm{MeHg}$ is less certain. The literature suggests that this conversion occurs in the biofilm associated with algal communities (Bell and Scudder 2007, Desrosiers et al. 2006, Tsui et al. 2009, Tsui et al. 2010). Because of this association, the model depicts the movement of the IHg in the streambed, after microbial conversion to $\mathrm{MeHg}$, as moving directly into the TROPHIC LVL 1 stock. The TROPHIC LVL 1 stock represents the $\mathrm{MeHg}$ contained within the periphyton as defined in the broad sense as including the community of algae, bacteria, fungi, and exudates. The MeHg can follow one of three pathways out of the TROPHIC LVL 1 stock. It can diffuse into the water column and be lost downstream; it can be contained within the declining periphyton and subsequently enter the detrital pathway; or it can be consumed by trophic level 2 organisms. Living organisms with their associated $\mathrm{MeHg}$ are assumed to remain within the stream system. Loss of $\mathrm{Hg}$ to the system is through movement to detritus and then loss downstream. The bioaccumulation process is represented by movement of $\mathrm{MeHg}$ from one trophic level to the next, with an alternate "Death" flow removing a portion of the $\mathrm{MeHg}$ at each trophic level. All MeHg in trophic level 4 eventually moves into the "Death" flow for that level. The "Death" flows move MeHg to the MeHg IN DETRITUS stock. From there, the $\mathrm{MeHg}$ can exit the system by being lost downstream or be recycled into the bioaccumulation process by consumption from trophic level 2 organisms.

The bioaccumulation of $\mathrm{MeHg}$ through the food web is represented by a series of stocks labeled as trophic levels. The mass of $\mathrm{MeHg}$ needed in each is calculated by determining the biomass of each trophic level and determining the concentration of $\mathrm{MeHg}$ based on the previous trophic level. The determination of the biomass of trophic 
level 1 is discussed below. The concentration of $\mathrm{MeHg}$ in each trophic level is then a function of the mass of $\mathrm{MeHg}$ in that trophic level and the corresponding biomass.

To determine the mass of MeHg that flows to subsequent trophic levels (TL), predator prey factors (PPFs) are used. The PPF is the ratio of MeHg concentrations of $\mathrm{TL}_{\mathrm{n}}$ to $\mathrm{TL}_{\mathrm{n}-1}$. A suggested mean value from several studies is given in the Mercury Study Report to Congress Volume III, Appendix D (USEPA 1997b). For a given amount of $\mathrm{MeHg}$, the eutrophic system, with a larger crop of algae, will distribute the $\mathrm{MeHg}$ through a larger number of algal cells resulting in a dilution effect at the base of the food web (Chen and Folt, 2005). This effect, called bloom dilution, affects all subsequent levels of the food chain. In addition, the algae in high-nutrient systems produce more biomass per unit ingested by consumers than in nutrient-poor systems, an effect called somatic growth dilution (Karimi et al., 2007). Bloom dilution and somatic growth dilution lead to eutrophic systems having lower predator prey factors than oligotrophic systems. These effects were combined in a function called "bloom growth dilution" and used to adjust the PPFs. The output of the graphical function is dependent on the mean productivity index, described below. The adjusted PPF is used to determine a target $\mathrm{MeHg}$ concentration and the corresponding mass of $\mathrm{MeHg}$ needed to achieve that concentration. The mass already resident in the stock is then subtracted from the amount needed to achieve the ideal concentration and that mass of $\mathrm{MeHg}$ is moved to the next trophic level.

The death flows for each trophic level move $\mathrm{MeHg}$ into the MeHg IN DETRITUS stock. For primary producers, the death flow is controlled by the seasonal pattern of periphyton loss, with highest loss in fall. When moving to subsequent trophic levels, 
lifespan tends to increase. For TL2, the assumption is made that organisms live for one year. The flow is controlled by removing $1 / 12$ of the mass each month. For TL3, the mortality rate for bluegill, $0.56 /$ year, was used to determine loss of $\mathrm{MeHg}$ through death. Trophic level 4 used the mean mortality rate for predatory fish found in Kentucky, 0.36/year (Froese and Pauly 2011).

MeHg IN DETRITUS represents the MeHg found in non-living organic matter in the system. Some of this matter is lost downstream based on retention while the remainder is taken up by detritivores, accounted for in trophic level 2 for this model.

\section{Subroutines}

The bioaccumulation model subroutines are shown in Figure 4.

IHg Input. The $\mathrm{Hg}$ Input sector determines the amount of $\mathrm{Hg}$ that enters the system. Typically, more than $90 \%$ of THg entering a stream is IHg (USEPA 1997b). For the Hg input, the mass of $\mathrm{THg}$ is calculated by multiplying the mean monthly $\mathrm{THg}$ concentration by the mean monthly flow. Particulate-bound $\mathrm{Hg}$ is not available for conversion to $\mathrm{MeHg}$, and, in the short term, is not available for bioaccumulation. Balogh et al. (1997) found that the concentration of dissolved $\mathrm{Hg}$ remained relatively constant while $\mathrm{THg}$ varied widely in association with suspended solids. In this model, only the dissolved $\mathrm{Hg}$ enters the modeled stream system, and the particulate-bound $\mathrm{Hg}$ is ignored. In the study by Balogh et al. (1997), the range of dissolved $\mathrm{Hg}$ was $0.2-0.7 \mathrm{ng} / \mathrm{l}$. Several additional sites on the upper Mississippi River showed little variation and had a maximum of approximately $1 \mathrm{ng} / \mathrm{l}$. Additional studies found ranges of dissolved $\mathrm{IHg}$ that were as high as 2-3 ng/L (Balogh et al. 2008, Dittman et al. 2009, Shanley et al. 2008, Tsui and Finlay 2011). These higher values were associated with higher concentrations of dissolved 
organic carbon (DOC), frequently associated with more wetlands or forested coverage (Tsui and Finlay 2011). DOC data were not available for the Kentucky sites. The model reflects the stable dissolved $\mathrm{IHg}$ concentration by using the minimum function in STELLA. This function returns the minimum of either the mean THg concentration or 1 $\mathrm{ng} / \mathrm{l}$ as the $\mathrm{Hg}$ input into the model. Because a lower $\mathrm{pH}$ is associated with an increased availability of $\mathrm{IHg}$ for methylation, an adjustment is made to the minimum value with a graphical function, "pH adjust". An increasing portion of the THg is designated as dissolved as the $\mathrm{pH}$ becomes more acidic, with the graphical function adding up to $3 \mathrm{ng} / \mathrm{l}$ to the dissolved $\mathrm{IHg}$ for a $\mathrm{pH}$ as low as 5.5 .

Retention. IHg input into the model is determined by the measured mean concentration and monthly discharge, which is the assumed throughput of water in the system for the monthly time period. From the IHg IN WATER stock, the $\mathrm{Hg}$ can be deposited to the stream bed or lost downstream. When contemplating the mass of $\mathrm{Hg}$ in a stream system, the majority of the mass is carried downstream and lost to the system. The amount that remains in the system does so by sedimentation, which may be minimal for many low to mid-order stream systems, or by deposition on banks during flood events (Allan and Castillo 2007). In this model, the amount of $\mathrm{Hg}$ that remains is characterized by the variable "retention" which is calculated in the "Degree of Retention" sector. The factors that are used to determine retention include sinuosity and flashiness. Higher sinuosity reflects a greater meander and slower movement through the system resulting in 
Figure 4. Subroutines for the bioaccumulation model.
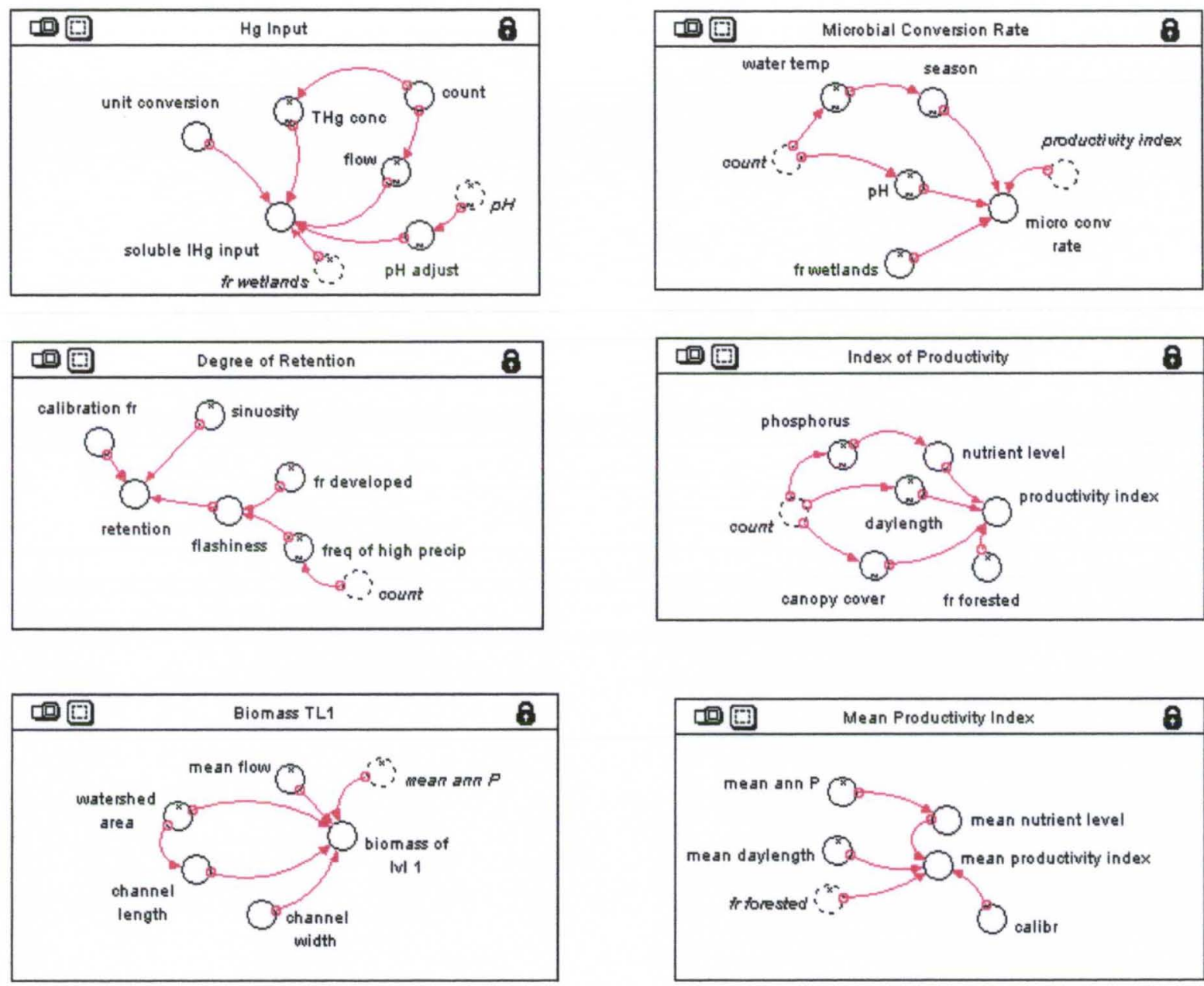
increased sedimentation. The calculation of sinuosity is discussed below. Flashiness reflects a decrease in the infiltration of precipitation in soils resulting in more rapid rise and fall of discharge. In the model, flashiness is determined by the fraction of developed land in the basin and the frequency of high precipitation. A calibration factor was applied to maximize model fit. For each iteration of the model, the mass of $\mathrm{Hg}$ that will be retained is determined and then the remaining $\mathrm{Hg}$ is lost downstream.

Microbial Conversion. The conversion of $\mathrm{IHg}$ to $\mathrm{MeHg}$ is complex and likely occurs by several processes. The model assumes that the conversion occurs in association with periphyton and is consistent with evidence that this conversion occurs within the biofilm (Bell and Scudder 2007, Cleckner et al. 1999, Tsui et al. 2009, Tsui et al. 2010). While microbial conversion may occur in other locations, it is likely that across the region for which the model was developed, the processes and locations of conversion are likely to be similar. The assumption is made that all $\mathrm{MeHg}$ is initially associated with periphyton and is represented with the MeHg IN TROPHIC LVL 1 stock. The MeHg can then move up the food chain from ingestion by consumers, or diffuse into the water column and subsequently be lost downstream. MeHg Diffusion is controlled by the converter "season", with warmer temperatures resulting in greater diffusion rates. $\mathrm{MeHg}$ Lost Downstream is controlled by the retention subroutine.

Variables used to calculate the microbial conversion rate were water temperature, $\mathrm{pH}$, fraction wetlands, fraction forested, productivity index, and day length.

Determination of this rate occurs in the "Microbial Conversion Rate" sector. Each of these variables was scaled to a 0 to 1 range and then weighted so that the full weights of the variables added to 1 . This value is then multiplied by 0.36 , the range of microbial 
conversion rates found in Warner et al. (2005) giving an estimate of the microbial conversion rate found in stream systems. The mean monthly water temperature is converted to a graphical function called "season" that reflects the increase in primary producer growth during warmer weather.

Productivity Index. An index was developed for the effect of productivity on the microbial conversion rate. Periphyton mats are thought to contribute to increased methylation rates. As mats grow and become denser, small anoxic microzones within the mat may develop. The large surface area within the mat favors microbial growth. The bacterial community, along with the oxic/anoxic borders, promotes conversion of $\mathrm{IHg}$ to MeHg (Mauro et al. 2002, Tsui et al. 2010, Ward et al. 2010a). This effect is accounted for in the "Index of Productivity" sector. Phosphorus was assumed to be the limiting nutrient for all sites, and was used as a surrogate for potential productivity. In stream systems, light often limits productivity. Light limitation was introduced to the index of productivity by including the fraction forested, canopy cover, and monthly length of daylight hours. "Canopy cover" is a graphical function that relates the effects of season to the fraction of the watershed that is forested. Stream productivity is often greatest in forested basins before spring leaf out. The graphical function limits the effect of shading to months with canopy coverage.

Biomass TL1. While the biomass of primary producers varies with the seasons, this pattern diminishes for subsequent trophic levels. The biomass of trophic level 1 is used to estimate the biomass of all subsequent trophic levels. In order to minimize this seasonal pattern in higher trophic levels, the mean annual biomass of trophic level 1 is estimated in the "Biomass TL1" sector. This variable is calculated by using the multiple 
regression equation determined by Lamberti and Steinman (1997). They found that watershed area, dissolved reactive phosphorus, and mean annual flow explained $70 \%$ of the variation in biomass of stream systems. The equation predicts areal gross primary production. To calculate total biomass, channel length and width are multiplied by the areal gross primary production. Channel length is calculated according to Leopold (1994, $\mathrm{p} 222$ ). A mean channel width of $5 \mathrm{~m}$ was estimated to be the productive area of the stream. After trophic level 1, the biomass of subsequent trophic levels is estimated to be $10 \%$ of the prior trophic level based on transfer efficiencies in the literature (Pauly and Christensen 1995).

While mean annual biomass is constant for each trophic level, monthly means were used to determine the movement of $\mathrm{Hg}$ through the system. This resulted in a slight sinusoidal wobble for projected fish tissue levels that is not likely to be reflected in a real system.

Mean Productivity Index. This index is determined in the "Mean Productivity Index" sector, and its determination is similar to the "productivity index" variable. The differences between the two are that mean annual phosphorus is used instead of the mean monthly value, canopy cover is not accounted for, and a calibration factor is applied.

\section{Data Sources}

The purpose of the model is to be a tool for regulators, therefore the model used existing data from regulatory sources for calibration and evaluation. Sources of data for all sites can be found in Table 2 with references for the sources in Appendix B.

Water Quality. Sites were chosen based on the availability and co-location of both fish tissue and water quality data. For calibration sites, water quality variables were 
obtained for the years 1999 through 2007 and included THg, phosphate-phosphorus as P, $\mathrm{pH}$, and water temperature. In general, the sampling strategy for each site was measurements taken bimonthly with monthly sampling every five years. This resulted in 2 to 9 samples for each month. Means were calculated, and for months with $n<4$, the means of the prior and subsequent months were included to diminish the effect of low sample numbers. THg measurements were used as inputs for the model. Prior to 2002, the limit of quantification (LOQ) was $50 \mathrm{ng} / \mathrm{L}$. Methods changed in 2002 and the subsequent LOQ was $0.5 \mathrm{ng} / \mathrm{L}$ (R. Payne, KDOW, personal communication, 10/26/2010). Because almost all samples tested before 2002 were below the higher quantification limit, only data collected after the change in methods were used to calculate monthly means for THg. While each site varied slightly in the total number of samples, the samples collected before 2002 represented approximately one third of all $\mathrm{Hg}$ samples for each site.

Water quality data for evaluation sites were limited. Often, co-located fish tissue and water quality data were not available and the closest monitoring station to the fish sampling site was used. When water quality data were sparse, data from one or more of the nearest monitoring sites were merged to determine a mean. Several evaluation sites had no THg data available. The default for these sites was set at $1 \mathrm{ng} / \mathrm{l}$.

Fish tissue. Fish tissue data were limited for calibration sites, with four sites having only one sample. The Mud River site had the largest sample size with 14 samples. Most samples were composites of the same species and similar size. Species, length, weight, and $\mathrm{Hg}$ concentration were available. Skin-on fillets were used to determine $\mathrm{Hg}$ concentrations in scaled fish, while skin-off fillets were used for scale-less fish (E. Eisiminger, KDOW, personal communication, 2/3/2011). Data availability varied 
between the evaluation sites. Georgia had the most fish tissue samples, 9 and 16 samples for Spring Creek and Talking Rock Creek, respectively. The remaining sites had three or more samples. Details of the available samples, including species, size, and $\mathrm{Hg}$ tissue concentrations, can be found in Appendix B.

Species sampled varied considerably. In order to strengthen the evaluation of the model, fish were grouped into trophic levels, with panfish assigned to TL3, piscivorous fish to TL4, and all other fish defined as TL3.5. Because fish tissue concentrations increase with size, a standard size fish was selected for model projection. Willis et al (1993) delineated length categories for the most commonly caught and consumed fish species. As an estimate of the most commonly consumed size fish, "quality" length was chosen. Samples that were between 0.75 and 1.25 times the quality length were included in the analyses. Tygarts Creek had only one fish tissue sample and it was outside the bounds stipulated for length. Consequently, this site was not included in error analysis, but was instructional in evaluating the effects of land cover on bioaccumulation. Several samples were of species without length categories. A boxplot of error rates by trophic level was used to identify any outliers from the samples without length categories. One outlier was identified and was excluded from further analyses. In addition, 2 striped bass from Talking Rock Creek in Georgia were excluded. These TL4 samples had a mean tissue concentration that was one third of the TL3.5 samples from the same site. Possible reasons for lower than expected $\mathrm{Hg}$ concentrations were small sample size or that the fish were thermally stressed and had migrated into the creek from the downstream 
Table 2. Data sources. References for sources can be found in Appendix B.

\begin{tabular}{|c|c|c|c|}
\hline & Variable & State & Source \\
\hline & \multirow{5}{*}{ Fish Tissue } & Georgia & USEPA Region 4 TMDL reports \\
\hline & & Indiana & Indiana Department of Environmental Management (IDEM)* \\
\hline & & Kentucky & Kentucky Division of Water (KDOW)* \\
\hline & & Tennessee & Tennessee Department of Environment and Conservation* \\
\hline & & West Virginia & West Virginia Department of Health and Human Services \\
\hline & \multirow{5}{*}{$\begin{array}{l}\text { Water } \\
\text { Quality }\end{array}$} & Georgia & STORET/Georgia Dept of Natural Resources \\
\hline & & Indiana & STORET/IDEM \\
\hline & & Kentucky & STORET/KDOW \\
\hline & & Tennessee & STORET/Tennessee Department of Environment and Conservation \\
\hline & & West Virginia & STORET/WV Division of Environmental Protection (WVDEP) \\
\hline & Discharge & & US Geological Survey \\
\hline & Precipitation & & National Climatic Data Center \\
\hline & Day length & & ptaff \\
\hline \multirow{6}{*}{ GIS } & Land cover & & National Land Cover 2001 Dataset \\
\hline & \multirow{5}{*}{$\begin{array}{c}\text { Streams/ } \\
\text { Basins }\end{array}$} & Georgia & Georgia GIS Data Clearinghouse \\
\hline & & Indiana & Indiana Spatial Data Portal \\
\hline & & Kentucky & Kentucky Geological Survey: Geospatial Data Library \\
\hline & & Tennessee & Tennessee Spatial Data Server \\
\hline & & West Virginia & West Virginia GIS Technical Center \\
\hline
\end{tabular}

*Data obtained directly from agency. All other data were obtained from internet sources, referenced in Appendix B. 
reservoir (J. Hakala, GA DNR, personal communication, 8/17/2011). Final sample sizes for trophic levels $3,3.5$, and 4 were 7,12 , and 3 respectively for calibration sites and 16 , 27 , and 2 for evaluation sites.

Geophysical Parameters. Using GIS methods, the contributing watershed for each site was delineated and the water monitoring and fish tissue sampling station marked. If the water monitoring station did not fall neatly at the downstream end of a sub-basin, the watershed boundary was redrawn to more accurately represent the contributing watershed. The smaller basins were dissolved to form the contributing watershed for the sample site, and the watershed area was calculated.

Land use was determined through the National Land Cover 2001 Dataset (Homer et al. 2004). The land use data were clipped by the contributing watershed. The three forested, two wetlands, and four developed categories were condensed into single categories and the fractions of the basin that were forested, wetlands, and developed were determined.

Sinuosity was calculated using the following equation (Allan and Castillo 2007):

$$
\text { Sinuosity }=\frac{\text { Channel distance }}{\text { Straightline downvalley distance }} .
$$

For each watershed, GIS methods were used to measure channel distance and straight-line distance for two headwater reaches, two mid-stream reaches and two reaches near the sample site. Sinuosity was calculated and the mean of the six calculations was used.

U.S. Geological Survey (USGS) data were used for mean monthly flow values. For sites that had a USGS station at the water monitoring station, the mean flow was 
taken from the USGS website. For other sites, the ratio approach described in Rashleigh et al. (2004) was employed. Frequency of high precipitation was determined from daily precipitation data for the NOAA station closest to each sample site (NCDC 2010). More than 50 years of data were available for all stations. Frequency of high precipitation was defined as the mean of the number of days with precipitation over half an inch for each month.

Variables are input into the model using a linked Excel file. For monthly means, these variables are frequency of high precipitation (freq of high precip), THg concentration ( $\mathrm{THg}$ conc), water temperature (water temp), $\mathrm{pH}$, phosphorus, day length, and flow. Variable constants are mean annual phosphorus (mean ann P), mean day length, mean flow, watershed area, sinuosity, fraction forested (fr forested), fraction wetlands (fr wetlands), and fraction developed (fr developed).

\section{Output and Options}

User options and model output are on the interface page of STELLA, shown in Figure 3. The user selects one of 10 populations to be simulated. Because different populations may consume substantially different types of fish, the interface contains sliders that the user sets to simulate the mean intake trophic level of the population of interest. A numeric display shows this mean trophic level after the program is run. For example, sports fishers may primarily be interested in piscivorous fish. For that population, the intake concentration desired would most likely be TL4. The sliders would be weighted $100 \%$ for TL4. A subsistence fisher population may rely primarily on panfish and catfish. No slider represents TL3.5, so if $60 \%$ of the intake were catfish, 
weighting would be $30 \%$ TL4 and $30 \%$ TL3, for catfish. The remaining $40 \%$ of consumption was panfish represented by TL3. Adding this $40 \%$, the final breakdown would be $70 \%$ TL3 and 30\% TL4. The mean trophic level consumed would be displayed as 3.3 .

In order to assess policy choices and drivers of the system, the user can modify several variables. The variables are THg input, $\mathrm{pH}$, nutrients, the fraction of the basin that is forested, developed, or in wetlands, and water temperature. The user selects the variable to be perturbed and then adjusts the corresponding slider to the desired value.

Output is given in graphical form. The fish tissue concentration for the userspecified trophic level is shown in one graph. Population outcomes are also shown. Graphs for blood $\mathrm{MeHg}$, total hair $\mathrm{Hg}$, and fetal blood $\mathrm{Hg}$ show the distribution of that projected biomarker for the population simulated. Because of the complexity of the system, a number of months are required for the model to adjust to a steady state condition based on individual site factors. In order to minimize confusion from this equilibration process, the graphical display begins after a steady state is achieved at 120 months and continues to 1200 months for the 100 year run.

\section{Policy and Climate Change Analyses}

\section{Fish Consumption Advisories and Population Choice}

Changing behavior by choosing a lower trophic level fish for consumption can modify exposure. This strategy examined how consumption guidelines might alter exposure by examining the response in population biomarkers to fish from the same basin but different trophic levels. While fish consumption advisories are typically set based on 
general criterion, in order to protect public health, decision makers must answer two questions: 1) which population has the greatest exposure? And 2) what portion of the population will be protected? An analysis was undertaken to demonstrate the response of the distribution of the blood $\mathrm{MeHg}$ biomarker of susceptible populations to changes in $\mathrm{Hg}$ concentration in fish tissue, and whether biomarkers for the examined populations fell below the USEPA fish tissue criterion. Fetal blood MeHg and total hair Hg biomarkers were also examined. The patterns of change in biomarkers for populations were compared.

\section{Emissions Reductions}

Because the model does not include an atmospheric component, $\mathrm{Hg}$ emission reduction scenarios cannot be directly simulated. Two strategies were used to project the consequences of possible reduction scenarios. The first strategy was to modify the $\mathrm{THg}$ input into the model; a method that simulates the implementation of a TMDL. This strategy allows the user to project the concentration of THg in the stream that would bring fish tissue into compliance. The second strategy projected the impacts of a percentage reduction in $\mathrm{Hg}$. This method looked at reducing $\mathrm{Hg}$ loads by set percentiles $(10 \%, 25 \%, 50 \%, 75 \%$, and $90 \%)$, and therefore is more reflective of possible regulations that reduce emissions from local sources. With this analysis, both $\mathrm{THg}$ input and dissolved IHg input reduction scenarios were examined. The emissions reductions scenarios were analyzed by projecting outcomes in three streams and trophic level 4 fish.

\section{Watershed Management Strategies}

Previously, the most sensitive input parameters were found to be nutrient loads and the fraction of the watershed that was forested or in wetlands. The effects of 
perturbing these three variables on susceptible populations were examined. The impact on the $95^{\text {th }}$ percentile intake rate of 6 populations was projected by modifying these basin variables from their measured values to plausible low and high values. Nutrient loads were tested at $0.0100 \mathrm{mg} / 1$ and $0.3500 \mathrm{mg} / 1$ phosphorus. The fraction of the basin that was forested was modified to 0.05 and 0.95 . The fraction wetlands coverage was set to 0.01 and 0.35 . Trophic level 4 fish were chosen for the intake concentration for all analyses.

\section{Climate Change}

Climate change is expected have varying impacts depending on location. In Kentucky, the impacts are expected to be an increasing temperature and more frequent and intense precipitation events (Partnership for a Green City 2011). In order to gain understanding of the possible impacts that climate change may have on the problem of Hg contamination, three climate change scenarios were analyzed. The first scenario looked at the changes that increased monthly temperature means might have on the problem of $\mathrm{Hg}$. The second scenario looked at the impact of more frequent highprecipitation events. The third scenario analyzed the impact of the combination of increased monthly temperatures and more frequent high-precipitation events.

\section{Data requirements needed for atmospheric model}

To model the entire system, a third step, a model that tracks $\mathrm{Hg}$ from emission source, to atmosphere, wet and dry deposition to the basin, and subsequent movement into the water column of the modeled stream system would be needed. This step was not completed. The two challenges that resulted in deferring the completion of this step were 
the paucity of monitoring data needed for this step and the degree of uncertainty already present within the two completed models (steps 1 and 2).

In order to calibrate and evaluate each section of the model, real data are needed for inputs and output in order to determine model accuracy. The third model was to simulate the movement of $\mathrm{Hg}$ from emission or atmospheric source to the water column of a specific stream system. Figure 5 shows a simplified structure of the system for the movement of $\mathrm{Hg}$ from atmospheric loading to water column, and as such provides a visual guideline for data needs.

Figure 5. STELLA representation of $\mathrm{Hg}$ movement from atmospheric loading to stream.

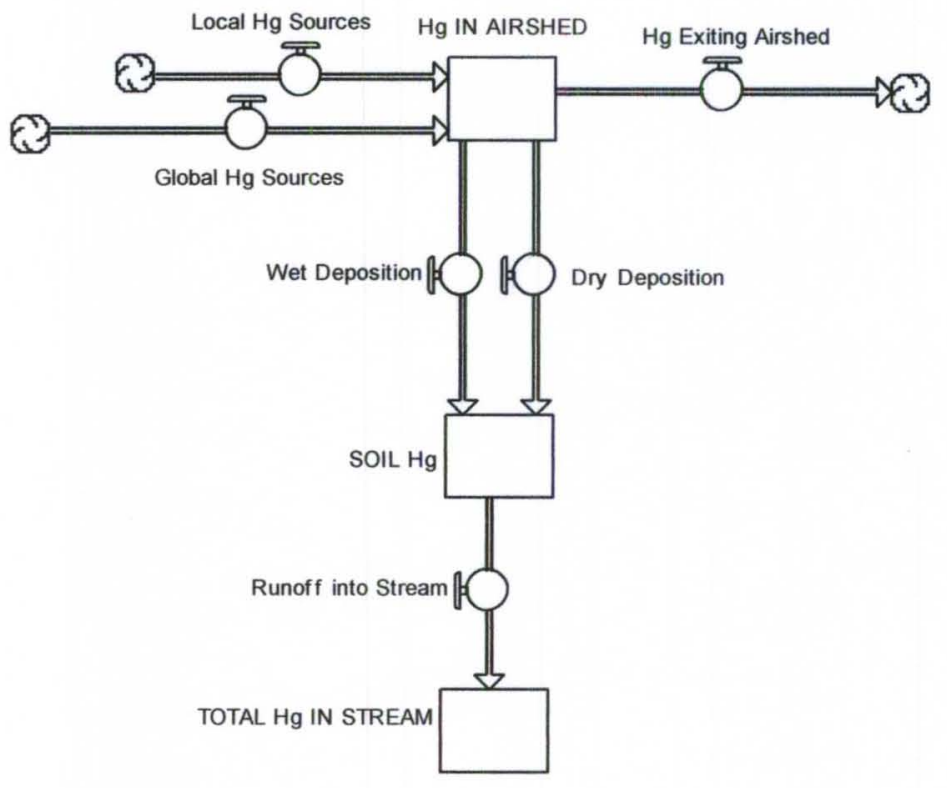

In order to determine the $\mathrm{Hg}$ load and loading into the airshed of a basin, data from local emissions is necessary as well as data on background levels of atmospheric $\mathrm{Hg}$ concentration in the region. $\mathrm{Hg}$ emission estimates are available from the USEPA on the TRI Explorer website. The Toxics Release Inventory (TRI) supplies industry-provided 
estimates of $\mathrm{Hg}$ stack emissions on an annual basis (USEPA 2011d). However, these are estimates and not measurements but can give a general idea of the quantity of local $\mathrm{Hg}$ emissions and show trends over time. The estimates are annual values, while the model is built with a monthly time step in order to simulate seasonal patterns. The majority of $\mathrm{Hg}$ stack emissions are from coal-fired electric utilities that may display seasonal patterns of coal use. Measurements of monthly stack emissions would reduce uncertainty to the greatest degree, and beyond that, monthly means of speciated measurements of $\mathrm{Hg}$ emissions would reduce uncertainty to the greatest extent. $\mathrm{Hg}$ emissions are comprised of gaseous elemental $\mathrm{Hg}$, reactive gaseous $\mathrm{Hg}$, and particulate-bound $\mathrm{Hg}$. The impact of local and regional sources on a watershed varies with the composition of species emitted, with reactive gaseous $\mathrm{Hg}$ and particulate-bound $\mathrm{Hg}$ with shorter half-lives and a greater tendency to deposit locally or regionally. The composition of species emitted varies with the type of coal and the air pollution control equipment installed at the facility (Strivastava 2010).

In addition to local sources of atmospheric $\mathrm{Hg}$, an idea of global sources is also necessary. Global sources could be determined by subtracting local sources from measurements of ambient air Hg. The Kentucky Division for Air Quality has monitored ambient air $\mathrm{Hg}$ at 2 sites in Kentucky (A. Keatley, KDAQ, personal communication, 1/2007). One site was downwind from a coal-fired utility, while the second was designated a control site, and was located away from emission sources. By comparing the two sites, an assumption could be made that the control site represents global sources to the region. With TRI and readily available wind direction data, an estimate of $\mathrm{Hg}$ loading 
into a defined watershed could be made. However, the uncertainty associated with this estimate would be great.

To simulate deposition of $\mathrm{Hg}$ from atmosphere to land, wet and dry deposition rates are needed. Data on wet deposition are available from the Mercury Deposition Network (MDN) (NADP 2011). This national network measures $\mathrm{Hg}$ in rain. A limitation of this source is that monitors are sited to be regionally representative of wet deposition, and consequently do not represent sites downwind from emission sources. Because divalent $\mathrm{Hg}$ can be a significant portion of emissions and is readily deposited through precipitation, an accurate measure of wet deposition is necessary to understand loading to a basin. A number of factors determine the portion of $\mathrm{Hg}$ emissions that is divalent and the fraction can vary widely depending on the utility in question. Without accurate measures of the speciation of stack emissions, basin-level wet deposition monitoring would be needed to reduce uncertainty to a reasonable level. KDAQ had undertaken wet deposition monitoring at several sites, but due to budget constraints has discontinued processing samples at most sites (A. Keatley, personal communication, KDAQ, 6/2008). Dry deposition stems from the elemental gaseous $\mathrm{Hg}$ component of atmospheric $\mathrm{Hg}$ and loading in a basin is largely dependent on land cover. Dry deposition data is not generally available. It could, however, be estimated by its relationship with land cover. Forested coverage increases dry deposition due to its increased surface area and the impact of litterfall (Rea et al. 2001, Sheehan et al. 2006). The relationship between forested coverage and deposition could be used to estimate dry deposition rates.

Soil type also influences the movement of $\mathrm{Hg}$ from land to waterway. Divalent $\mathrm{Hg}$ tends to bind to organic matter, so soils with larger amounts of organic matter would 
slow the movement of $\mathrm{Hg}$ from land to waterway (Demers et al. 2007). Soil data are available from the Natural Resources Conservation Service (NRCS no date). In addition to soil type, land cover would also have to be factored into the movement of $\mathrm{Hg}$ to a waterway. Land cover determines the speed at which overland runoff occurs. Typically, urban areas have greater overland runoff than forested areas as a result of impervious and compacted surfaces. This information, combined with precipitation data, would be the key factor in determining the timeframe for the movement of $\mathrm{Hg}$ from soil to waterway. Soil is typically a sink for divalent $\mathrm{Hg}$, so for emission reduction scenarios, this compartment would be a major control point in determining the time it takes from implementation of the new loading scenario to reaching steady state in fish tissue.

$\mathrm{Hg}$ in the water column is the input for the bioaccumulation model and therefore is the output for this model, and as such is necessary for calibrating and evaluating this model. Each state or tribe has a different sampling regimen. While THg in the water column data are readily available for the simulated Kentucky basins, water column $\mathrm{Hg}$ data for many of the basins in the surrounding region are scarce.

Much of the data necessary to complete this portion of the model have substantial natural variability. Wind speed and direction data are necessary to determine the portion of local emissions that enter the basin airshed. Precipitation data are needed to calculate wet deposition and runoff. The natural variability in weather increases uncertainty in model output. While weather data are available for many years which decreases confidence intervals around monthly means, climate change is modifying weather patterns, reducing confidence that monthly means reflect current patterns. While climate change scenarios are one use of the overall model, the data used to calibrate the model 
may not reflect more recent trends than the long term monthly means obtained from weather data.

The greatest source of uncertainty for this portion of the model stems from the lack of sufficient emissions and deposition data. The literature supports the concept that nearby sources can contribute to local loading creating Hg hotspots (Hatcher and Filippelli 2011, Volz et al. 2007, White et al. 2009). Without sufficient measurement of loading and deposition, identification of hotspots will be uncertain. An example is the Indiana sites used to evaluate the bioaccumulation model. Fish tissue $\mathrm{Hg}$ concentrations were much higher than the model projected. These basins were located downwind from several emission sources. Wet deposition data indicated that $\mathrm{Hg}$ in precipitation was much higher in that area of the state than other areas. Studies have linked $\mathrm{Hg}$ in wet deposition to bioaccumulation in fish (Gorski et al. 2008, Hammerschmidt and Fitzgerald 2006, Orihel et al. 2007). To accurately project loading from atmosphere into waterways, wet deposition data is essential at the basin level.

If the atmospheric model were developed, the uncertainty in the output of this model would amplify the uncertainty already associated with the bioaccumulation and human disposition models. The uncertainty associated with these portions of the $\mathrm{Hg}$ problem is already significant. Figure 6 shows the $95 \%$ confidence interval around the sample mean. This confidence interval represents the natural variability found in fish tissue samples from the National Fish Tissue database (USGS et al. 2006). The graph shows that the uncertainty associated with fish tissue samples is often larger than the USEPA fish tissue criterion. Adding the considerable uncertainty associated with the 
atmospheric model would push the level of uncertainty to the point that model output would be meaningless.

While certain portions of the system could be adequately represented, the lack of data for $\mathrm{Hg}$ emissions and wet deposition combined with the natural variability inherent in environmental systems makes completing the system by adding the atmospheric and terrestrial compartments untenable. The output of this step would be the loading of IHg into the water column, which is the input to the bioaccumulation model. The uncertainty found in the bioaccumulation and population biomarker models would be amplified to an unacceptable degree if this component was added to the system. 
Figure 6. Uncertainty around the sample mean of fish tissue $\mathrm{Hg}$ for site and trophic level combinations. The $95 \%$ confidence interval is based on an analysis of the National Fish Database. For site abbreviations, see Table 6.

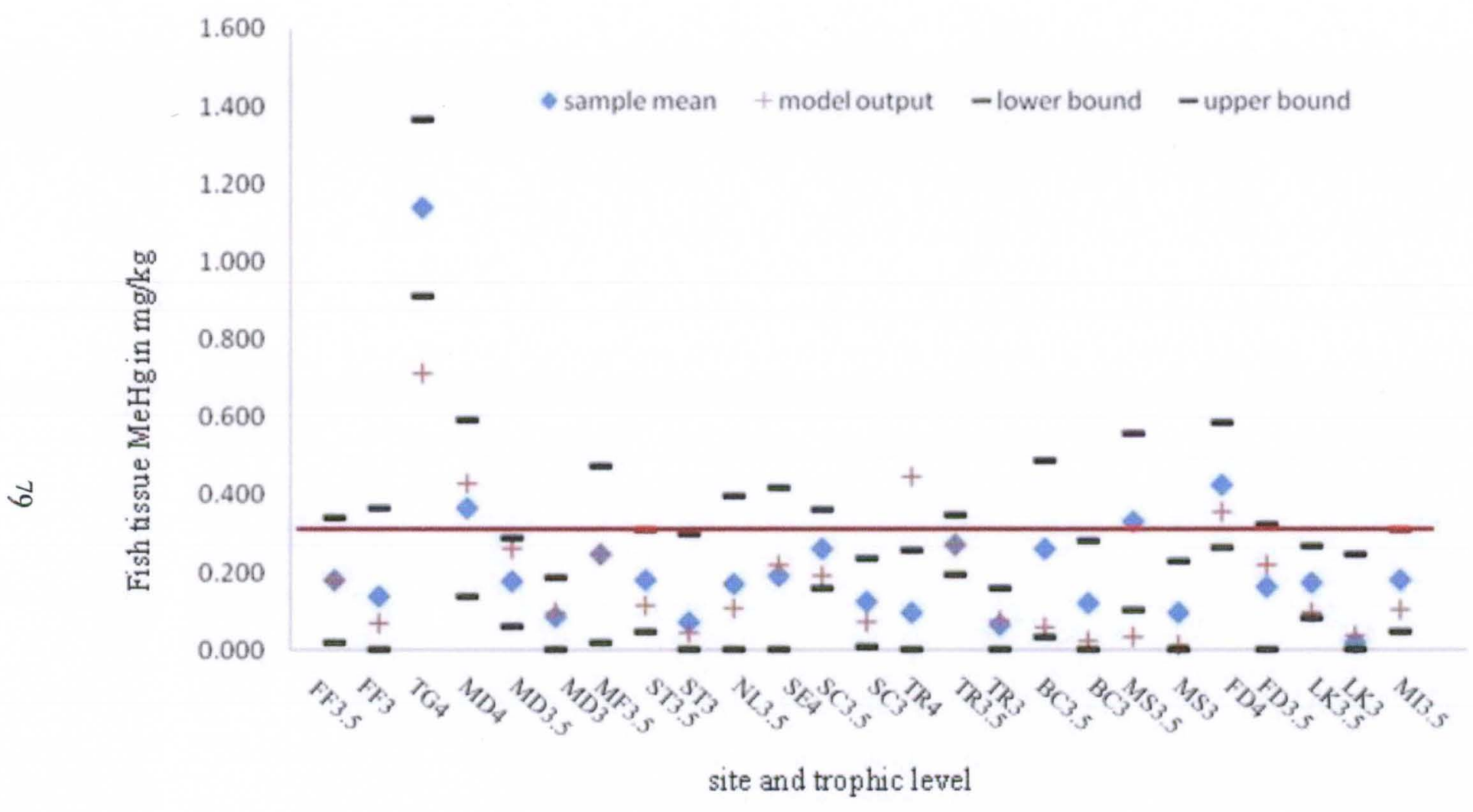




\section{CHAPTER IV}

\section{RESULTS}

\section{Calibration and Evaluation}

\section{Population Biomarkers}

The model was calibrated to literature sources to maximize biomarker accuracy. The relationship between ingestion of $\mathrm{MeHg}$ and blood $\mathrm{MeHg}$ level was calibrated according to Sherlock et al. (1984). Instead of estimating dose, this study measured fish intake with known $\mathrm{MeHg}$ levels over a period of time to relate ingestion to blood $\mathrm{MeHg}$ levels at steady state. The results found a steady state blood $\mathrm{MeHg}$ concentration of 0.8 $\mu \mathrm{g} / \mathrm{L}$ for every $1 \mu \mathrm{g} /$ day ingested. Because children weigh less than adults, this figure is unlikely to hold true for the modeled populations of children. No literature source was found that related ingestion to steady state $\mathrm{MeHg}$ concentrations in children, so the assumption was made that disposition between blood, hair, and tissue in children was the same as in adults, and the ratio was derived from model output. The ratio for children was found to be $1.3 \mu \mathrm{g} / \mathrm{L}$ for every $1 \mu \mathrm{g} /$ day ingested.

The ratio between hair $\mathrm{Hg}$ and blood $\mathrm{MeHg}$ shows a greater degree of variation between individuals than other biomarkers (Budtz-Jorgensen et al. 2004, Cernichiari et al. 2007, Phelps et al. 1980). A ratio of $250 \mathrm{ug} / \mathrm{kg}$ total hair $\mathrm{Hg}$ to $1 \mathrm{ug} / \mathrm{L}$ blood $\mathrm{MeHg}$, which is the most commonly used ratio in epidemiology studies (Clarkson et al. 2007), was selected for use in this model. 
Stern and Smith (2003) did a meta-analysis of studies measuring the relationship between maternal and cord blood. Their analysis reported ratios from studies that looked at MeHg only, THg only, and combined both $\mathrm{MeHg}$ and $\mathrm{THg}$ studies. They reported that studies measuring $\mathrm{MeHg}$ only produced a higher ratio (mean ratio of 1.9 ) than the metaanalysis that combined both $\mathrm{MeHg}$ and $\mathrm{THg}$ (mean ratio of 1.7). They recommended the ratio from all studies combined be used because of uncertainty in the source of $\mathrm{IHg}$ and the small difference it produced in ratios. This model was calibrated with the ratio from the $\mathrm{MeHg}$ only analyses (1.9). The model structure shows movement of $\mathrm{MeHg}$ from maternal blood to the fetal blood compartment, with no inflow of $\mathrm{IHg}$. While $\mathrm{IHg}$ does cross the placenta, it does not concentrate in fetal blood like MeHg. Vahter et al. (2000) reported a mean ratio of 0.9 for the relationship of cord blood to maternal blood IHg. Because maternal blood volume is greater than fetal blood volume, the inclusion of IHg in the measurements to determine the ratio between fetal and maternal blood levels lowers this ratio. $\mathrm{MeHg}$ is thought to be more toxic to the fetus and crosses the placental barrier with greater ease than IHg. Use of the higher ratio for decision making is more protective of the fetus.

Consistency of model output was examined across the distribution of intake rates for all biomarkers. Chi-squared analyses were conducted using PASW Statistics 18, comparing the expected values from literature sources to the observed model output. In addition, scatterplots were generated for a visual assessment of the comparisons.

Table 3 shows the outcomes from the distribution of ingestion rates from various populations. Model output is similar for all biomarkers to values predicted from literature sources. Table 4 shows the p-values from chi-squared analyses. There were no significant 
differences between model output and the literature values (all p-values $>0.05$ ).

Scatterplots of predicted versus observed values demonstrate that, while not significantly different, the model appears to slightly overestimate biomarker concentrations at the highest ingestion rates (Figure 7A-C).

For evaluation, the model's projections were compared to additional literature sources to further strengthen confidence in the output. Table 5 lists the literature sources that were used to evaluate the relationships between ingestion and blood $\mathrm{MeHg}$, blood $\mathrm{MeHg}$ and total hair $\mathrm{Hg}$, and maternal and fetal blood $\mathrm{MeHg}$ concentrations. Scatterplots were generated to visually assess if model output differed from these sources. In addition, the mean and $95 \%$ confidence interval of the slopes of the literature sources for each biomarker were compared to the slope of model output (Figure 8A-C).

For the literature values that measure the relationship between intake and steady state blood concentrations of $\mathrm{MeHg}$, values were generated from the equations taken from the seven literature sources listed in Table 3 from the WHO (1976) and Kershaw et al. (1980). A range of intake rates were selected (25, 50, 75, and $100 \mathrm{ug} / \mathrm{d})$ and entered into the regression equation from each literature source to generate steady state blood concentrations. For comparison to ingestion rates from the model, the daily intake rates were converted to monthly rates and new regression equations were determined. 
Table 3. Model outcome compared to predicted outcome for the distribution of ingestion rates for various populations.

\begin{tabular}{|c|c|c|c|c|c|c|c|c|c|c|c|c|c|}
\hline \multirow[b]{2}{*}{ Population } & & \multicolumn{4}{|c|}{$\begin{array}{c}\text { Blood concentration } \\
\text { ug/L }\end{array}$} & \multicolumn{4}{|c|}{$\begin{array}{c}\text { Hair concentration } \\
\mathrm{ug} / \mathrm{kg}\end{array}$} & \multicolumn{4}{|c|}{$\begin{array}{c}\text { Fetal blood concentration } \\
\text { ug/L }\end{array}$} \\
\hline & & mean & 90 & 95 & 99 & mean & 90 & 95 & 99 & mean & 90 & 95 & 99 \\
\hline General & $\begin{array}{l}\text { predicted } \\
\text { model output }\end{array}$ & $\begin{array}{l}1.3 \\
1.2 \\
\end{array}$ & $\begin{array}{r}3 \\
3.2 \\
\end{array}$ & $\begin{array}{l}7.7 \\
8.2 \\
\end{array}$ & $\begin{array}{r}19.8 \\
21\end{array}$ & $\begin{array}{l}325 \\
300 \\
\end{array}$ & $\begin{array}{l}750 \\
804 \\
\end{array}$ & $\begin{array}{l}1925 \\
2053 \\
\end{array}$ & $\begin{array}{l}4950 \\
5262 \\
\end{array}$ & $\begin{array}{l}2.5 \\
2.3 \\
\end{array}$ & $\begin{array}{l}5.7 \\
6.1 \\
\end{array}$ & $\begin{array}{l}14.6 \\
15.5 \\
\end{array}$ & $\begin{array}{l}37.6 \\
39.8 \\
\end{array}$ \\
\hline Consumers & $\begin{array}{l}\text { predicted } \\
\text { model output }\end{array}$ & $\begin{array}{l}16.3 \\
17.3 \\
\end{array}$ & $\begin{array}{r}41 \\
43.6 \\
\end{array}$ & $\begin{array}{l}53.9 \\
57.3 \\
\end{array}$ & $\begin{array}{r}90 \\
95.6 \\
\end{array}$ & $\begin{array}{l}4075 \\
4337 \\
\end{array}$ & $\begin{array}{l}10250 \\
10895 \\
\end{array}$ & $\begin{array}{l}13475 \\
14339 \\
\end{array}$ & $\begin{array}{l}22500 \\
23901 \\
\end{array}$ & $\begin{array}{r}31 \\
32.5 \\
\end{array}$ & $\begin{array}{l}77.9 \\
82.5 \\
\end{array}$ & $\begin{array}{l}102.4 \\
108.5 \\
\end{array}$ & $\begin{array}{r}171 \\
180.9 \\
\end{array}$ \\
\hline Women (15-44) & $\begin{array}{l}\text { predicted } \\
\text { model output }\end{array}$ & $\begin{array}{r}1 \\
1.1 \\
\end{array}$ & $\begin{array}{l}2.6 \\
2.8 \\
\end{array}$ & $\begin{array}{l}6.9 \\
7.3 \\
\end{array}$ & $\begin{array}{r}17 \\
18.1 \\
\end{array}$ & $\begin{array}{l}250 \\
274 \\
\end{array}$ & $\begin{array}{l}650 \\
695 \\
\end{array}$ & $\begin{array}{l}1725 \\
1836 \\
\end{array}$ & $\begin{array}{l}4250 \\
4520 \\
\end{array}$ & $\begin{array}{l}1.9 \\
2.1 \\
\end{array}$ & $\begin{array}{l}4.9 \\
5.3 \\
\end{array}$ & $\begin{array}{l}13.1 \\
13.9 \\
\end{array}$ & $\begin{array}{l}32.3 \\
34.2 \\
\end{array}$ \\
\hline Women (15-44) consumers & $\begin{array}{l}\text { predicted } \\
\text { model output }\end{array}$ & $\begin{array}{l}14.7 \\
15.7 \\
\end{array}$ & $\begin{array}{r}35.7 \\
38 \\
\end{array}$ & $\begin{array}{l}44.6 \\
47.4 \\
\end{array}$ & $\begin{array}{l}87.3 \\
92.8 \\
\end{array}$ & $\begin{array}{l}3675 \\
3916 \\
\end{array}$ & $\begin{array}{l}8925 \\
9490 \\
\end{array}$ & $\begin{array}{l}11150 \\
11857 \\
\end{array}$ & $\begin{array}{l}21825 \\
23191 \\
\end{array}$ & $\begin{array}{l}27.9 \\
29.6 \\
\end{array}$ & $\begin{array}{l}67.8 \\
71.8 \\
\end{array}$ & $\begin{array}{l}84.7 \\
89.6\end{array}$ & $\begin{array}{l}165.9 \\
175.3 \\
\end{array}$ \\
\hline Children $(0-14)^{*}$ & $\begin{array}{l}\text { predicted } \\
\text { model output }\end{array}$ & $\begin{array}{l}0.7 \\
0.7 \\
\end{array}$ & $\begin{array}{l}0.5 \\
0.5 \\
\end{array}$ & $\begin{array}{r}5 \\
5.4 \\
\end{array}$ & $\begin{array}{l}14.7 \\
15.7 \\
\end{array}$ & $\begin{array}{l}175 \\
170 \\
\end{array}$ & $\begin{array}{l}125 \\
116 \\
\end{array}$ & $\begin{array}{l}1250 \\
1241 \\
\end{array}$ & $\begin{array}{l}3675 \\
3644 \\
\end{array}$ & & & & \\
\hline Children $(0-14)$ consumers* & $\begin{array}{l}\text { predicted } \\
\text { model output }\end{array}$ & $\begin{array}{l}16.4 \\
17.6 \\
\end{array}$ & $\begin{array}{r}39 \\
41.8 \\
\end{array}$ & $\begin{array}{r}49 \\
52.5 \\
\end{array}$ & $\begin{array}{l}77.2 \\
82.8 \\
\end{array}$ & $\begin{array}{l}4100 \\
4082 \\
\end{array}$ & $\begin{array}{l}9750 \\
9683 \\
\end{array}$ & $\begin{array}{l}12250 \\
12166 \\
\end{array}$ & $\begin{array}{l}19300 \\
19169 \\
\end{array}$ & & & & \\
\hline Anglers 1 & $\begin{array}{l}\text { predicted } \\
\text { model output }\end{array}$ & $\begin{array}{l}1.8 \\
1.9 \\
\end{array}$ & $\begin{array}{l}4.9 \\
5.3 \\
\end{array}$ & $\begin{array}{l}5.9 \\
6.3 \\
\end{array}$ & $\begin{array}{r}19.7 \\
21 \\
\end{array}$ & $\begin{array}{l}450 \\
472 \\
\end{array}$ & $\begin{array}{l}1225 \\
1313 \\
\end{array}$ & $\begin{array}{l}1475 \\
1569 \\
\end{array}$ & $\begin{array}{l}4925 \\
5242 \\
\end{array}$ & $\begin{array}{l}3.4 \\
3.6 \\
\end{array}$ & $\begin{array}{l}9.3 \\
9.9 \\
\end{array}$ & $\begin{array}{l}11.2 \\
11.9 \\
\end{array}$ & $\begin{array}{l}37.4 \\
39.6 \\
\end{array}$ \\
\hline & predicted & 1.2 & 3.2 & 4.3 & 9.5 & 300 & 800 & 1075 & 2375 & 2.3 & 6.1 & 8.2 & 18.1 \\
\hline Anglers 2 & model output & 1.2 & 3.4 & 4.6 & 10.2 & 312 & 842 & 1141 & 2537 & 2.4 & 6.4 & 8.6 & 19.2 \\
\hline & predicted & 12.8 & 48.7 & 52 & 57.6 & 3200 & 12175 & 13000 & 14400 & 24.3 & 92.5 & 98.8 & 109.4 \\
\hline Subsistence Fishers 1 & model output & 13.6 & 51.8 & 55.3 & 61.2 & 3399 & 12949 & 13823 & 15309 & 25.7 & 98 & 104.6 & 115.8 \\
\hline & predicted & 14.1 & 26.4 & 40.8 & 93.4 & 3525 & 6600 & 10200 & 23350 & 26.8 & 50.2 & 77.5 & 177.5 \\
\hline Subsistence Fishers 2 & model output & 15 & 28.1 & 43.4 & 99.2 & 3744 & 7016 & 10842 & 24811 & 28.2 & 53 & 82 & 187.6 \\
\hline
\end{tabular}

Fish tissue concentration for all samples was $0.3 \mathrm{mg} / \mathrm{kg}$. Predicted values for blood concentration are based on Sherlock et al. (1984).

Predicted hair concentrations were calculated based on Clarkson (2007). Predicted fetal blood concentrations were based on Stern and Smith (2003).

*Blood concentrations for the populations of children was not taken from Sherlock because his work was based on an adult body weight. The predicted values were back-calculated from the model, with the assumption that disposition in children is the same as disposition in adults. 

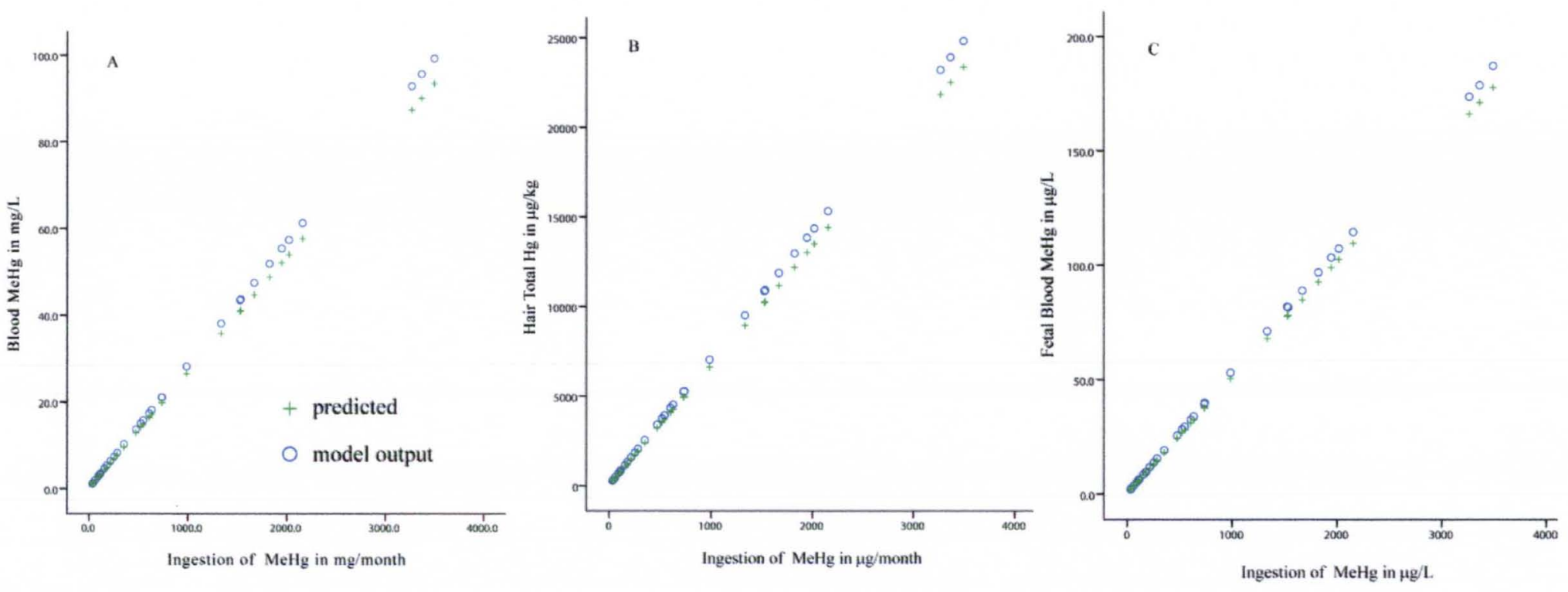

Figure 7. Comparison of model output to predicted values based on calibration sources for each biomarker of interest. Predicted values were generated from defined intake rates for each population and based on a $\mathrm{MeHg}$ fish tissue concentration of $300 \mu \mathrm{g} / \mathrm{kg}$. The comparison show the relationship between ingestion and (A) blood $\mathrm{MeHg}$, (B) total hair $\mathrm{Hg}$, and (C) fetal blood MeHg. 

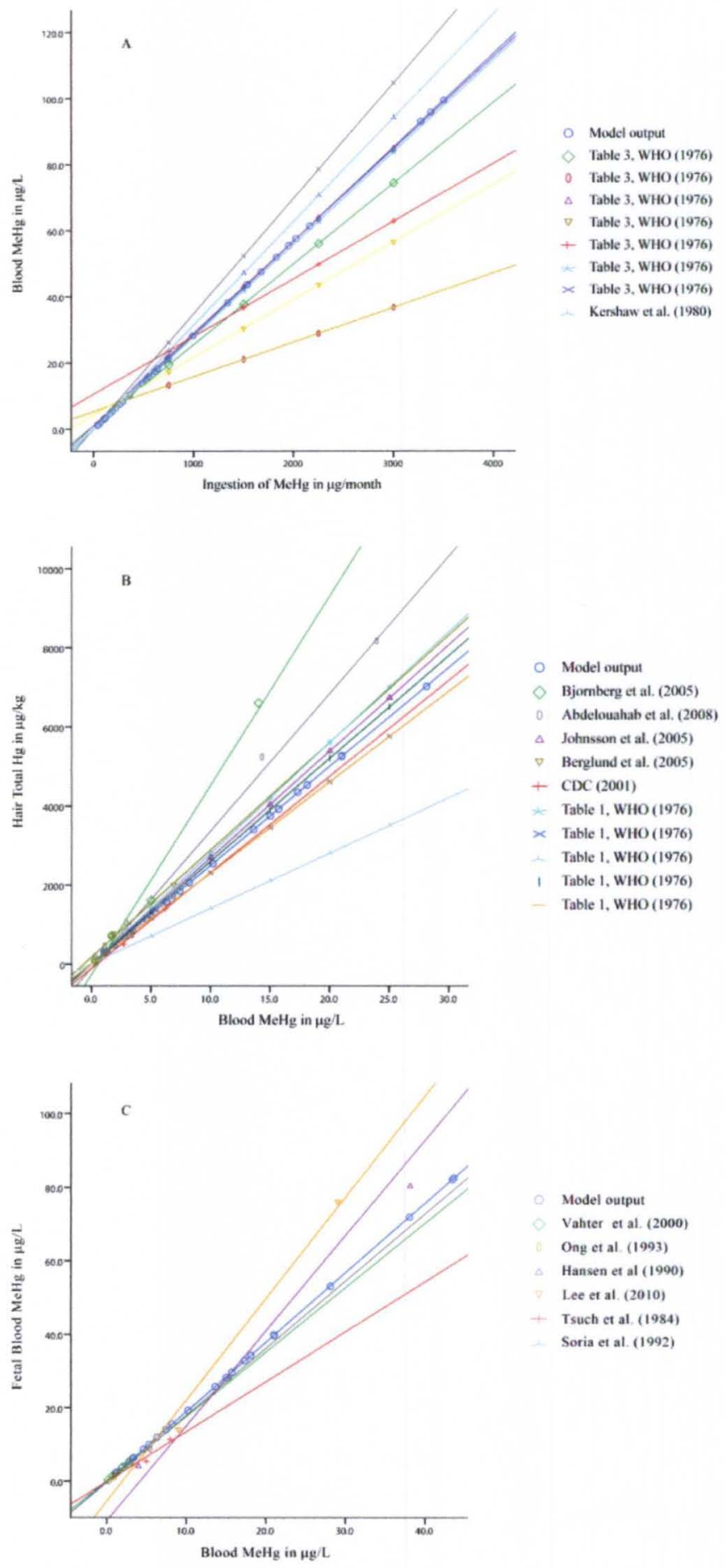

Figure 8. The model was evaluated by comparing output to literature sources for each biomarker for a range of exposures. The relationships shown are between (A) ingestion and blood $\mathrm{MeHg}$, (B) blood $\mathrm{MeHg}$ and total hair $\mathrm{Hg}$, and (C) blood $\mathrm{MeHg}$ and fetal blood MeHg. 
Table 4. Chi-squared analysis p-values of predicted versus observed model output.

\begin{tabular}{|c|r|r|r|}
\hline Ingestion rate & Blood & Hair & $\begin{array}{c}\text { Fetal } \\
\text { Blood }\end{array}$ \\
\hline mean & 0.500 & 0.456 & 0.450 \\
\hline 90 & 0.524 & 0.395 & 0.450 \\
\hline 95 & 0.395 & 0.395 & 0.382 \\
\hline 99 & 0.395 & 0.395 & 0.382 \\
\hline
\end{tabular}

Table 5. Literature sources for evaluation.

\begin{tabular}{|l|c|c|c|}
\hline \multicolumn{1}{|c|}{ Literature Source } & $\begin{array}{c}\text { Ingestion/ } \\
\text { Blood MeHg }\end{array}$ & $\begin{array}{c}\text { Blood MeHg// } \\
\text { Hair THg }\end{array}$ & $\begin{array}{c}\text { Blood MeHg/ } \\
\text { Fetal Blood } \\
\text { MeHg }\end{array}$ \\
\hline as cited in Table 3 of WHO (1976) & $\mathbf{X}$ & & \\
\hline Kershaw et al. (1980) & $\mathbf{X}$ & & \\
\hline Abdelhouahab, et al. (2008) & & $\mathbf{X}$ & \\
\hline Bjornberg et al. (2005b) & & $\mathbf{X}$ & \\
\hline as cited in Table 1 of WHO (1976) & & $\mathbf{X}$ & \\
\hline Vahter et al. (2000) & & & $\mathbf{X}$ \\
\hline Tsuchiya et al. (1984) & & & $\mathbf{X}$ \\
\hline Ong et al. (1993) & & & $\mathbf{X}$ \\
\hline Hansen et al. (1990) & & & \\
\hline
\end{tabular}

For evaluation of the relationship between maternal and fetal blood, the summary statistics reported from five literature sources were used as data points to generate regression equations. These summary statistics included the mean for all studies and the range or the $95 \%$ confidence interval. In addition, some studies also reported the median or a range of percentiles. The slope of the regression for each literature source was then determined.

The relationship between blood $\mathrm{MeHg}$ and hair $\mathrm{THg}$ was evaluated by comparing the slope of model output to the slopes of nine literature sources that studied 11 populations. Summary statistics were used to generate a regression equation for five 
literature sources. For the remaining six sources, regression equations were reported and a range of blood $\mathrm{MeHg}$ concentrations were input into the equations to generate hair concentrations for the scatterplot. The regression equations for five of these sources were reported in Table 1 from the WHO (1976).

Figure 8A compares the model output to eight literature sources for the relationship between ingestion and blood $\mathrm{Hg}$ levels. The mean and $95 \%$ confidence interval of the slope for the literature values was $0.024(0.008-0.040)$. The slope for model output was 0.028 . The slope of model output was not different from literature values.

The relationship between blood $\mathrm{MeHg}$ and total hair $\mathrm{Hg}$ concentrations for model output and the results of 9 literature sources that reported on 11 populations is shown in Figure 8B. Model output falls within the range of measurements found in the literature. The mean of the slopes for the literature values was 283 with a $95 \%$ confidence interval of 235 to 331 . The slope of model output, 250 , falls within that range, reflecting no difference between model output and literature sources.

The relationship between maternal and fetal blood $\mathrm{MeHg}$ for five literature sources and model output is shown in Figure 8C. The slopes of literature sources had a mean and $95 \%$ confidence interval of $2.06(1.49-2.62)$. The slope of model output was 1.89 and falls within the range of literature sources.

\section{Bioaccumulation}

Seven watersheds in Kentucky were chosen to calibrate the model. Seven basins from outside of Kentucky were chosen to evaluate the model and to determine the limits 
of model application. All basins were selected based on the availability of fish tissue and water quality data. Evaluation basins were further limited to sites with similarities to calibration sites in basin area and wetlands coverage. Locations of calibration and evaluation watersheds are shown in Figure 9, with general site characteristics given in Table 6. More detailed maps showing land cover for calibration and evaluation basins can be found in Appendix C. The Floyds Fork basin, at $70 \mathrm{~km}^{2}$, was substantially smaller than the other calibration watersheds, which had areas between 399 and $930 \mathrm{~km}^{2}$. Evaluations basins similarly had one smaller basin, Spring Creek in Georgia with an area of $98 \mathrm{~km}^{2}$. The range of the remaining basins was 220 to $1440 \mathrm{~km}^{2}$.

Natural variability in environmental systems is considerable. Examination of fish tissue data showed considerable variability with samples of the same species from the same site. In order to compare model output to trophic level means for a particular site, an understanding of the natural variability inherent within stream systems was necessary. The National Fish Database contains over 100,000 records of $\mathrm{Hg}$ in fish tissue from various sources compiled by the USGS (USGS and NIEHS 2006). This database was analyzed to quantify the natural variability found between fish of the same species of similar size from the same site and collection year. Many of these samples were composites of similarly sized fish of the same species. The dataset was analyzed by selecting for the most commonly sampled species that fit within the range of 0.75 and 1.25 times the quality length for that species. Selections were further grouped and limited to samples that had six or more of the same species from the same site and collected the same year. This resulted in 1010 groups. The standard deviation was determined for each of these 
Table 6. Site characteristics.

\begin{tabular}{|c|c|c|c|c|c|c|c|c|c|}
\hline Site & $\begin{array}{l}\text { Site } \\
\text { Abbr }\end{array}$ & $\begin{array}{c}\text { Area } \\
\mathrm{sq} \\
\mathrm{km}\end{array}$ & $\begin{array}{c}\text { Mean } \\
\text { annual } \\
\mathrm{Q} \\
\mathrm{m} 3 / \mathrm{s}\end{array}$ & $\begin{array}{c}\text { Mean } \\
\mathrm{pH}\end{array}$ & $\begin{array}{c}\text { Mean P } \\
\mathrm{mg} / 1\end{array}$ & $\begin{array}{l}\text { fraction } \\
\text { forested }\end{array}$ & $\begin{array}{c}\text { fraction } \\
\text { develop } \\
\text { ed }\end{array}$ & $\begin{array}{l}\text { fraction } \\
\text { wetlands }\end{array}$ & Sinuosity \\
\hline \multicolumn{10}{|l|}{ Calibration Sites $^{\mathrm{a}}$} \\
\hline Floyds Fork & $\mathrm{FF}$ & 70 & 1.0 & 7.79 & 0.1920 & 0.359 & 0.375 & 0.006 & 1.81 \\
\hline Mayfield Creek & $\mathrm{MF}$ & 759 & 12.2 & 6.96 & 0.1972 & 0.234 & 0.064 & 0.042 & 1.00 \\
\hline Mud River & MD & 689 & 11.1 & 7.37 & 0.0607 & 0.497 & 0.059 & 0.007 & 2.00 \\
\hline Nolin & NL & 930 & 14.1 & 7.46 & 0.2139 & 0.246 & 0.093 & 0.000 & 1.59 \\
\hline Salt River & ST & 451 & 7.2 & 8.03 & 0.2889 & 0.244 & 0.088 & 0.000 & 2.13 \\
\hline Slate Creek & SE & 399 & 5.7 & 7.85 & 0.1005 & 0.343 & 0.027 & 0.000 & 1.44 \\
\hline Tygarts Creek & TG & 720 & 8.8 & 7.63 & 0.0193 & 0.688 & 0.078 & 0.000 & 1.60 \\
\hline \multicolumn{10}{|l|}{ Evaluation Sites } \\
\hline Big Creek, IN & $\mathrm{BC}$ & 220 & 2.1 & 8.06 & 0.0704 & 0.099 & 0.092 & 0.000 & 1.48 \\
\hline Little Kanawha River, WV & LK & 1448 & 17.0 & 7.32 & 0.2085 & 0.857 & 0.051 & 0.000 & 1.40 \\
\hline Middle Island Creek, WV & MI & 1282 & 16.1 & 7.36 & 0.2085 & 0.877 & 0.046 & 0.000 & 1.25 \\
\hline Muscatatuck River, IN & MS & 733 & 8.0 & 8.05 & 0.1506 & 0.471 & 0.050 & 0.000 & 1.19 \\
\hline N. Fork Forked Deer River, TN & FD & 448 & 5.2 & 6.85 & 0.2141 & 0.162 & 0.077 & 0.095 & 1.06 \\
\hline Spring Creek, GA & SC & 98 & 1.4 & 8.07 & 0.0796 & 0.477 & 0.072 & 0.005 & 1.21 \\
\hline Talking Rock Creek, GA & TR & 738 & 8.1 & 7.83 & 0.0441 & 0.796 & 0.064 & 0.003 & 1.25 \\
\hline
\end{tabular}




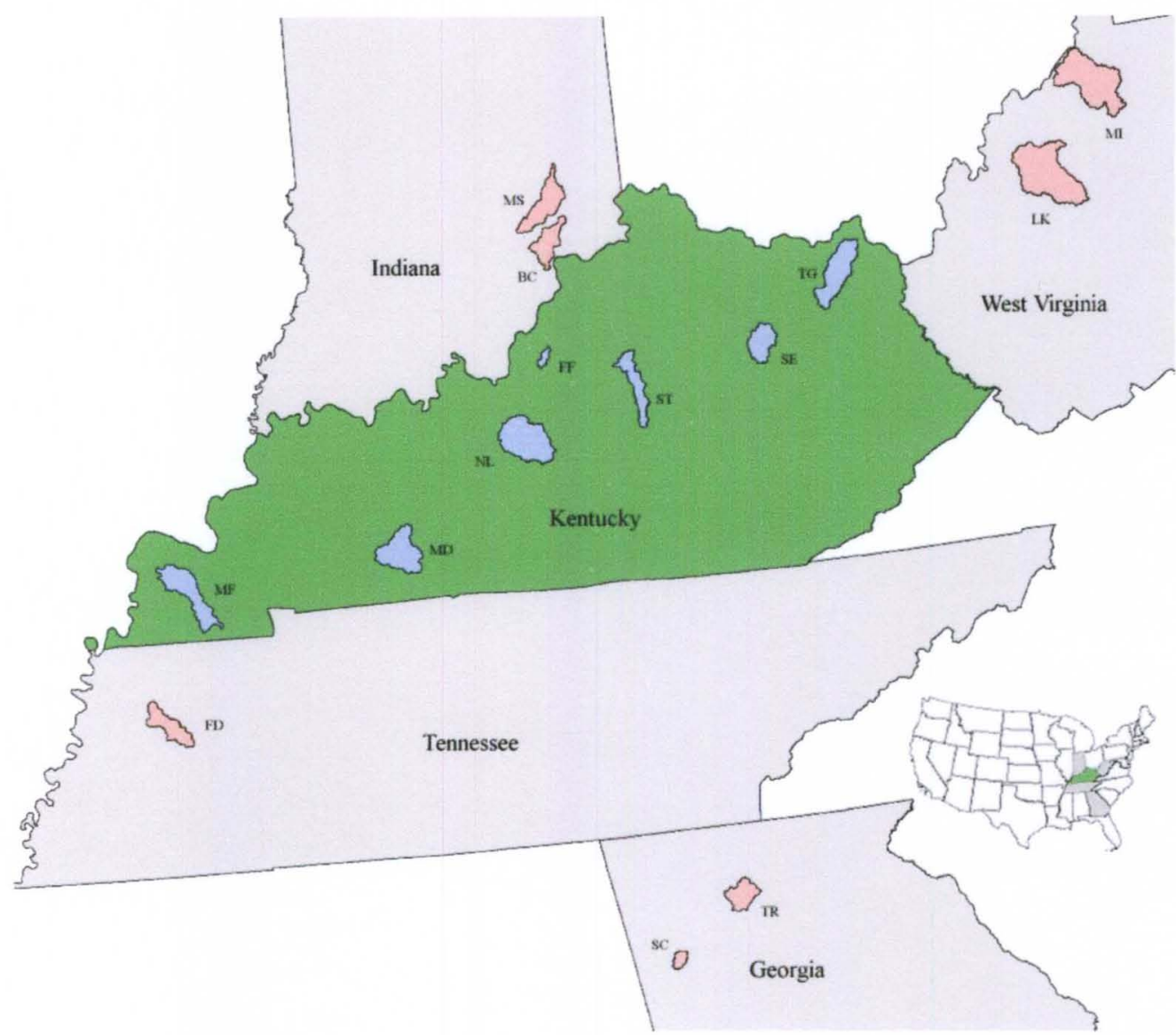

Figure 9. Map of calibration and evaluation basins. Sites in the green state are calibration basins, while sites in the gray states are evaluation basins. See Table 6 for abbreviations of site names.

groups, and the mean of these standard deviations was found to be 0.116 . This mean was used to calculate a $95 \%$ confidence interval $(\mathrm{CI})$ around the fish tissue means for calibration and evaluation sites. If the calculated lower bound of the confidence interval was negative, this lower bound was set to 0 .

Fit was evaluated by two methods; by calculating prediction error and comparing model output to the $95 \%$ CI. Sample means, the bounds of the $95 \%$ CI, and prediction error are shown in Table 7. Mean error for calibration sites was $26 \%$ and $51 \%$ for 
evaluation sites. The model projection fell within the $95 \%$ CI for all but one of the 23 trophic level-site combinations. The site that was outside of these bounds was the Muscatatuck River in Indiana. The model projection was much lower than the sample mean. Error for the two Indiana sites and TL3 of the Little Kanawha River in West Virginia was more than twice that of other evaluation sites. The model projection was much lower than the actual samples for all four trophic level-site combinations in Indiana, but higher for TL3 of the Little Kanawha River. Without these three sites, the mean error for the remaining evaluation sites was $26 \%$. Mean error was lowest for TL4 and highest for TL3 (Table 8).

Land cover varied between basins. Forested coverage varied widely while wetlands coverage was minimal to non-existent for all but two basins. With one exception, most basins were in rural areas with little development. Regression analyses of land cover fractions compared to error were undertaken to evaluate if the model performed more accurately based on land cover attributes. No difference was found for model accuracy based on land cover (data not shown).

To test the robustness of the model a sensitivity analysis was performed. For sensitivity to $\mathrm{Hg}$ loading, both total and dissolved $\mathrm{Hg}$ were manipulated for three systems with a range of land cover uses. Figure 10 shows the response of fish tissue to percent reductions in both total and dissolved $\mathrm{Hg}$ for Tygarts Creek, the Mud River, and Mayfield Creek. Reductions in THg showed a threshold effect in fish tissue levels, while reductions in dissolved $\mathrm{Hg}$ were linear. 
Table 7. Fish tissue $\mathrm{Hg}(\mathrm{mg} / \mathrm{kg})$ of sample mean with $95 \%$ confidence interval compared to model output and calculated prediction error.

\begin{tabular}{|c|c|c|c|c|c|c|}
\hline \multicolumn{7}{|c|}{$\begin{array}{c}\text { Error calculation } \\
\qquad 95 \% \mathrm{CI}\end{array}$} \\
\hline Site & $\mathrm{TL}$ & sample & lower & upper & model & error \\
\hline \multicolumn{7}{|c|}{ Calibration sites } \\
\hline FF & 3.5 & 0.179 & 0.018 & 0.340 & 0.177 & 0.01 \\
\hline FF & 3 & 0.138 & 0.000 & 0.365 & 0.068 & 0.51 \\
\hline MD & 4 & 0.366 & 0.139 & 0.593 & 0.430 & 0.17 \\
\hline MD & 3.5 & 0.176 & 0.062 & 0.290 & 0.260 & 0.48 \\
\hline MD & 3 & 0.085 & 0.000 & 0.186 & 0.096 & 0.13 \\
\hline MF & 3.5 & 0.247 & 0.020 & 0.474 & 0.248 & 0.00 \\
\hline ST & 3.5 & 0.179 & 0.048 & 0.310 & 0.114 & 0.36 \\
\hline ST & 3 & 0.073 & 0.000 & 0.300 & 0.045 & 0.38 \\
\hline NL & 3.5 & 0.170 & 0.000 & 0.397 & 0.106 & 0.38 \\
\hline \multirow[t]{2}{*}{ SE } & 4 & 0.190 & 0.000 & 0.417 & 0.217 & 0.14 \\
\hline & & & & & MEAN & 0.26 \\
\hline \multicolumn{7}{|c|}{ Evaluation sites } \\
\hline $\mathrm{SC}$ & 3.5 & 0.262 & 0.160 & 0.364 & 0.191 & 0.27 \\
\hline $\mathrm{SC}$ & 3 & 0.123 & 0.009 & 0.237 & 0.071 & 0.42 \\
\hline TR & 3.5 & 0.271 & 0.195 & 0.347 & 0.268 & 0.01 \\
\hline $\mathrm{TR}$ & 3 & 0.065 & 0.000 & 0.158 & 0.076 & 0.17 \\
\hline $\mathrm{BC}$ & 3.5 & 0.260 & 0.033 & 0.487 & 0.057 & 0.78 \\
\hline $\mathrm{BC}$ & 3 & 0.120 & 0.000 & 0.281 & 0.022 & 0.82 \\
\hline MS & 3.5 & 0.330 & 0.103 & 0.557 & 0.033 & 0.90 \\
\hline MS & 3 & 0.097 & 0.000 & 0.228 & 0.012 & 0.88 \\
\hline FD & 4 & 0.426 & 0.265 & 0.587 & 0.355 & 0.17 \\
\hline FD & 3.5 & 0.162 & 0.001 & 0.323 & 0.217 & 0.34 \\
\hline LK & 3.5 & 0.174 & 0.081 & 0.267 & 0.096 & 0.45 \\
\hline LK & 3 & 0.018 & 0.000 & 0.245 & 0.035 & 0.94 \\
\hline \multirow[t]{2}{*}{ MI } & 3.5 & 0.179 & 0.048 & 0.310 & 0.103 & 0.42 \\
\hline & & & & & MEAN & 0.51 \\
\hline
\end{tabular}

Table 8. Prediction error by trophic level.

\begin{tabular}{lccc} 
& \multicolumn{3}{c}{ Trophic Level } \\
& 3 & 3.5 & 4 \\
Calibration sites & 0.34 & 0.25 & 0.16 \\
Evaluation sites & 0.65 & 0.38 & 0.17
\end{tabular}




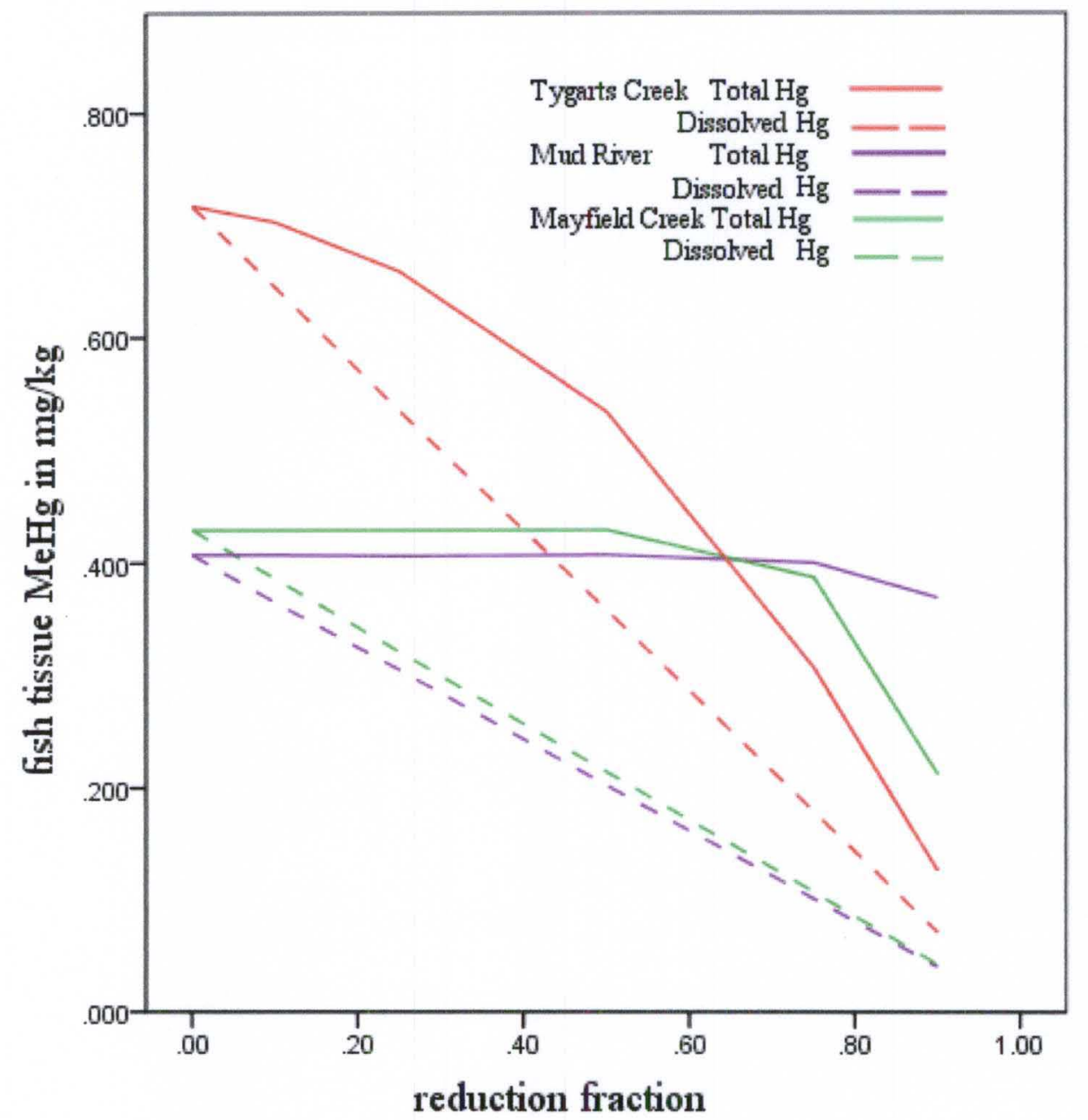

Figure 10. Sensitivity of model output to reductions in total and dissolved $\mathrm{Hg}$ for three basins representing a range of land cover characteristics.

The sensitivity of the model to other input variables was tested by assessing the impact of manipulating these variables one at a time within a plausible natural range for one of the modeled systems. The Mud River site was chosen for the sensitivity analysis because of ample water quality and fish tissue data and land cover and water quality parameters that were average compared to the other systems. Parameters that were manipulated included the nutrient level, $\mathrm{pH}$, sinuosity, water temperature, and the fractions of land cover that were forested, wetlands, or developed. Model output in 
response to these changes is shown in the Table 9. When phosphorus levels were increased by $300 \%$, model output decreased by $10 \%$, but when levels were halved, model output increased by more than $50 \%$. Similarly, when the fraction of land cover that was forested was halved, a 5\% change in output was realized, but when it was doubled, the model projected fish tissue levels more than $100 \%$ greater. An increase of wetlands coverage to $35 \%$ resulted in a fish tissue increase of more than $300 \%$. Alternatively, manipulating the water temperature, $\mathrm{pH}$, and the fraction of the watershed that was developed resulted in changes in output of less than $10 \%$. Modifying sinuosity resulted in an output change of less than $15 \%$. 
Table 9. Sensitivity analysis. Manipulation of variables for the Mud River system. Output is fish tissue $\mathrm{Hg}$ in $\mathrm{mg} / \mathrm{kg}$.

\begin{tabular}{|c|c|c|c|c|c|c|c|c|c|c|c|c|}
\hline \multirow[b]{2}{*}{ TL } & \multirow[b]{2}{*}{ Initial } & \multicolumn{2}{|c|}{ nutrient level } & \multicolumn{2}{|c|}{ fraction forested } & \multicolumn{2}{|c|}{ fraction wetlands } & \multicolumn{2}{|c|}{$\mathrm{pH}$} & \multirow{2}{*}{$\begin{array}{l}\text { sinuosity } \\
\Delta \text { to } 1.0\end{array}$} & \multicolumn{2}{|c|}{$\begin{array}{c}\text { water } \\
\text { temperature }\end{array}$} \\
\hline & & X 3 & $\mathrm{X} 0.5$ & X 0.5 & X 2 & X 3 & $\begin{array}{l}\Delta \text { to } \\
0.35 \\
\end{array}$ & -2.0 & +1.0 & & $+1^{0} \mathrm{C}$ & $+3^{0} \mathrm{C}$ \\
\hline 4 & 0.446 & 0.399 & 0.797 & 0.424 & 0.910 & 0.449 & 1.880 & 0.451 & 0.438 & 0.386 & 0.438 & 0.426 \\
\hline 3.5 & 0.246 & 0.223 & 0.436 & 0.235 & 0.500 & 0.248 & 1.040 & 0.249 & 0.243 & 0.214 & 0.243 & 0.236 \\
\hline 3 & 0.051 & 0.047 & 0.080 & 0.049 & 0.088 & 0.051 & 0.215 & 0.051 & 0.050 & 0.044 & 0.050 & 0.048 \\
\hline
\end{tabular}

$\mathrm{TL}$ - trophic level

"Initial" indicates model output before variable manipulation. 


\section{Policy and Climate Change Analyses}

\section{Fish Consumption Advisories and Population Choices}

Figure 11 illustrates the blood $\mathrm{MeHg}$ biomarker for the intake rates of the mean, $90^{\text {th }}, 95^{\text {th }}$, and $99^{\text {th }}$ percentile of each population in response to a range of fish tissue $\mathrm{Hg}$ levels. Comparing the biomarker across populations, it is apparent that the angler populations had the lowest exposure levels, and the children and women consumers had the highest exposures, illustrating the importance of the population chosen to determine if populations are adequately protected. In addition to the general level of exposure, each population had a unique pattern of blood $\mathrm{MeHg}$ concentrations. For the anglers 1 and 2 and children consumers populations, the pattern shows the $99^{\text {th }}$ percentile intake rate had a much higher blood $\mathrm{MeHg}$ concentration than the mean, $90^{\text {th }}$ and $95^{\text {th }}$ percentiles.

Conversely, for the women consumers and subsistence fishers 2 populations, the blood $\mathrm{MeHg}$ levels were fairly evenly spaced between each distribution rate. For the subsistence fishers 1 population, the $90^{\text {th }}, 95^{\text {th }}$, and $99^{\text {th }}$ percentile intake rates had very similar blood MeHg levels, well above the mean. While the response pattern of each population was unique in the distribution of blood $\mathrm{MeHg}$ biomarker, for a given population, this pattern was the same for total hair $\mathrm{Hg}$ and fetal blood $\mathrm{Hg}$ biomarkers (data not shown). 

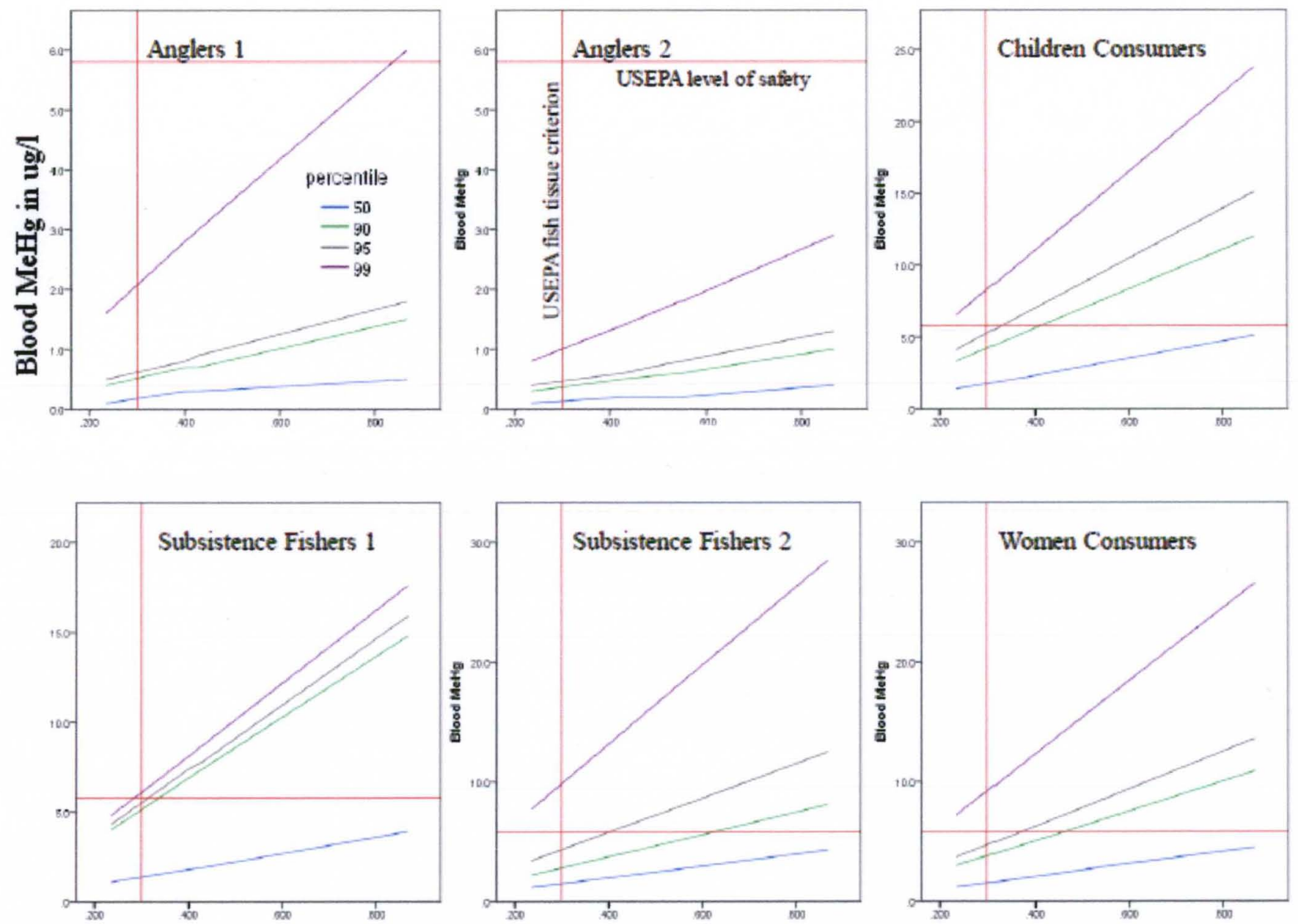

Fish tissue in $\mathrm{mg} / \mathrm{kg}$

Figure 11. Response of the blood MeHg biomarker to changes in fish tissue concentration for susceptible populations. 
In addition to identifying the population most at risk from a particular water body, agencies must also choose a level of action. Commonly, the central tendency, $90^{\text {th }}$ or $95^{\text {th }}$ percentile of intake rates is selected (Shilling et al. 2010). Figure 11 includes both the USEPA level of safety for MeHg in blood (5.8 ug/l) (USEPA 2010a) and the USEPA criterion for $\mathrm{MeHg}$ in fish tissue $(0.300 \mathrm{mg} / \mathrm{kg}$ ) (USEPA $201 \mathrm{e})$. The figures illustrate that $95 \%$ of all the simulated populations are protected when fish tissue concentrations of $\mathrm{MeHg}$ are below the USEPA criterion of $0.300 \mathrm{mg} / \mathrm{kg}$. However, as evidenced by the number of fish consumption advisories, many stream systems exceed this level. In this model simulation, the $95^{\text {th }}$ percentile of the subsistence and consumer populations exceeded the USEPA level of safety for MeHg in blood at levels just above the USEPA fish tissue criterion. Thus, while the criterion is protective for these populations, the margin of error is small. For the Subsistence Fishers 1 population, the $90^{\text {th }}, 95^{\text {th }}$, and $99^{\text {th }}$ percentile intake rates are very similar. While only the $99^{\text {th }}$ percentile exceeds the level of safety for blood $\mathrm{MeHg}$ at intake concentrations at the USEPA criterion, the $90^{\text {th }}$ and $95^{\text {th }}$ percentile exceed the level of safety at fish tissue concentrations just above the criterion. Compared to the Women Consumers population, a fish tissue concentration of 0.360 $\mathrm{mg} / \mathrm{kg}$ is required for the $95^{\text {th }}$ percentile to exceed the level of safety, while a concentration of 0.460 is required for the $90^{\text {th }}$ percentile to exceed the safety level. Clearly, the choice of population and the portion of the population to be protected are both critical decisions in determining the action level for setting fish consumption advisories. 


\section{Emissions Reductions}

Figure 12 shows the response of the Subsistence Fishers 1 population to reductions in $\mathrm{THg}$ for three stream systems. For all three stream systems, the portion of the population that consumes fish at or below the mean intake rate for that population remains below the level established as protective of the developing fetus by the USEPA. However, as the concentration of $\mathrm{Hg}$ is decreased, the portion of the population that is protected is dependent on the stream system being simulated. Ninety-nine percent of the population is protected with a $\mathrm{Hg}$ concentration in water of $0.5 \mathrm{ng} / \mathrm{l}$ for the Mud River, but that level of reduction only affords protection for $90 \%$ of the population fishing from Mayfield Creek, and does less than that for Tygarts Creek. For Mayfield and Tygarts Creeks, a $\mathrm{Hg}$ concentration of $0.3 \mathrm{ng} / \mathrm{L}$ would be needed to protect $99 \%$ of the Subsistence Fisher 1 population. Even though these 2 systems offer the same degree of protection at this level, the reduction in blood $\mathrm{MeHg}$ is much greater in Tygarts Creek than Mayfield Creek for a reduction from $1 \mathrm{ng} / \mathrm{l}$ to $0.3 \mathrm{ng} / \mathrm{lof} \mathrm{THg}$ in the water column. 

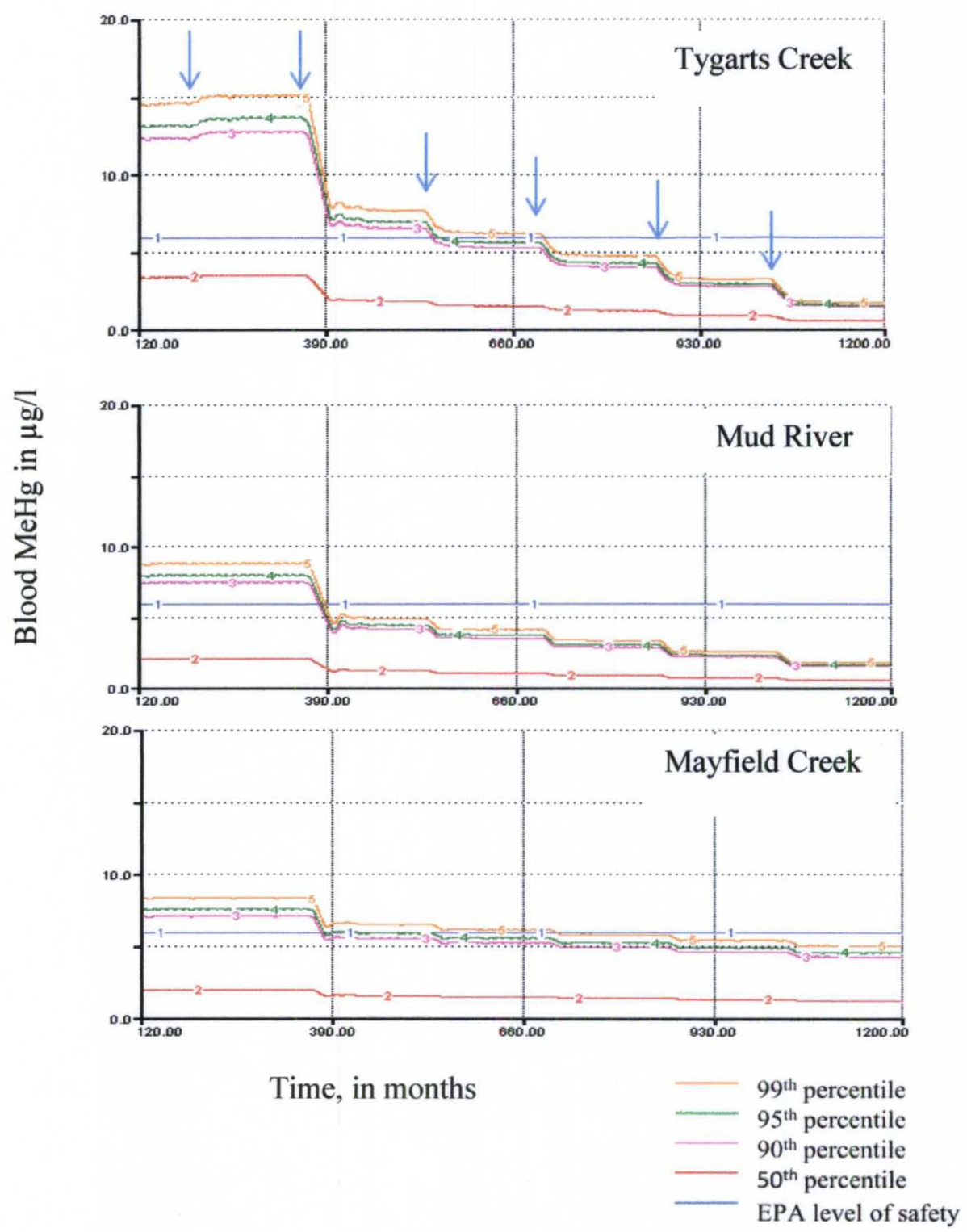

Figure 12. Impact of reduction in $\mathrm{THg}$ on blood $\mathrm{MeHg}$ biomarker for the Subsistence Fisher 1 population. Arrows reflect changes in $\mathrm{THg}$ in water concentration from measured mean monthly $\mathrm{THg}$, to $1.0,0.5,0.4,0.3,0.2,0.1$ ng/l. 


\section{Watershed Management Strategies}

Figure 13 shows the response in population biomarkers to modification of sensitive watershed parameters. The degree of change in fish tissue $\mathrm{Hg}$ and subsequent population exposure resulting from changes in watershed variables depend on the modeled basin and the variable being modified. Whether this change in a watershed parameter has substantial impacts on population biomarkers also depends on the population being simulated.

The previous analysis of the bioaccumulation model found that the system was sensitive to perturbations in three watershed variables: nutrient loads and the fraction of the watershed that was forested or in wetlands. When nutrient levels were set at a minimal level (Figure 13A), population Hg biomarkers increased substantially for 4 of the 6 populations in the Mayfield Creek and Mud River basins while all blood MeHg levels remained relatively unchanged for Tygarts Creek. Nutrient levels were highest in Mayfield Creek (mean annual P of $0.1972 \mathrm{mg} / \mathrm{l}$ ), average in the Mud River (mean annual $\mathrm{P}$ of $0.0607 \mathrm{mg} / \mathrm{l}$ ), and low in Tygarts Creek (mean annual P of $0.0193 \mathrm{mg} / \mathrm{l}$ ). As expected, the deviation in nutrient levels imposed by the user for Tygarts Creek caused no change because this system already had low nutrient levels. Surprisingly, the magnitude of response for both Mayfield Creek and the Mud River were similar even though the default levels of phosphorus differed by a factor of 3 . Setting a high level of phosphorus reduced population biomarkers for 4 of the 6 populations in Tygarts Creek, but elicited little change in any populations in Mayfield Creek or the Mud River over the default level. These responses suggest a threshold range of phosphorus over which higher 
levels will not decrease fish tissue further and lower levels of the nutrient will not result in further increases in fish tissue. Within this range, nutrient levels impact the efficiency of bioaccumulation. When assessing a stream system, regulators can use this information to determine if changes in fertilizer use in the basin will modify bioaccumulation efficiency.

No response in population biomarkers was found for Mayfield Creek when the fraction of the basin that was forested was set to a low fraction (Figure 13B). This reflects the existing low forested coverage in the basin. When the fraction that was forested was increased, 4 populations had a greater than $200 \%$ increase in blood $\mathrm{MeHg}$. The Anglers 1 and 2 populations increased to a lesser degree than the other populations. The Mud River showed a minimal response to a reduction in forested coverage for 4 populations, but a substantial increase in blood $\mathrm{MeHg}$ for those same populations when the fraction of forested coverage was high. Tygarts Creek showed a greater response to a low forested coverage level for 4 populations, while no response was found for a higher fraction of forested coverage. Forested coverage increases bioaccumulation efficiency, substantially increasing exposure for populations with high consumption rates. 
A. basin variable: nutrients

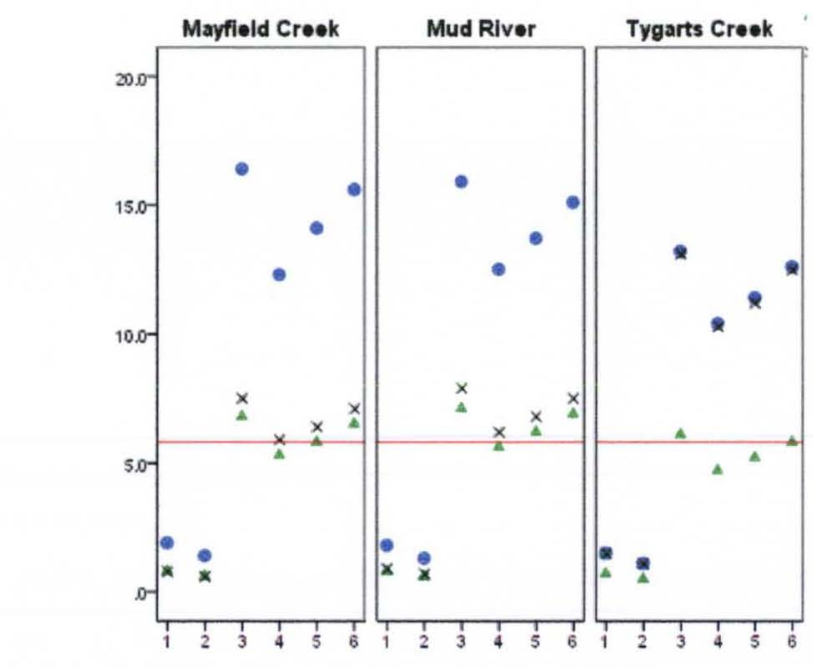

¿̊

- low

A high

$\times$ default

USEPA level of safety
B. basin variable: forested land cover

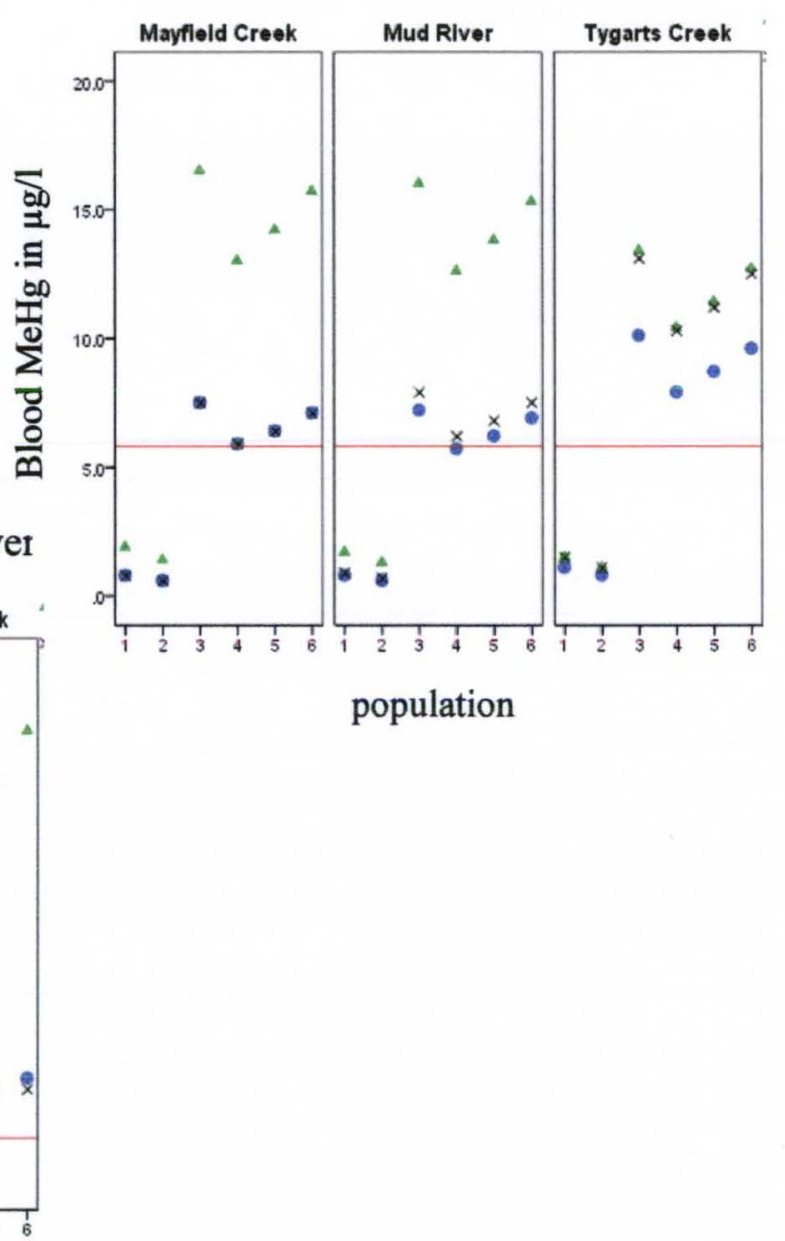

Figure 13. Impact of changes in sensitive basin parameters on populations. X-axis: population: $1=$ anglers $1,2=$ anglers 2 , $3=$ subsistence fishers $1,4=$ subsistence fishers $2,5=$ children consumers, $5=$ women consumers 
Manipulating wetlands coverage from low to high values showed a similar pattern (Figure 13C). Mayfield Creek, which had the highest wetlands coverage of the three streams at $4 \%$, showed little change in blood $\mathrm{MeHg}$ when lowering coverage to $1 \%$, but a strong response of increased blood $\mathrm{MeHg}$ when wetlands coverage was raised to $35 \%$ for 4 of the populations. Population blood MeHg responded similarly for the Mud River, although a slightly larger response was seen in the Anglers 1 and 2 populations for high wetlands coverage. Biomarker response was greatest for Tygarts Creek which has no wetlands coverage. Setting wetlands coverage to the low level resulted in a slight increase in blood $\mathrm{MeHg}$ for 4 populations, and the high wetlands coverage setting showed substantial increases in all population biomarker levels. The presence of wetlands in a basin increases exposure to susceptible populations.

\section{Climate Change Scenarios}

Table 10 shows the outcome of climate change on TL4 fish tissue. Water temperature had little effect on bioaccumulation efficiency in these streams. Increasing the frequency of high precipitation events, as defined by the number of events greater than 0.5 inches, resulted in substantial reductions in fish tissue $\mathrm{Hg}$ for the three simulated stream systems. The combination of increased water temperature and high precipitation also resulted in reductions in fish tissue $\mathrm{Hg}$, reflecting the stronger effects of intense precipitation events. 
Table 10. Climate change scenarios. TL4 fish tissue in $\mathrm{mg} / \mathrm{kg}$.

\begin{tabular}{|ll|lll|}
\hline \multirow{2}{*}{ Parameter } & $\begin{array}{l}\text { Parameter } \\
\text { change }\end{array}$ & $\begin{array}{l}\text { Mayfield } \\
\text { Creek }\end{array}$ & $\begin{array}{l}\text { Mud } \\
\text { River }\end{array}$ & $\begin{array}{l}\text { Tygarts } \\
\text { Creek }\end{array}$ \\
\hline \multirow{3}{*}{ water temperature $\left({ }^{\circ} \mathrm{C}\right)$} & none & 0.406 & 0.427 & 0.717 \\
\hline \multirow{3}{*}{ frequency of high precip } & +1 & 0.407 & 0.428 & 0.715 \\
\cline { 3 - 5 } & +2 & 0.407 & 0.431 & 0.717 \\
\cline { 3 - 5 } & +3 & 0.407 & 0.432 & 0.720 \\
\hline \multirow{2}{*}{$\begin{array}{l}\text { combined analysis } \\
\text { water temp }\left({ }^{\circ} \mathrm{C}\right) / \text { high precip }\end{array}$} & +1 & 0.379 & 0.405 & 0.675 \\
\cline { 3 - 5 } & +1.5 & 0.354 & 0.380 & 0.632 \\
\cline { 3 - 5 } & $+1 /+0.5$ & 0.328 & 0.357 & 0.591 \\
\cline { 3 - 5 } & $+3 /+1.5$ & 0.355 & 0.406 & 0.671 \\
\cline { 3 - 5 } & +1 & 0.329 & 0.364 & 0.594 \\
\hline
\end{tabular}




\section{CHAPTER V}

\section{DISCUSSION}

The purpose of the project was to design a model to evaluate the problem of human exposure to $\mathrm{Hg}$ from consumption of fish from local waterways. This model could assist decision-makers in the process of determining regulations or management strategies to protect populations of interest from excess $\mathrm{Hg}$ exposure. The model has two components. The human disposition model projects exposures to various populations based on fish tissue concentrations that are input by the user. The bioaccumulation model projects fish tissue $\mathrm{Hg}$ levels in defined basins. While models are available that focus on different aspects of this problem, combining the bioaccumulation and human disposition components facilitates the decision making process by directly connecting environmental contamination to the exposure of susceptible populations.

In the development of any model, a balance is sought between generating an accurate forecast with the simplest representation of the system, while being transparent. Transparency refers to a clear understanding of the model by both peer reviewers and the actual users of the model. Simplicity calls for breaking a system down to its most basic components so that it is easier to understand. Enough details of the system must be included for the model to be accurate for a variety of scenarios. The balance between simplicity and enough details can be difficult to judge. The ideal balance for these three competing goals depends on the purpose of the model (NRC 2007). Because the purpose 
of this model is to be a tool for regulatory decision-makers who may need to explain policy or management recommendations to lawmakers or stakeholders with limited scientific background, the goal is to accurately forecast population outcomes with the greatest simplicity in a format that could be understood by the educated layperson. The stock and flow diagrams will further enable these stakeholders to understand the parts of the system that may aid or hinder the reaching of ecosystem and human health goals, and the need for regulatory or management strategies that may not be intuitive.

The use of STELLA as a modeling tool has been successful in helping lay stakeholders understand complex systems in the process of developing policies that require stakeholder support for implementation. Stave (2003) developed a STELLA model to simulate the dynamics of water supply and use in Las Vegas. The model was used to analyze the impact of various policy options in order to maximize water supply over time. An important component of the policy analysis was to garner public support for the final policy recommendation. The STELLA model was successful in creating an understanding of the system without overwhelming the stakeholders with complicated technical equations. This understanding of the system was instrumental in implementing a water conservation policy that required stakeholder cooperation.

\section{Human disposition model}

It is important to distinguish between projected biomarkers of exposure and risk of an adverse effect (ECETOC 2005). The USEPA set the reference dose for MeHg at 5.8 $\mu \mathrm{g} / \mathrm{L}$ in cord blood for protection of the developing fetus and includes a safety factor of 10 (USEPA 2010a). The reference dose is often applied to maternal blood, but was established with the assumption that the ratio between fetal and maternal blood $\mathrm{MeHg}$ 
was unity. Fetal blood concentrations of $\mathrm{MeHg}$ are approximately $90 \%$ higher than in maternal blood, so a corresponding maternal blood level would be expected to be lower than the reference dose (Stern and Smith 2003). Decisions made from interpreting biomarkers of exposure must consider the uncertainty surrounding the relationship between biomarker levels and adverse effects as well as the natural variability in individuals and populations of the pharmacokinetics of MeHg (ECETOC 2005). With the long-term objective of linking proposed $\mathrm{Hg}$ regulations or management strategies to the protection of human populations, it is important to remember that this model does not simulate changes in an individual over a lifetime, but progressive changes in $\mathrm{Hg}$ levels in a population over 100 years. In analyzing population biomarkers, $\mathrm{Hg}$ disposition in individuals representing the distribution of intake rates for a given population are simulated. While the most accurate method of forecasting effects would be to model the movement of $\mathrm{Hg}$ through these individuals, the literature provides conflicting information on exactly how $\mathrm{Hg}$ is transported and transformed within the human body. A simplification of the dynamics of $\mathrm{Hg}$ disposition in the body was used to simulate common biomarkers and loss to the human system. Because of this simplification, this model should not be used to predict $\mathrm{Hg}$ concentrations in individuals or specific tissues. The model only forecasts the central tendency of certain biomarkers for a distribution of intake rates of defined populations.

The human disposition model forecasts blood $\mathrm{MeHg}$, fetal blood $\mathrm{MeHg}$, and total hair $\mathrm{Hg}$ concentrations in response to the intake rates of freshwater fish for various populations. The distribution of intake rates gives the user the opportunity to project what portion of the population would fall below the USEPA reference dose if fish tissue 
concentrations of $\mathrm{Hg}$ are reduced by a given amount. By limiting the intake to freshwater fish, the model more accurately simulates exposure from local sources. However, many populations consume larger amounts of marine or store-bought freshwater fish from nonlocal waters and exposure for those populations are likely to be inaccurate with this model. Subsistence fishers and anglers are likely to have the greatest portion of their fish intake from local sources, and therefore this model is expected to characterize $\mathrm{Hg}$ exposure in these higher risk populations more accurately than populations that ingest fish from other sources.

Ten population choices, described in Table 1, are available for users. Regulatory decision-makers should choose the population whose fish intake most closely resembles the population of concern. With a basic understanding of STELLA modeling, a user could alter the model to include the intake rates for any population of interest. While it seems counterintuitive that angler populations have lower intake rates at the highest percentiles than the general population, sampling methods and the frequency of fish meals impact the intake rates. With the exception of the angler and subsistence fisher populations, intake rates were derived from a national survey that asked subjects about fish meals over the past three days (USEPA and NCEA 1997). Consumers were those that reported any fish consumption during those three days. Because fish meals may be infrequent, a 3-day diary may have overestimated daily intake when extrapolated to a monthly rate. Both angler populations and the Subsistence Fishers 2 population used a 1year assessment of fish consumption (CRITFC 1994, Connelly et al. 1996, USEPA and NCEA 1997). The Subsistence Fishers 1 population was assessed over an eight-month period (Burger et al. 1999). Many anglers fish more frequently during certain seasons, 
and therefore fish intake may be much higher at certain times of the year. A longer assessment period for those who consume fish seasonally would result in a lower daily intake rate than if the assessment was taken during the highest consumption period. These methods may have resulted in a bias toward higher daily intake rates for the more general populations and lower daily intake rates for the angler and subsistence fisher populations.

The user sets a mean trophic level for consumption for the chosen population. While the trophic level can be adjusted during the model run, it cannot be adjusted to simulate the variability of trophic levels consumed by individuals. Anglers often prefer to fish for the predatory fish, such as largemouth bass and walleye, that tend to have the highest levels of $\mathrm{Hg}$ contamination. Subsistence fishers and children may consume more panfish because they are easier to catch. Panfish are typically lower on the food chain and subsequently have lower $\mathrm{Hg}$ concentrations. Because local consumers typically do not limit themselves to one species, the user may conservatively choose to enter the highest trophic level consumed, or, less conservatively, adjust the trophic level by weighting to reflect the intake of various species by a particular population from a particular waterway.

Perhaps the greatest challenge to the development of this model originates from varying time scales. Hg movement through environmental compartments occurs on a slower time scale than $\mathrm{Hg}$ movement through the human body. While changes in steady state levels in environmental compartments may take years or decades, changes within the human body can occur relatively quickly. In STELLA, a single time scale must be chosen for the entire model. The time scale of months was chosen to allow for simulation of seasonal changes in environmental compartments and to allow a 100 year model run 
without encountering memory problems. However, for human disposition, this time scale introduced complications. Movement from one stock to another takes at least 1 month, whereas in vivo, this movement may occur in hours or days. In order to minimize this limitation, the human sector of the model was streamlined. This streamlining was achieved by consolidating certain pathways. One consolidated pathway was the enterohepatic shunt. The model structure shows only the loss of $\mathrm{MeHg}$ through defecation instead of representing the entire pathway. The entire pathway includes $\mathrm{MeHg}$ removal from blood by the liver and subsequent secretion into the gut where most is reabsorbed into the blood and the remainder is lost through defecation. Streamlining pathways assisted the model in achieving steady state more quickly.

Because of the monthly time scale, time to reach steady state and the half-life of $\mathrm{Hg}$ in the human system is slower than what is found in the literature. The literature suggests that steady state for a new intake rate of $\mathrm{Hg}$ is reached in approximately a year (Sherlock et al. 1984). For this model, steady state within the human takes almost three years to be attained. Similarly, the half-life of $\mathrm{Hg}$ in the body is approximately $2 \frac{112}{2}$ months (Miettinen et al. 1971).The half-life of $\mathrm{Hg}$ in the model is about 12 months. When projecting changes over the short term, these differences are unacceptable. However, when examining change in populations over decades along with the uncertainty associated with $\mathrm{Hg}$ movement through environmental compartments, the imprecision of reaching steady state in three years instead of one year is likely to have a negligible effect on regulatory decision making.

The notion of steady state Hg levels in blood and other human compartments is somewhat misleading. Exposure to $\mathrm{Hg}$ occurs through periodic meals of contaminated 
fish and is therefore intermittent. After a meal, blood $\mathrm{Hg}$ levels peak after several hours and then have a biphasic decline. An initial rapid drop in $\mathrm{Hg}$ levels is followed by a much slower decline with a half-life of about $2 \frac{1}{2}$ months (Kershaw et al. 1980, Miettinen et al. 1971). For individuals that only occasionally eat fish, use of a steady state ratio to predict a biomarker of exposure could be misleading because the actual concentration in any sample would be highly dependent on the amount of time that had passed since the last meal. For individuals and populations that consume fish on an almost daily basis, the assumption that a steady state concentration has been attained is more reasonable. $\mathrm{Hg}$ concentration in blood would still be close to peak levels when the next exposure occurred. The question of biological relevance for projected biomarkers that have been derived by assuming a steady state ratio for individuals with intermittent exposures depends on whether acute or chronic exposure to $\mathrm{Hg}$ is responsible for adverse effects in the developing fetus. That question has not yet been answered, but these values based on steady state intake give some approximation for the amount of exposure. The steady state assumption is more accurate for populations that eat frequent fish meals. These populations are more likely to have the highest exposures to $\mathrm{Hg}$, and subsequently are at greater risk for adverse effects.

To investigate whether the values obtained from the model developed in this study are similar to the expected values based on previous literature, traditional Chisquared techniques were employed. These techniques test for differences between observed and expected values. Model output values were not significantly different than the calibration sources over a wide range of exposure levels. That is, the values obtained from the model were expected based on previous research. It should be noted however, 
that the model slightly overestimates biomarkers at the highest ingestion rates. At these levels, though, the variation in sampled populations is also at its greatest. The slight overestimation of biomarkers was shown to be negligible and insignificant when compared to population variability as shown by evaluation of the model and does not threaten the validity of the model.

Evaluation of the model consisted of comparing the model's parameter estimates (e.g. regression coefficients) with parameter estimates observed in the relevant literature. The relationship between ingestion and blood $\mathrm{MeHg}$ was validated using parameter estimates observed in eight studies (Table 5). The parameter estimates from these studies varied somewhat, perhaps reflecting variability in the populations sampled or bias from sampling methods. The current model's parameter estimates were similar to the mean of parameter estimates from the eight studies and fell within the range of parameter estimates from these studies. This comparison established that the model produces valid and reliable estimates for blood $\mathrm{MeHg}$ levels based on a given consumption rate of contaminated fish.

Similarly, parameter estimates for the model for fetal blood $\mathrm{MeHg}$ relative to maternal blood $\mathrm{MeHg}$ also fell within the range of literature sources. Unfortunately, only summary statistics from the literature were available for comparison. The use of summary statistics, instead of actual measurements or the regression equation derived from actual data, may introduce a limitation for this comparison. There is a theoretical potential that the variation is greater for one of the comparison groups (maternal or fetal blood). Therefore, when the mean, range, or other markers of the sample are compared, this may bias the ratio between the two datasets. However, because these are summary 
statistics and several data points were used, the effect of possible outliers is likely minimized, but may need to be studied in future more sophisticated studies.

The relationship between blood $\mathrm{MeHg}$ and hair $\mathrm{THg}$ was compared to nine literature sources describing 11 populations. No difference was found between model output and these sources. Hair is frequently preferred as a biomarker for $\mathrm{Hg}$ exposure because it is easy to collect, is highly correlated with blood $\mathrm{MeHg}$, and shows the history of exposure over time (Cernichiari et al. 2007). However, hair Hg levels are more variable than blood $\mathrm{MeHg}$ levels for a given exposure. This model was designed to give the central tendency after a given exposure, so users need to be cognizant that hair $\mathrm{Hg}$ concentrations in individuals from a given population will vary widely with an identical exposure.

The results suggest the developed human disposition model accurately projects the central tendency of biomarkers of exposure based on ingestion rates and fish tissue concentrations for populations of interest. It is a first step in linking environmental $\mathrm{Hg}$ levels to effects on nearby populations. With knowledge of the $\mathrm{Hg}$ concentration in fish from local waters, decision-makers can use the model to assess the portion of a population that is at risk and subsequently determine the decrease in fish tissue concentration needed to protect susceptible populations. The human disposition model depicts the disposition of $\mathrm{Hg}$ after ingestion in a simplified, yet understandable format, balancing accuracy, simplicity, and transparency. 


\section{Bioaccumulation model}

The bioaccumulation model simulates the fate of $\mathrm{Hg}$ from water column into fish tissue in several steps. The first step controls the process of conversion of $\mathrm{IHg}$ into $\mathrm{MeHg}$ or its movement downstream. This process is treated as a single mixed-box reactor; that is, the individual processes that determine the reaction rate are not simulated. Land use determines the physical and chemical factors that determine the portion of $\mathrm{IHg}$ that is retained in the stream system, converted into $\mathrm{MeHg}$, or is lost downstream. From this point forward, the model is a simple, multi-compartment bioaccumulation model, with minimal impact from land cover factors.

Others have developed models that simulate the fate and bioaccumulation of $\mathrm{Hg}$ in aquatic systems. The $\mathrm{Hg}$ Cycling Model (MCM) simulates the fate and bioaccumulation of $\mathrm{Hg}$ in lake systems, (Hudson et al. 1994). The Spreadsheet-based Ecological Risk Assessment for the Fate of $\mathrm{Hg}$ (SERAFM) model looks at $\mathrm{Hg}$ in aquatic systems with a focus on contaminated sites (Knightes and Ambrose 2006). The Hg module in the Water Quality Analysis Simulation Program (WASP) simulates the fate of $\mathrm{Hg}$ in both lentic and lotic water bodies; however, it does not simulate bioaccumulation in the food web (USEPA 2011f). The MERGANSER model is a $\mathrm{Hg}$ model that looks at predictors of fish tissue and piscivorous bird blood $\mathrm{Hg}$ levels. This model is specific to the northeast US and limited to lakes and reservoirs (Simcox et al. 2011). Each of these $\mathrm{Hg}$ models has its own strengths and weaknesses and focuses on a specific area of $\mathrm{Hg}$ dynamics. The STELLA model described here is unique in that it focuses on how watershed characteristics of stream systems affect bioaccumulation. With the exception of the SERAFM model that looks at contaminated sites, the other $\mathrm{Hg}$ models simulate $\mathrm{Hg}$ 
dynamics in lake systems. This effort expands $\mathrm{Hg}$ models into stream systems which differ from lakes in terms of drivers of microbial conversion and movement of $\mathrm{Hg}$ out of the system. With more than 1.2 million river miles under a fish consumption advisory for $\mathrm{Hg}$, a more complete understanding of the drivers of bioaccumulation in stream systems is needed (USEPA 2011a).

Phosphorus is assumed to be the limiting nutrient and is used as a surrogate for potential productivity and to estimate the biomass of trophic level 1 . In a review of studies of nutrient limitation in North America, Borchardt (1996) found that nutrient limitation varied by region. The analysis found the northern half of the US was predominantly phosphorus limited, the Southwest and Ozarks nitrogen limited, and the Pacific Northwest was co-limited. The study sites were located in the region that Borchardt identified as to be most likely phosphorus limited. While the nutrient that limits potential productivity within a region may vary, it is likely that the limiting nutrient was phosphorus. If not, then co-limitation was the next most likely condition. In forested basins, productivity is more frequently limited by light, not nutrients. Limitation by light was also simulated in the model structure.

DOC is a heterogeneous group of organic molecules consisting primarily of humic substances. Although IHg is thought to bind to thiol groups on DOC, the relationship between DOC and $\mathrm{Hg}$ is complex (Haitzer et al. 2003). Dissolved THg and DOC in stream systems are highly correlated (Brigham et al. 2009, Dittman et al. 2009, Tsui and Finlay 2011). Increasing levels of DOC have been found to be associated with both increased and lowered bioavailabiliity in aquatic systems (Tsui and Finlay 2011). DOC is thought to increase $\mathrm{Hg}$ in stream systems by transporting $\mathrm{Hg}$ into stream systems 
(Balogh et al. 2004). Wetlands have been shown to export increased amounts of DOC and dissolved $\mathrm{MeHg}$ during rain events, while forested systems show increased $\mathrm{THg}$ inputs into streams during rain events (Balogh et al. 2004, Brigham et al. 2009). For systems with wetlands or soils with high humic content, $\mathrm{Hg}$ levels have been found to be correlated with DOC. In contrast, DOC has been shown to lower methylation rates by making IHg unavailable through complexation (Gorski et al. 2008, Miskimmin et al. 1992, Ravichandran 2004). However, this relationship breaks down for systems that primarily have $\mathrm{Hg}$ loading directly from the atmosphere (Ravichandran 2004). The Kentucky study sites have little, if any, wetland coverage. While DOC data were not available, data were available for total organic carbon (TOC). A test to determine if adjusting the dissolved $\mathrm{IHg}$ input into the model based on TOC as a surrogate for DOC found no improvement in fit. As a result, TOC was not included as an input into the model. Because $\mathrm{Hg}$ loading in Kentucky is primarily from atmospheric sources, the relationship between DOC and $\mathrm{Hg}$ may not be strong. Systems with a strong relationship between DOC and $\mathrm{Hg}$, such as systems with significant wetlands coverage, may have improved fit with adjustment of the dissolved $\mathrm{IHg}$ fraction by adding $\mathrm{DOC}$ as a variable.

Wetlands have been shown to contribute significant loads of $\mathrm{MeHg}$ to stream systems during hydrologic events and connectivity to wetlands is associated with higher fish tissue $\mathrm{MeHg}$ while a lower $\mathrm{pH}$ has been shown to increase methylation and bioaccumulation (Balogh et al. 1997, Balogh et al. 2008, Haitzer et al. 2003, Miskimmin et al. 1992, Scudder et al. 2009). The $\mathrm{pH}$ of a system influences the relationship between DOC and $\mathrm{Hg}$ methylation. While DOC transports increased amounts of $\mathrm{Hg}$ into stream systems, the availability of that $\mathrm{Hg}$ is dependent on $\mathrm{pH}$. In more acidic systems, the 
competition for binding sites from hydrogen ion increases and results in more availability of $\mathrm{Hg}$ for methylation. The dissolved $\mathrm{IHg}$ input was adjusted by taking into account the $\mathrm{pH}$ of the system, although this adjustment did not improve overall mean prediction error. Calibration sites went from $28 \%$ to $26 \%$ and evaluation sites from $50 \%$ to $51 \%$.

However, improvement was substantial for higher trophic levels at those few sites with higher wetlands coverage and lower pHs. Error for Mayfield Creek decreased from $36 \%$ to $0 \%$ for TL3.5. For N. Fork Forked Deer River, prediction error for TL4 dropped from $46 \%$ to $17 \%$. Error increased, however, for TL3.5 from $13 \%$ to $34 \%$ at that Tennessee site. Because improvement for the systems with lower $\mathrm{pH}$ and higher wetlands coverage was substantial, this adjustment was included in the model. These systems were not well represented in this study but are likely to be closely looked at by regulators.

The minimal variation in wetlands coverage and the small range of $\mathrm{pHs}$ between the modeled basins are certainly limitations in the evaluation of the model. Only 2 sites had wetlands coverage greater than $1 \%$ and a mean $\mathrm{pH}$ below 7.0 . While the two systems with higher wetlands coverage and lower $\mathrm{pH}$ had minimal error, more testing is needed to build confidence that the model adequately represents the impact of wetlands coverage and $\mathrm{pH}$ on bioaccumulation.

Unlike lentic systems, nutrient levels may not be the limiting factor in primary productivity in stream systems. Light is often limiting for smaller streams. Canopy cover in conjunction with stream width may limit productivity in the stream and consequently be a primary driver for bioaccumulation within the biota (Lamberti and Steinman 1997, Vannote et al. 1980). In lower order streams, the canopy may shade the entire stream, and productivity may be minimal after leaf out. As stream order increases, the width of the 
stream increases and the canopy opens up resulting in higher levels of productivity for intermediate sized streams. Larger rivers are deeper and tend to carry more suspended solids, both of which reduce light penetration to periphyton-bearing substrates, lowering productivity. Watersheds that are largely forested have reduced productivity compared to stream systems with abundant light. A reduction in the biomass of primary producers leads to a higher concentration of $\mathrm{MeHg}$ at the base of the food web. This effect magnifies through the food web, leading to higher fish tissue concentrations in more pristine settings. The modeled basins were small to intermediate in size. Tygarts Creek in particular is a smaller, heavily forested basin. The model predicted this basin to have the highest fish tissue concentrations, which was confirmed by the collected sample.

Although the sample was beyond the upper bound of the length range and therefore not included in the error analysis, the model projected this sample, a sauger, to have the highest fish tissue concentration at $0.708 \mathrm{mg} / \mathrm{kg}$. The actual sample was $1.140 \mathrm{mg} / \mathrm{kg}$. Quality length for sauger is $300 \mathrm{~mm}$, and this sample was $432 \mathrm{~mm}$. The model does not adjust for length, but the model projection supported the expectation that this system would have elevated bioaccumulation.

In the sensitivity analysis, the response to changes in $\mathrm{Hg}$ loading differed for total and dissolved $\mathrm{Hg}$. Changes in $\mathrm{THg}$ input had little effect on reductions in fish tissue for Mayfield Creek and the Mud River until the amount was reduced to levels below the 1 ng/l dissolved Hg default. Tygarts Creek, however, showed greater responsiveness to THg reductions. Compared to the other 2 systems, Tygarts Creek is more forested, has substantially less agricultural coverage, and has the lowest mean $\mathrm{THg}$ concentrations. Despite having lower $\mathrm{THg}$ loading, fish tissue levels are highest in this system. In all 
three systems, dissolved $\mathrm{Hg}$ showed a linear relationship with fish tissue $\mathrm{Hg}$. Balogh et al. (1997) found that in areas with high suspended solids, $\mathrm{THg}$ does not correlate to $\mathrm{Hg}$ that is available for microbial conversion. The responses to reductions in loading of both $\mathrm{THg}$ and dissolved $\mathrm{Hg}$ for these three systems support the concept that measures of $\mathrm{THg}$ do not correlate with $\mathrm{Hg}$ available for methylation and that dissolved $\mathrm{Hg}$ is a better predictor of methylation potential. While $\mathrm{Hg}$ must be available for bioaccumulation to occur, basin characteristics drive the availability and efficiency with which $\mathrm{Hg}$ enters the food web and bioaccumulates. The sensitivity analysis of $\mathrm{Hg}$ loading shows the model accurately simulates the differences that basin characteristics impose on $\mathrm{Hg}$ availability and bioaccumulation efficiency.

The sensitivity analysis also showed that manipulation of $\mathrm{pH}$, and the fraction of land cover that was developed resulted in minimal changes in output. Changes in the nutrient level or the forested or wetlands coverage, however, had a non-trivial impact on fish tissue concentrations. While a lower $\mathrm{pH}$ does make $\mathrm{IHg}$ more bioavailable, this is only one factor in determining the mass of $\mathrm{Hg}$ that enters the food web. Development in a basin increases the speed of transport of $\mathrm{Hg}$ through the system, but does not increase or decrease methylation rates. While each of these variables had some influence on bioaccumulation, the combination of nutrient levels, and forested and wetlands coverage of the basin appear to be the strongest drivers within the modeled systems. The structure of the stream system, as illustrated by the STELLA model, reveals the basis for the greater impact of the most critical variables. These variables impact the structure of the system at multiple points. 
Nutrient levels and forested coverage are both related to primary productivity. The relationship between bioaccumulation and productivity is complex. Productivity impacts the model at several points in the system including the calculation of the microbial conversion rate, the estimate of biomass in the system, and the trophic transfer factors. Increased productivity in the form of extensive periphyton mats increases the methylation of $\mathrm{Hg}$, thereby increasing the mass of $\mathrm{MeHg}$ in the biota. Countering this, increased productivity decreases bioaccumulation through both bloom dilution and somatic growth dilution. Hill and Larsen (2005) found that light limitation increased the concentration of $\mathrm{MeHg}$ in biofilm in artificial streams. Hg uptake was constant under different light regimes, but growth of microalgae was dependent on light. Ward et al. (2010) studied somatic growth dilution in Atlantic salmon. Fry raised under the same conditions were stocked in various streams and sampled approximately 4 months later. Individual growth rate accounted for $38 \%$ of the variation in $\mathrm{Hg}$ concentration in fish tissue, building support for somatic growth dilution as being an important factor in bioaccumulation in stream systems.

The largest impact on bioaccumulation came from land cover factors that influence the amount of $\mathrm{IHg}$ in the stream that is converted into $\mathrm{MeHg}$. Chasar et al. (2009) found that, across wide environmental conditions, the supply of $\mathrm{MeHg}$ at the base of the food web was the largest factor to influence bioaccumulation, and that trophic structure and transfer efficiencies were only important predictors when comparing streams with similar land cover and Hg loading. Riva-Murray et al. (2011) similarly found that $\mathrm{MeHg}$ at the base of the food web was more important than trophic structure across larger environmental scales. At a smaller scale, when examining biota from 
different reaches of the same stream system, they found significant spatial heterogeneity in $\mathrm{Hg}$ in biota within basins that had heterogeneous in-stream habitat. This heterogeneity may be reflecting the different mix of functional feeding groups. Of the functional feeding groups at the base of the food web, scrapers would feed directly on periphyton, shredders on coarse particulate organic matter (CPOM)-of which the biofilm is an important nutritive component, and omnivores that feed from both categories. While the algal-based periphyton would be expected to be the food source with the highest $\mathrm{MeHg}$ concentrations, the biofilm associated with CPOM may also be a source. Without having a thorough survey of the feeding groups in each stream, the proportions for each stream will be unknown. The assumption is made that the variation in the composition of functional feeding groups at the base of the food web is relatively small across the region depicted. Bradley et al. (2011) also observed spatial variation in filtered $\mathrm{MeHg}$ concentrations in stream reaches corresponding to connectivity to wetlands or floodplains or shallow, open-water areas. Smaller reaches may have atypical land cover and habitat characteristics compared to the characteristics of the larger basin containing that reach. Therefore, when using the model, the size of the basin should be considered. The model was developed and calibrated primarily for mid-sized streams. Use for smaller or larger basins has not been tested and is likely beyond the scope of the current model's performance.

Ecological variation within natural settings is large. Stream flow, sunshine and rain, temperature, nutrient levels, growth rates, and other variables fluctuate daily and from year to year. Fish of the same species and size sampled from the same location will vary in tissue $\mathrm{Hg}$ concentration. Variable inputs into the model are monthly or annual 
means from several years of monitoring. While flow and meteorological data represent many years, water quality data were typically means from eight or nine years for calibration sites and fewer for evaluation sites. The assumption in these simulations is that these means represent a steady state system. It is not known whether the means from these years are typical for these basins over the long term, whether the samples encompass data that are outliers, or whether there have been recent changes in water quality, weather, or flow. If the assumption of steady state is incorrect, then model output may be biased.

A limitation of this model is that input parameters inherently have a high degree of variability and the use of regulatory data further compounds the issue. Fish tissue and water quality monitoring may be undertaken by different regulatory programs and therefore may not be coordinated in time and place. Budget concerns may also limit sampling. Frequent and coordinated sampling of variables would minimize uncertainty. The natural variation between fish tissue samples from the same species and site limits confidence in the ability to accurately project the concentration of $\mathrm{Hg}$ in any particular sample. A mean standard deviation of 0.116 was found when examining groups of 6 or more samples from the National Fish Database. When monitoring for regulatory purposes, the number of samples are often limited due to the cost of analyzing the samples. The combination of considerable variability and low sample size, even when these are pooled samples, generally results in a wide $95 \%$ confidence interval. Because confidence intervals are wide, the accuracy of model output is more difficult to assess. The ultimate purpose of the overall model is to gain insight into the complex problem of $\mathrm{Hg}$ in the environment and to understand the factors that control bioaccumulation and its 
impact on local susceptible populations. Regulatory agencies sample fish tissue to determine which waterways present a risk to populations from fish consumption. At times, agencies have based consumption advisories on as few as one sample (E. Eisiminger, KDOW, personal communication, 10/2010). More frequent and intensive sampling efforts would ensure that an elevated sample was truly representative of the $\mathrm{Hg}$ concentrations in that system.

This model seeks to project the fish tissue $\mathrm{MeHg}$ concentration in a generic fish species based on trophic level and basin characteristics. Accuracy will vary based on the species and size of fish to which the model output is compared. When examining prediction error by trophic level at each site, the mean error for projecting fish tissue $\mathrm{Hg}$ levels was $26 \%$ for sites in Kentucky and $51 \%$ for sites in nearby states. This is comparable to other models that project fish tissue concentrations. The National Descriptive Model for $\mathrm{Hg}$ in Fish Tissue developed by the USGS reported a prediction error of $38 \%$ (Wente 2004). The model developed by Trudel and Rasmussen (2006) was within $25 \%$ of actual value for $70 \%$ of predictions.

One difficulty in developing this model was defining $\mathrm{Hg}$ loading to the stream system. $\mathrm{Hg}$ was simulated from water column to fish tissue. The model was developed to be helpful to the regulatory community, and as such, uses only available regulatory data. The model was developed and calibrated using data from the Kentucky Division of Water, and monthly means of THg in the water column were used for the input into the system. Dissolved Hg is considered a more accurate measure of $\mathrm{IHg}$ that is available for conversion to $\mathrm{MeHg}$, but dissolved $\mathrm{Hg}$ data were not available. Dissolved $\mathrm{Hg}$ levels are not always correlated to THg levels, especially in systems with high suspended solids 
(Balogh et al. 1997). Measures of DOC, which are more closely related to dissolved $\mathrm{Hg}$ levels in stream systems, were not available (Brigham et al. 2009). Actual loading is dependent on a number of variables including the amount of precipitation and the concentration of $\mathrm{Hg}$ in that precipitation, the $\mathrm{pH}$ of the soil in the watershed, land use, and more. Using the monthly mean for $\mathrm{Hg}$ loading introduces uncertainty. Spikes of $\mathrm{Hg}$ loading, both particulate and dissolved, may occur during precipitation events that may not be reflected in monthly sampling, particularly in basins that may be downwind of emission sources. Simulating the processes that influence loading into the stream would increase model accuracy. This step would require the development of the third model for which data are not available.

The bioaccumulation model was evaluated by comparing model output to fish tissue data for seven basins in the region surrounding Kentucky. The model was not as consistent in projecting fish tissue concentrations for evaluation sites. Surprisingly, sites proximal to the state of Kentucky had higher prediction errors than other evaluation sites. In particular, the 2 sites in Indiana had prediction errors ranging from $78 \%$ to $90 \%$ for the 4 trophic level-site combinations. These sites are in the southeast portion of the state downwind from a number of coal-fired power plants. A report by the USGS on $\mathrm{Hg}$ in precipitation in Indiana found that portion of the state to consistently have the highest $\mathrm{Hg}$ wet deposition, suggesting that these 2 watersheds may be located in a Hg hotspot (Risch and Fowler 2008). Hammerschmidt and Fitzgerald (2006) found a positive correlation between wet deposition of $\mathrm{Hg}$ and $\mathrm{MeHg}$ concentrations in largemouth bass fillets. Gorski et al. (2008) found that $\mathrm{Hg}$ in precipitation was more bioavailable than $\mathrm{Hg}$ in surface waters. The higher loading of dissolved $\mathrm{Hg}$ in precipitation may account for the 
elevated $\mathrm{Hg}$ in fish samples at the Indiana sites compared to model output. Without the Indiana sites, mean prediction error for the evaluation sites was $35 \%$. Adding wet deposition of $\mathrm{Hg}$ to the model might improve model performance. However, wet deposition data at a spatial scale that is relevant to modeling basins in the Ohio River Valley are lacking.

In addition to the elevated error at the Indiana sites, TL3 of the Little Kanawha River in West Virginia had the highest error, 94\%. This elevated error is misleading. For the lower trophic levels, the magnitude of projected and actual values were lower, so differences between those values resulted in higher error even though the differences were not be biologically relevant. For the Little Kanawha River, the sample mean was $0.018 \mathrm{mg} / \mathrm{kg}$ and the projected value was $0.035 \mathrm{mg} / \mathrm{kg}$ resulting in an error of $94 \%$. If we look at TL3.5 of Spring Creek, the sample mean was $0.262 \mathrm{mg} / \mathrm{kg}$ and the projected outcome was $0.191 \mathrm{mg} / \mathrm{kg}$ for an error of $27 \%$. The difference of $0.017 \mathrm{mg} / \mathrm{kg}$ found at Little Kanawha is biologically less significant than the difference of $0.071 \mathrm{mg} / \mathrm{kg}$ found at Spring Creek. The error calculations do not convey the biological significance or magnitude of the error. This scaling of error values at least partially explains the decreasing error with increasing trophic level found in Table 8. Mean prediction error for evaluation sites without the Indiana and Little Kanawha sites was $26 \%$, the same error found for calibration sites.

The basins used to both calibrate and evaluate the model represent a wide variety of geomorphic land types and land uses. In general, the more forested basins were located in more mountainous areas. While there was considerable variability in prediction error between sites, land cover was not associated with error. This diversity of land types and 
uses build confidence in the ability of the model to be generalized to other basins in humid temperate regions with similar basin size and wetlands coverage.

As the understanding of the factors that influence bioaccumulation increases, regulators can begin to predict which stream systems are most likely to have fish with elevated $\mathrm{Hg}$ levels. This knowledge can inform regulatory agencies as to which stream systems should be given priority for sampling and interventions. This becomes more important as state budgets become leaner and cost-effectiveness is demanded in all programs. An understanding of watershed factors can also begin to suggest possible management strategies to reduce bioaccumulation in streams that are out of compliance.

The dynamic bioaccumulation model effectively predicts fish tissue $\mathrm{MeHg}$ levels based on watershed characteristics and $\mathrm{THg}$ concentrations in the water column. The model was calibrated and evaluated using 14 diverse basins in or near the Ohio River Valley, a region of North America that is not well-represented in the $\mathrm{Hg}$ bioaccumulation literature. The physiographic diversity and wide span of land uses convey confidence that the model will project with reasonable accuracy fish tissue $\mathrm{Hg}$ levels in other similar basins in the temperate humid domain. Because natural variability in many of the variables examined in the stream systems is great, more consistent and intensive sampling of water quality and fish tissue would improve confidence in model output. If wet deposition data were available on the scale of the individual basin, adding this factor might further improve model accuracy. Additional evaluation of the model is needed before simulating bioaccumulation in basins with significant wetlands coverage. 


\section{Projecting policy and climate change scenarios}

Combining the human disposition and bioaccumulation models provided a means to examine the interaction between the environment and susceptible populations. The central problem examined in this project was human exposure to $\mathrm{Hg}$ through the consumption of locally caught fish. Understanding the entire system, including both the environmental fate of $\mathrm{Hg}$ and the dynamics of population exposure, are necessary to devise a strategy to protect populations.

\section{Fish Consumption Advisories}

The current strategy for protecting populations from the adverse impacts of $\mathrm{Hg}$ exposure from fish consumption is to limit exposure by issuing fish consumption advisories and educating the public about these advisories. However, fish consumption also provides substantial health benefits. It reduces coronary heart disease mortality and stroke and increases cognitive development in the developing fetus (Cohen et al. 2005, Driscoll et al. 2011). The message these advisories attempt to convey is that women of child-bearing age and young children should reduce consumption of fish with high levels of $\mathrm{Hg}$ contamination and substitute fish with lower concentrations, thus preserving health benefits while reducing risks. Cohen et al. (2005) found the gains from reduced neurodevelopmental effects were offset by decreased cognitive development in children and increased coronary heart disease mortality and stroke. Consequently, improvements in public health were less than expected or even negative, particularly when non-targeted portions of the population reduced total consumption along with the targeted women of child-bearing age. Effectively communicating the benefits and risks of fish consumption 
to susceptible populations becomes more difficult as the message becomes more complex.

Certain populations may have substantially higher exposures from consumption of locally caught fish than the general population. Some Native American tribes, Inuit, and certain Asian populations have been found to have higher fish consumption rates than the general US population (Hightower et al. 2006, Shilling et al. 2010). Because of cultural differences and practices, risk communication messages must be tailored to each unique population to be effective. Even when tailored to a specific population, fish consumption advisories are not always successful in producing the desired behavior changes. Driscoll et al. (2011) found that, after being presented with culturally specific fish consumption information, one targeted population intended to cease all fish consumption while another indicated no intention to modify consumption behavior at all.

Understanding the degree to which these populations are exposed and directing risk communication to those most affected is essential to protecting those most at risk (Burger et al. 1999, Shilling et al. 2010). This study used populations described in the literature that were not specific to the basins being simulated, although it is assumed that some of the fishers in the modeled basins would have characteristics similar to the literature derived populations. For decision makers, it is important to consider the unique populations that consume fish from the waterway being examined. While the USEPA criterion for fish protected the $95^{\text {th }}$ percentile for all of the populations examined in this study, there may be other subsistence populations that have higher intake rates. These populations may not be protected. For some of the simulated populations, the $99^{\text {th }}$ percentile intake rate had substantially greater exposures, showing biomarkers well above 
the USEPA level of safety. For these populations, educational campaigns targeted to the population of concern would be essential to protect those at the upper end of the intake distribution.

The unique distributions of intake rates for each population demonstrate that both the population examined and the percentile chosen for action contribute to the impact of a chosen policy. For decision makers, these population profiles evoke the better questions: what population is most at risk? What portion of the population is protected by the USEPA fish tissue criterion? And what percentile of intake rate adequately protects that population? An important use of this model is that decision makers can project the unique profile of biomarkers of exposure for a population of concern.

\section{Emissions Reductions}

The CWA mandates that states set TMDLs for pollutants that are out of compliance for the designated use for a given waterway. As required by law, many states have established TMDLs for $\mathrm{Hg}$ in waterways as a result of non-compliance of fish tissue levels for $\mathrm{Hg}$. The TMDL approach, however, is limited by the reality that setting a maximum loading rate for a non-point source pollutant does not actually mean that controls exist to limit loading. The CWA specifies watershed management strategies to reduce non-point source loading into waterways. These strategies are not relevant to atmospherically deposited pollutants like $\mathrm{Hg}$. In order to reduce loading from the atmosphere, atmospheric sources must be reduced. Emission reduction regulations are the obvious means to reducing $\mathrm{Hg}$ contamination in fish, but these regulations have been difficult to promulgate, and the relationship between emissions and loading into waterways is complex and needs further study. 
When a waterway exceeds an established criterion, the regulating agency determines the daily amount of contaminant the waterway can receive to come back into compliance. Because each stream system is unique, the TMDL will vary depending on the unique characteristics of the basin. While regulating agencies set TMDLs to bring fish tissue $\mathrm{Hg}$ into compliance, the impact on a susceptible population will depend on several variables. We can view the reduction in THg inputs (Figure 12) as scenarios of possible TMDLs put forth by a regulating agency. Because of its greater forested coverage and lower nutrient levels, Tygarts Creek exhibited greater efficiency in bioaccumulation of $\mathrm{MeHg}$ than Mayfield Creek; therefore changes in $\mathrm{Hg}$ loading had a greater response in fish tissue and a greater subsequent impact on populations.

The relationship between emissions reductions and loading to streams is complicated and not simulated by this model. Atmospheric deposition occurs through precipitation and dry deposition, and subsequent loading is dependent on many variables including soil type, land cover, and rain events. Because of the importance of global sources, reductions in local or regional emissions will result in a smaller reduction to loading in streams. While this model does not project the decrease in loading to streams from a particular emissions reduction scenario, it can look at percent reductions from established monthly means. Balogh et al. (1997) found that THg in streams varied with suspended solids while dissolved $\mathrm{Hg}$ remained stable. Particulate-bound $\mathrm{Hg}$ is not likely to be immediately available for conversion to $\mathrm{MeHg}$, which would account for the threshold effect found in Figure 10. For systems with heavy loads of particulate-bound $\mathrm{Hg}$, large reductions in inputs may be necessary before a response is seen in fish tissue levels. The linear relationship between percent reduction in dissolved $\mathrm{Hg}$ input and fish 
tissue $\mathrm{Hg}$ further support the concept that dissolved $\mathrm{Hg}$, as opposed to $\mathrm{THg}$, is a driver of bioaccumulation in stream systems. The slope of the relationship between the percent reduction of dissolved $\mathrm{Hg}$ and fish tissue is steeper for systems with more efficient bioaccumulation. In terms of policy implications, systems that have low suspended solids and efficient bioaccumulation can be expected to respond more quickly to reductions in $\mathrm{Hg}$ loading. Targeting these systems for reduced loading would result in a greater impact in lowering fish tissue $\mathrm{Hg}$ than systems that have more anthropogenic influences.

\section{Watershed Management Strategies}

While the extent of the response in population biomarkers was different depending on the basin variable that was perturbed, a similar pattern of response was seen for the 6 populations examined. The magnitude of biomarker change for the Anglers 1 and 2 populations was less than the subsistence and consumer populations. This pattern was independent of the stream that was simulated or the variable that was perturbed and points to the importance of population choice for decision makers when setting guidelines for setting a level of safety. Having a clear understanding of how population intake rates were assessed is also necessary when evaluating a system. Intake rates for the angler populations and Subsistence Fishers 2 population were assessed over a year (CRITFC 1994, Connelly et al. 1996). The Subsistence Fishers 1 population was assessed over 8 months (Burger et al. 1998). Many anglers fish seasonally, and deriving a monthly rate from annual intake may underestimate intake for certain seasons. Conversely, the consumer population intake rates were extrapolated from a 3-day diary. Anyone who had consumed fish in this time was considered a consumer, and the monthly rate was then determined. This may have overestimated the monthly intake for these populations 
(USEPA and NCEA 1997). While many populations may have little exposure from local waterways, certain populations may have heavy exposures. Knowledge of the populations that consume fish from a stream system under consideration and their consumption patterns is essential to the decision making process.

While changes in basin variables can change bioaccumulation rates and subsequent population exposures, the environmental changes that decrease fish contamination would be viewed by many as detrimental because these same variables provide essential ecosystem services. An inverse relationship exists between nutrient loads and bioaccumulation efficiency. High nutrient loads, however, lead to eutrophication. Eutrophic stream systems provide a lower level of ecosystem services, with algal blooms, murky water, and, at high enough levels of nutrients, the loss of the ability to support aquatic life. Bioaccumulation is lower in basins with less forested coverage. Ecosystem services provided by forests include recreational opportunities, production of oxygen, carbon sequestration, soil production and retention, promotion of the recharging of groundwater, and regulation of flow regimes (UNEP 2009). Wetlands coverage is also correlated with bioaccumulation efficiency. Wetlands ecosystem services include flood control, groundwater recharge, sediment and nutrient removal and storage, and water purification (Ramsar 2011). For all three basin variables examined, changes that reduced contamination in fish also reduced the ecosystem services provided by that system. Because systems with greater bioaccumulation efficiency also have a greater response to changes in loading, targeting these systems for reductions in loading would provide the benefit of reduced contamination and greater services. 


\section{Climate Change}

Increases in mean temperature and the frequency of high precipitation events were projected to simulate the expected effects of climate change in three basins in Kentucky. An increase in mean temperature resulted in a negligible increase in fish tissue $\mathrm{Hg}$. Increases in the frequency of high precipitation events; however, resulted in marked decreases in fish tissue $\mathrm{Hg}$. The combination of these two factors similarly resulted in decreases in fish tissue $\mathrm{Hg}$, with little mitigating effect from increased temperatures. These decreases were the result of increased flashiness in streams leading to a decrease in retention of $\mathrm{Hg}$ in the stream system. That is, $\mathrm{Hg}$ moved out of the basin faster and therefore was not available for conversion and bioaccumulation.

Climate change is expected to bring more extremes in weather, including more frequent flooding in some areas while other areas are expected to experience more frequent droughts. In considering changes in precipitation, the second and third climate change scenarios only simulated the expected impacts resulting from more frequent high precipitation events as it relates to retention in the basin. It did not consider the increased loading that may occur from wet deposition if total precipitation were to increase. $\mathrm{Hg}$ wet deposition has been associated with total precipitation and the pattern of precipitation. Several studies have found the highest $\mathrm{Hg}$ concentrations in precipitation events that were high intensity or short duration (Risch and Fowler 2008, Keeler et al. 2005, Keeler et al. 2006, Mason et al. 1997). As discussed previously, $\mathrm{Hg}$ in wet deposition has been found to be more available for conversion to $\mathrm{MeHg}$ and subsequently leads to more efficient bioaccumulation in a system (Hammerschmidt and Fitzgerald 2006, Gorski et al. 2008). Therefore, changes in precipitation patterns will likely lead to changes in $\mathrm{Hg}$ loading in a 
basin. While the expected result of increased flashiness is reduced retention, an increase in precipitation could counteract the rapid movement of $\mathrm{Hg}$ out of the system through increased loading. Because the model was not developed to specify loading sources and patterns, the effects of increased wet deposition into the system could not be simulated.

\section{Limitations}

The purpose of the proposed model is two-fold: to be a tool for regulatory decision makers in determining if proposed policy scenarios reduce risk to susceptible populations; and to gain a better understanding of the interactions that control $\mathrm{Hg}$ dynamics and human exposure. The scope of this model is large in terms of both time frame and the size and complexity of the simulated system. Considerable parameter uncertainty results from the lack of sufficient data for many parameters. In addition, uncertainty about climate change decreases confidence in meteorological parameters for which a great deal of data were available. Model uncertainty is also present in that certain relationships in the structure of the model are ill-defined. Examples include retention rate of $\mathrm{Hg}$ in the stream, methylation rates, and oversimplification of the food web in calculating bioaccumulation in predatory fish. Estimations were made with expert judgment by consulting literature sources and professionals with experience in the field.

Despite the uncertainties, a system dynamics approach, with its emphasis on relationships and feedback loops between the many parts of the system, can reasonably describe the behavior of this complex problem. The information available to describe these relationships included clearly defined boundaries, a wealth of research in the literature describing the relationships of most parts of the system, and adequate 
regulatory data for the specific sites to be modeled. The usefulness of this project is not how precisely it predicts fish tissue $\mathrm{Hg}$ levels or the decrease in risk to susceptible populations at some time in the future; its usefulness comes from the foresight gained by better understanding how the system responds to various regulatory scenarios.

\section{Conclusion}

The dynamic model simulated the problem of $\mathrm{Hg}$ exposure by examining the system from the point of $\mathrm{Hg}$ in the water column to its concentration in population biomarkers. Combining the environmental and population exposure components permitted the assessment of the interplay of watershed and population characteristics on human exposure. Possible policy scenarios were evaluated while viewing the problem as one system, suggesting important questions to be considered when assessing a contaminated system. These questions include:

- What population has the greatest exposure from this stream?

- What does the pattern of intake of fish for this population look like?

- What portion of this population is protected by the USEPA level of safety?

- How efficient is bioaccumulation in this stream system?

Ultimately, the CWA requires the reduction of $\mathrm{Hg}$ levels in fish tissue to meet water quality criterion. One approach would be to alter the efficiency of bioaccumulation. However, efficiency is related to watershed characteristics and changes in sensitive variables that reduce efficiency also reduce valued ecosystem services to an unacceptable extent. Meeting water quality criterion will require regulations that reduce the loading of $\mathrm{Hg}$ into waterways and this can only be achieved by regulating $\mathrm{Hg}$ emissions. Bringing 
these waterways into compliance through $\mathrm{Hg}$ emissions regulations is expected to take decades to centuries, and therefore shorter term policies are required to protect populations from adverse exposures (Selin 2011). For the short term, fish consumption advisories must be used to protect populations from adverse exposures. Ultimately, the unique characteristics of a basin combined with the unique pattern of intake rates of susceptible populations determine the risk associated with fish consumption of a given waterway, and this combination should be the determinant for setting advisories and determining a risk communication strategy.

The combined bioaccumulation and population biomarker model can be an effective tool for regulators when assessing a stream system for $\mathrm{Hg}$ contamination. The model simulates both the pattern of uptake of a designated population and the unique basin characteristics as one system. By projecting reductions in $\mathrm{THg}$, an appropriate TMDL can be determined and a general idea of the responsiveness of the system can be evaluated. In addition, by focusing on the populations that fish from the system, knowledge of the degree of risk for those populations can be assessed and risk communication messages can be designed to target those most at risk. 


\section{REFERENCES}

Abdelouahab N, Vanier C, Baldwin M, Garceau S, Lucotte M, Mergler D. 2008.

Ecosystem matters: Fish consumption, mercury intake and exposure among fluvial lake fish-eaters. Sci Total Environ 407: 154-164.

Allan JD, Castillo MM. 2007. Stream Ecology: Structure and Function of Running Waters. Dordrecht, The Netherlands: Springer.

Bakir F, Damluji SF, Amin-Zaki L, Murtadha M, Khalidi, A, Al-Rawi NY, Tikriti S, Dhahir, Clarkson TW, Smith JC, Doherty RA . 1973. Methylmercury poisoning in Iraq. Science 181: 230-241.

Balogh SJ, Huang Y, Offerman HJ, Meyer ML, Johnson DK. 2003. Methylmercury in rivers draining cultivated watersheds. Science of the Total Environment, 304, 305313.

Balogh SJ, Meyer ML, Johnson DK. 1997. Mercury and suspended sediment loadings in the Lower Minnesota River. Environ Sci Technol 31: 198-202.

Balogh SJ, Nollet YH, Swain EB. 2004. Redox chemistry in Minnesota streams during episodes of increased methylmercury discharge. Environmental Science and Technology, 38, 4921-4927.

Balogh SJ, Swain EB, Nollet YH. 2008. Characteristics of mercury speciation in Minnesota rivers and streams. Environ Pollut 154: 3-11. 
Bell AH, Scudder BC. 2007. Mercury accumulation in periphyton of eight river ecosystems. Journal of the American Water Resources Association 43: 958-968.

Bjornberg KA, Vahter M, Berglund M, Niklasson B, Blennow M, Sandborgh-Englund G. 2005a. Transport of methylmercury and inorganic mercury to the fetus and breastfed infant. Environmental Health Perspectives, 113, 1381-1385.

Bjornberg KA, Vahter M, Grawe KP, Berglund M. 2005b. Methyl mercury exposure in Swedish women with high fish consumption. Sci Total Environ 341: 45-52.

Borchardt M. 1996. Nutrients in Stevenson R, Bothwell M, Lowe R, eds. Algal Ecology: Freshwater Benthic Ecosystems. San Diego, CA: Academic Press.

Box GEP, Draper,N. 1987. Empirical Model-Building and Response Surfaces. Wiley, p. 424.

Bradley PM, Burns DA, Riva-Murray K, Brigham M, Button DT, Chasar LC, MarvinDiPasquale M, Lowery MA, Journey CA. 2011. Spatial and seasonal variability of dissolved methylmercury in two stream basins in the eastern United States. Environ Sci Technol 45: 2048-2055.

Brigham M, Wentz DA, Aiken GR, Krabbenhoft DP. 2009. Mercury cycling in stream ecosystems. 1. Water column chemistry and transport. Environ Sci Technol 43: $2720-2725$.

Budtz-Jorgensen E, Grandjean P, Jorgensen PJ, Weihe P, Keiding N. 2004. Association between mercury concentrations in blood and hair in methylmercury-exposed subjects at different ages. Environ Res 95: 385-393.

Burger J. 1998. Fishing and risk along the Savannah River: possible intervention. Toxicol Environ Health, Part A 55: 405-419. 
Burger J, Stephens WL, Boring CS, Kuklinski M, Gibbons JW, Gochfeld M. 1999.

Fishing and risk along the Savannah River: possible intervention. Toxicol Environ Health, Part A 55: 405-419.

[CDC] Centers for Disease Control and Prevention. 2004. Blood mercury levels in young children and childbearing-aged women -- United States, 1999-2002. MMWR 53: 1018-1020.

[CIESD] Center for Interdisciplinary Excellence in System Dynamics 2006. What is system dynamics. (7 February 2012; www.ciesd.org/understanding/systemdynamics.shtml)

Cernichiari E, Myers GJ, Ballatori N, Zareba G, Vyas J, Clarkson, T. 2007. The biological monitoring of prenatal exposure to methylmercury. NeuroToxicology, $28,1015-1022$.

Chasar LC, Scudder BC, Stewart AR, Bell AH, Aiken GR. 2009. Mercury cycling in stream ecosystems. 3. Trophic dynamics and methylmercury bioaccumulation. Environmental Science and Technology, 43, 2733-2739.

Chen CY, Folt CL. 2005. High plankton densities reduce mercury biomagnification. Environ Sci Technol 39: 115-121.

Clarkson TW, Magos L. 2006. The Toxicology of Mercury and Its Chemical Compounds. Critical Reviews in Toxicology 36: 609-662.

Clarkson T, Vyas J, Ballatori N. 2007. Mechanisms of mercury disposition in the body. Am J Ind Med 50: 757-764.

Clean Air Act: Section 111, 42 U.S.C. 7411. 1970.

Clean Air Act Amendment of 1990: Section 112, 42 U.S.C. 7412. 1990. 
Cleckner LB, Gilmour CC, Hurley JP, Krabbenhoft DP. 1999. Mercury methylation in periphyton of the Florida Everglades. Limnology and Oceanography, 44, 1815 1825.

Cohen JT, Bellinger DC, Connor WE, Kris-Etherton PM, Lawrence RS, Savitz DA, Shaywitz BA, Teutsch SM, Gray GM. 2005. A quantitative risk-benefit analysis of changes in populaton fish consumption. Am J Prev Med 29: 325-334.

(CRITFC) Columbia River Inter-Tribal Fish Commission. 1994. A fish consumption survey of the Umatilla, Nez Perce, Yakama, and Warm Springs tribes of the Columbia River Basin. Portland, OR: CRITFC. Technical Report No. 95-3.

Connelly N, Knuth BA, Brown TL. 1996. Sportfish consumption patterns of Lake Ontario anglers and the relationship to health advisories. N Am J Fish Manage 16: 90-101.

Cowan CE, Mackay D, Feijtel TCJ, Van De Meent D, DiGuardo A, Davies J, Mackay N. 1995. The Multi-Media Fate Model: A Vital Tool for Predicting the Fate of Chemicals. Pensacola, FL: SETAC Press.

Demers JD, Driscoll CT, Fahey TJ, Yavitt JB. 2007. Mercury cycling in litter and soil in different forest types in the Adirondack Region, New York, USA. Ecological Applications, 17, 1341-1351.

Desrosiers M, Planas D, Mucci A. 2006. Mercury methylation in the epilithon of Boreal Shield aquatic ecosystems. Environ Sci Technol 40: 1540-1546.

Diamond ML. 1999. Development of a fugacity/aquivalence model of mercury dynamics in lakes. Water Air Soil Poll 111: 337-357. 
Dittman JA, Shanley JB, Driscoll CT, Aiken GR, Chalmers AT, Towse JE. 2009.

Ultraviolet absorbance as a proxy for total dissolved mercury in streams. Environ Pollut 157: 1953-1956.

Driscoll D, Sorensen A, Deerhake M. 2011. A multidisciplinary approach to promoting healthy subsistence fish consumption in culturally distinct communities. Health Promot Pract.

[ECETOC] European Centre for Ecotoxicology and Toxicology of Chemicals. 2005. Guidance for interpretation of biomonitoring data. Brussels, Belgium: ECETOC. Emery EB, Spaeth JP. 2011. Mercury concentrations in water and hybrid striped bass (Morone saxatilis X $M$. chrysops) muscle tissue samples collected from the Ohio River, USA. Arch Environ Contam Toxicol 60: 486-495.

EPPC, CHFS, Commerce Cabinet (2006). Mercury task force report to the Environmental Quality Commission. EPPC. (6 February 2012; http://chfs.ky.gov/NR/rdonlyres/AD485CD4-39BD-4E30-865BOD232C9DE432/0/FinalMercuryReport.pdf)

Farris FF, Dedrick RL, Allen PV, Smith JC. 1993. Physiological model for the pharmacokinetics of methyl mercury in the growing rat. Toxicol Appl Pharm 119: 74-90.

Federal District Court of Appeals for the District of Columbia 2008. New Jersey et al v. EPA. Federal District Court of Appeals for the District of Columbia. from http://pacer.cadc.uscourts.gov/docs/common/opinions/200802/05-1097a.pdf

Fleck JA, Grigal DF, Nater EA. 1999. Mercury uptake by trees: An observational experiment. Water, Air, and Soil Pollution, 115, 513-523. 
Forrester JW, Senge PM. (1980). Tests for building confidence in system dynamics models. TIMS Studies in the Management Sciences, 14, 209-228.

Froese R, Pauly D. Editors. 2011. Fishbase. (15 October 2011; www.fishbase.org)

Galbreath KC, Zygarlicke CJ. 1996. Mercury speciation in coal combustion and gasification flue gases. Environmental Science and Technology, 30, 2421-2426.

Gorski PR, Armstrong DE, Hurley JP, Krabbenhoft DP. 2008. Influence of natural dissolved organic carbon on the bioavailability of mercury to a freshwater alga. Environ Pollut 154: 116-123.

Gorski PR, Cleckner LB, Hurley JP, Sierzen ME, Armstrong DE. 2003. Factors affecting enhanced mercury bioaccumulation in inland lakes of Isle Royale National Park, USA. Science of The Total Environment, 304, 327-348.

Haitzer M, Aiken GR, and Ryan JN. 2003. Binding of mercury(II) to aquatic humic substances: Influence of $\mathrm{pH}$ and source of humic substances. Environmental Science and Technology, 37, 2436-2441.

Hammerschmidt CR, Fitzgerald WF. 2006. Methylmercury in freshwater fish linked to atmospheric mercury deposition. Environ Sci Technol 40: 7764-7770.

Hansen JC, Tarp U, Bohm J. 1990. Prenatal exposure to methyl mercury among Greenlandic Polar Inuits. Arch Environ Health 45: 355-358.

Harris RC, Rudd JWM., Amyot M, Babiarz CL, Beaty KG, Blanchfield PJ et al. 2007. Whole-ecosystem study shows rapid fish-mercury response to changes in mercury deposition. PNAS, 104, 16586-16591. 
Hatcher CL, Filippelli GM. 2011. Mercury cycling in an urbanized watershed: the influence of wind distribution and regional subwatershed geometry in Central Indiana, USA. Water, Air, and Soil Pollution 219: 251-261.

Hightower JM, O'Hare A, Hernandez GT. 2006. Blood mercury reporting in NHANES: Identifying Asian, Pacific Islander, Native American, and multiracial groups. Environ Health Persp 114: 173-175.

Hill WR, Larsen IL. 2005. Growth dilution of metals in microalgal biofilms. Environ Sci Technol 39: 1513-1518.

Homer, Huang C, Yang L, Wylie B, Coan M. 2004. Development of a 2001 National Landcover Database for the United States. Photogramm Eng Rem S 70: 829-840. Hope, B. 2003. A basin-specific aquatic food web biomagnification model for estimation of mercury target levels. Environmental Toxicology and Chemistry, 22, 2525-2537.

Hudson R, Gherini S, Watras C, Porcella D. 1994. Modeling the biogeochemical cycle of mercury in lakes: The Mercury Cycling Model (MCM) and its application to the MTL Study lakes. Pages 473-523 in Watras C, Huckabee J, eds. Mercury as a global pollutant: Toward integration and synthesis. Boca Raton, FL: Lewis Publishers.

isee systems. 2010. STELLA: Systems thinking for education and research. (6 February 2012; www.iseesystems.com/softwares/education/stellasoftware.aspx)

Karimi R, Chen CY, Pickhard, PC, Fisher NS, Folt CL. 2007. Stoichiometric controls of mercury dilution by growth. PNAS, 104, 7477-7482.

Keeler GJ, Gratz LE, Al-Wali K. 2005. Long-term atmospheric mercury wet deposition at Underhill, Vermont. Ecotoxicology 14: 71-83. 
Keeler GJ, Landis MS, Norris GA, Christianson EM, Dvonch JT. 2006. Sources of mercury wet deposition in eastern Ohio, USA. Environ Sci Technol 40: 5874-5881.

Kellie S, Duan Y, Cao Y, Chu P, Mehta A, Carty R. et al. 2004. Mercury emissions from a 100-MW wall-fired boiler as measured by semicontinuous mercury monitor and Ontario Hydro Method. Fuel Processing Technology, 85, 487-499.

Kentucky Department of Fish and Wildlife Resources. 2010. Fish consumption advisories. (3 February 2012; http://fw.ky.gov/fishadvisory.asp?lid $=900 \& N a v P a t h=C 101)$

Kershaw TG, Clarkson TW, Dhahir PH. 1980. The relationship between blood levels and dose of methylmercury in man. Archives of Environmental Health, 35, 28-36.

Knightes CD, Ambrose RB. 2006. Development of an Ecological Risk Assessment Methodology for Assessing Wildlife Exposure Risk Associated with MercuryContaminated Sediments in Lake and River Systems. USEPA. Report no. EPA/600/R-06/073.

Knightes CD, Sunderland EM, Barber MC, Johnston JM, Ambrose RB. 2009. Application of ecosystem-scale fate and bioaccumulation models to predict fish mercury response times to changes in atmospheric deposition. Environmental Toxicology and Chemistry, 28, 881-893.

Lamberti GA, Steinman AD. 1997. A comparison of primary production in stream ecosystems. J N Am Benthol Soc 16: 95-104.

Lindberg SE, Stratton WJ. 1998. Atmospheric mercury speciation: Concentrations and behavior of reactive gaseous mercury in ambient air. Environmental Science and Technology, 32, 49-57. 
Macleod M., McKone TE, Mackay D. 2005. Mass balance for mercury in the San Francisco Bay area. Environmental Science and Technology, 39, 6721-6729.

Mason RP, Lawson NM, Sullivan KA. 1997. The concentration, speciation and sources of mercury in Chesapeake Bay precipitation. Atmospheric Environment 31: 35413550.

Mauro J, Guimaraes J, Hintelmann H, Watras C, Haack E, Coelho-Souza S. 2002. Mercury methylation in macrophytes, periphyton, and water - comparative studies with stable and radio-mercury additions. Anal Bioanal Chem 374: 983-989.

McColl S, Hicks J, Craig L, Shortreed J. 2000. Environmental Health Risk Management: A Primer for Canadians. Waterloo, ON: Institute for Risk Research.

Meadows DH, Robinson JM. 1985. The Electronic Oracle: Computer Models and Social Decisions. New York: John Wiley and Sons.

Miettinen JK, Rahola T, Hattula T, Rissanen K, Tillander M. 1971. Elimination of ${ }^{203} \mathrm{Hg}-$ methylmercury in man. Annals of Clinical Research, 3, 116-122.

Miskimmin BM, Rudd JWM, Kelly CA. 1992. Influence of dissolved organic carbon, $\mathrm{pH}$, and microbial respiration rates on mercury methylation and demethylation in lake water. Can J Fish Aquat Sci 49: 17-22.

Moye HA, Miles CJ, Phlips EJ, Sargent B, Merritt KK. 2002. Kinetics and uptake mechanisms for monomethylmercury between freshwater algae and water. Environmental Science and Technology, 36, 3550-3555.

[NADP] National Atmospheric Deposition Program. 2011. National Atmospheric Deposition Program: Mercury Deposition Network. (8 December 2011; http://nadp.sws.uiuc.edu/mdn/). 
[NCDC] National Climatic Data Center. 2010. Climate-radar data inventories. (30 March 2011; www.ncdc.noaa.gov/oa/climate/stationlocator.html)

[NRC] National Research Council. 2007. Models in Environmental Regulatory Decision Making. Washington, DC: The National Academies Press.

[NRCS] Natural Resources Conservation Service. Soil Survey Geographic (SSURGO)

Database. (7 December 2011; http://soils.usda.gov/survey/geography/ssurgo/)

Ong CN, Chia SE, Foo SC, Ong HY, Tsakok M, Liouw P. 1993. Concentrations of heavy metals in maternal and umbilical cord blood. BioMetals 6: 61-66.

Orihel DM, Paterson MJ, Blanchfield PJ, Bodaly RA, Gilmour CC, Hintelmann H. 2008. Temporal changes in the distribution, methylation, and bioaccumulation of newly deposited mercury in an aquatic ecosystem. Environmental Pollution, 154, 77-88.

Orihel DM, Paterson MJ, Blanchfield PJ, Bodaly RA, Hintelmann H. 2007. Experimental evidence of a linear relationship between inorganic mercury loading and methylmercury accumulation by aquatic biota. Environ Sci Technol 41: 4952-4958.

Partnership for a Green City. 2011. Climate action report and related documents. (7 December 2011; www.louisvilleky.gov/APCD/ClimateChange/Report.htm)

Passos CJS, Mergler D, Lemire m, Fillion M, Guimaraes JRD. 2007. Fish consumption and bioindicators of inorganic mercury exposure. Sci Total Environ 373: 68-76.

Pauly D, Christensen V. 1995. Primary production required to sustain global fisheries. Nature 374: 255-257.

Phelps RW, Clarkson TW, Kershaw TG, Wheatley B. 1980. Interrelationships of blood and hair mercury concentrations in a North American population exposed to methylmercury. Arch Environ Health 35: 161-168. 
Pickhardt PC, Folt CL, Chen CY, Klaue,B, Blum JD. 2002. Algal blooms reduce the uptake of toxic methylmercury in freshwater food webs. Proceedings of the National Academy of Sciences, 99, 4419-4423.

[Ramsar] The Ramsar Convention on Wetlands. 2011. Wetland ecosystem services. (10 November 2011; www.ramsar.org/cda/en/ramsar-pubs-info-ecosystemservices/main/ramsar/1-30-103\%5E24258_4000_0_)

Rashleigh B, Barber MC, Cyterski MJ, Johnston JM, Parmar R, Mohamoud Y. 2004. Population Models for Stream Fish Response to Habitat and Hydrologic Alteration: The CVI Watershed Tool. Research Triangle Park, NC: USEPA. Report no. EPA/600/R-04/190.

Ravichandran M. 2004. Interactions between mercury and dissolved organic matter--a review. Chemosphere 55: 319-331.

Rea AW, Lindberg SE, Keeler GJ. 2001. Dry deposition and foliar leaching of mercury and selected trace elements in deciduous forest throughfall. Atmospheric Environment, 35, 3453-3462.

Rea AW, Lindberg SE, Scherbatskoy T, Keeler GJ. 2002. Mercury accumulation in foliage over time in two northern mixed-hardwood forests. Water, Air, and Soil Pollution, 133, 49-67.

Risch MR, Fowler KK. 2008. Mercury in Precipitation in Indiana, January 2004December 2005. U.S. Geological Survey Scientific Investigations Report. Report no. 2008-5148.

Riva-Murray K, Chasar LC, Bradley PM, Burns DA, Brigham M, Smith MJ, Abrahamsen TA. 2011. Spatial patterns of mercury in macroinvertebrates and 
fishes from streams of two contrasting forested landscapes in the eastern United States. Ecotoxicology 20: 1530-1542.

Scudder BC, Chasar LC, Wentz DA, Bauch NJ. 2009. Mercury in Fish, Bed Sediment, and W ater from Streams across the United States, 1998-2005. Scientific Investigations Report. Report no. 2009-5109.

Seigneur C, Vijayaraghavan K, Lohman K, Karamchandani P, Scott C. 2004. Global source attribution for mercury deposition in the United States. Environ Sci Technol 38: $555-569$.

Selin NE, Jacob DJ. 2008. Seasonal and spatial patterns of mercury wet deposition in the United States: Constraints on the contribution from North American anthropogenic sources. Atmospheric Environment 42: 5193-5204.

Selin NE. 2011. Science and strategies to reduce mercury risks: a critical review. J Environ Monit 13: 2389-2399.

Shanley JB, et al. 2008. Comparison of total mercury and methylmercury cycling at five sites using the small watershed approach. Environ Pollut 154: 143-154.

Sheehan KD, Fernandez IJ, Kayl JS, Amirbahman A. 2006. Litterfall mercury in two forested watersheds at Acadia National Park, Maine, USA. Water, Air, and Soil Pollution 170: 249-265.

Sherlock J. Hislop J, Newton D, Topping G, Whittle K. 1984. Elevation of mercury in human blood from controlled chronic ingestion of methylmercury in fish. Human Toxicol., 3, 117-131.

Shilling F, White A, Lippert L, Lubell M. 2010. Contaminated fish consumption in California's Central Valley Delta. Environmental Research 110: 334-344. 
Shore M. 2003. Out of Control and Close to Home: Mercury Pollution from Power Plants Environmental Defense.

Simcox A, Nacci J, Shanley JB, Johnston JM, Shields L. 2011. MERGANSER-Predicting Mercury Levels in Fish and Loons in New England Lakes. Report no. EPA 901-F-10-030.

Smith JC, Allen PV, Turner MD, Most B, Fisher HL, Hall LL. 1994. The kinetics of intravenously administered methyl mercury in man. Toxicol Appl Pharm 128: 251-256.

Stave KA. 2003. A system dynamics model to facilitate public understanding of water management options in Las Vegas, Nevada. Journal of Environmental Management, 67, 303-313.

Sterman JD. 1991. A skeptic's guide to computer models. In Barney GO et al (eds.), Managing a Nation: The Microcomputer Software Catalog (pp. 209-229). Boulder, CO: Westview Press.

Stern AH. 2005. A revised probabilistic estimate of the maternal methyl mercury intake dose corresponding to a measured cord blood mercury concentration. Environmental Health Perspectives, 113, 155-163.

Stern AH, Smith AE. 2003. An assessment of the cord blood:maternal blood ratio: Implications for risk assessment. Environmental Health Perspectives, 111, 14651470 .

Strivastava R. 2010. Control of Mercury Emissions from Coal Fired Electric Utility Boilers: An Update. National Risk Management Research Laboratory. Report no. EPA/600/R-10/006. 
Trudel M, Rasmussen JB. 2006. Bioenergetics and mercury dynamics in fish: a modelling perspective. Can J Fish Aquat Sci 63: 1890-1902.

Tsuchiya H, Mitani K, Kodama K, Nakata T. 1984. Placental transfer of heavy metals in normal pregnant Japanese women. Arch Environ Health 39: 11-17.

Tsui MTK, Finlay JC. 2011. Influence of dissolved organic carbon on methylmercury bioavailability across Minnesota stream ecosystems. Environ Sci Technol 45: 5981-5987.

Tsui MTK, Finlay JC, Nater EA. 2009. Mercury bioaccumulation in a stream network. Environ Sci Technol 43: 7016-7022.

Tsui MTK, Finlay JC, Balogh SJ, Nollet YH. 2010. In situ production of methylmercury within a stream channel in northern California. Environ Sci Technol 44: 69987004.

[UNEP] United Nations Environmental Programme. 2009. Ecosystem management programme: A new approach to sustainability.

[USEPA] U.S. Environmental Protection Agency, [NCEA] National Center for Environmental Assessment. 1997. Intake of Fish and Shellfish. Exposure Factors Handbook. Office of Research and Development.

[USEPA] US Environmental Protection Agency. 1997a. Mercury Study Report to Congress Volume IV: Assessment of Exposure to Mercury in the United States. Office of Air Quality Planning \& Standards and Office of Research and Development. Report no. EPA-452/R-97-006.

[USEPA] US Environmental Protection Agency. 1997b. Mercury Study Report to Congress Volume III: Fate and Tranport of Mercury in the Environment. Office of 
Air Quality Planning \& Standards and Office of Research and Development, Report no. EPA-452/R-97-005.

[USEPA] US Environmental Protection Agency. 2006. EPA's Roadmap for Mercury. Report no. EPA-HQ-OPPT-2005-0013.

[USEPA] US Environmental Protection Agency. 2008. Clean Water Act- Watershed academy. (7 February 2012; www.epa.gov/watertrain/cwa/rightindex.htm)

[USEPA] US Environmental Protection Agency. 2009. The National Water Quality Inventory: Report to Congress for the 2004 reporting cycle - a profile. Office of Water. Report no. EPA 841-F-08-003.

[USEPA] US Environmental Protection Agency. 2010a. Integrated Risk Information System: Methymercury (MeHg) (CASRN 22967-92-6). (19 March 2010; http://www.epa.gov/ncea/iris/subst/0073.htm)

[USEPA] US Environmental Protection Agency. 2010b. Mercury: Human exposure. (7 February 2012; www.epa.gov/mercury/exposure.htm)

[USEPA] US Environmental Protection Agency. 2010c. Mercury emissions: The global context. (7 February 2012; www.epa.gov/mercury/control_emissions/global.htm)

[USEPA] US Environmental Protection Agency. 2010d. Mercury: Controlling power plant emissions: Decision process and chronology. (7 February 2012; www.epa.gov/mercury/control emissions/decision.htm\#Chronology)

[USEPA] US Environmental Protection Agency. 2010e. Mercury: Basic information. (7 February 2012; www.epa.gov/mercury/about.htm)

[USEPA] US Environmental Protection Agency. 2011a. National listing of fish advisories: Technical fact sheet 2010. (19 December 2011; 
http://water.epa.gov/scitech/swguidance/fishshellfish/fishadvisories/technical_fact sheet_2010.cfm\#figure4)

[USEPA] US Environmental Protection Agency. 2011b. Controlling power plant emissions: Overview. (7 February 2012; www.epa.gov/mercury/control_emissions/index.htm)

[USEPA] US Environmental Protection Agency. $2011 \mathrm{c}$. Fact Sheet: Mercury and Air Toxics Standards for power plants. (22 January 2012; http://epa.gov/mats/pdfs/20111221MATSsummaryfs.pdf)

[USEPA] US Environmental Protection Agency. 2011d. Toxics Release Inventory (TRI) Program. (7 December 2011; www.epa.gov/tri/triprogram/whatis.htm)

USEPA. 2011e. Human health criteria - Methylmercury fish tissue criterion. (8 November 2011; http://water.epa.gov/scitech/swguidance/standards/criteria/aqlife/pollutants/methyl mercury/factsheet.cfin)

[USEPA] US Environmental Protection Agency. 2011f. Water Quality Analysis Simulation Program (WASP). (19 December 2011; http://epa.gov/athens/wwqtsc/html/wasp.html)

[USEPA] US Environmental Protection Agency. 2012. Mercury: Laws and Regulations. (25 January 2012; www.epa.gov/hg/regs.htm)

[USGS] US Geological Survey, [NIEHS] National Institute for Environmental Health Sciences, US Department of Interior. 2006. National Fish Data.

Vannote RL, Minshall GW, Cummins KW, Sedell JR, Cushing CE. 1980. The River Continuum Concept. Can J Fish Aquat Sci 37: 130-137. 
Vahter M, Akesson A, Lind B, Bjors U, Schutz A, Berglund M. 2000. Longitudinal study of methylmercury and inorganic mercury in blood and urine of pregnant and lactating women, as well as in umbilical cord blood. Environmental Research, 84, 186-194.

Volz C et al. 2007. Mercury, arsenic and selenium in channel catfish from the Allegheny, Monogahela and Ohio rivers near Pittsburgh, PA: Implications for metallotoxin source identification and fish consumption by local anglers. Presented at American Public Health Association $135^{\text {th }}$ Annual Meeting: Policy, Politics and Public Health; 3-7 November 2007, Washington DC.

Ward DM, Nislow KH, Folt CL. 2010a. Bioaccumulation syndrome: identifying factors that make some stream food webs prone to elevated mercury bioaccumulation. Ann NY Acad Sci 1195: 62-83.

Ward DM, Nislow KH, Chen CY, Folt CL. 2010b. Rapid, efficienct growth reduces mercury concentrations in stream-dwelling Atlantic salmon. Transactions of the American Fisheries Society 139: 1-10.

Warner KA, Bonzongo J-CJ, Roden EE, Ward GM, Green AC, Chaubey I, Lyons WB, Arrington DA. 2005. Effect of watershed parameters on mercury distribution in different environmental compartments in the Mobile Alabama River Basin, USA. Science of the Total Environment 347: 187-207.

Wente SP. 2004. A statistical model and national data set for partitioning fish-tissue mercury concentration variation between spatiotemporal and sample characteristic effects. Report no. US Geological Survey Scientific Investigation Report 20045199. 
White D, Johnston K, Miller M. 2005. Ohio River Basin. Pages 375-424 in Benke AC, Cushing CE, eds. Rivers of North America. Burlington, MA: Elsevier Academic.

White EM, Keeler GJ, Landis MS. 2009. Spatial variability of mercury wet deposition in eastern Ohio: Summertime meteorological case study analysis of local source influences. Environ Sci Technol 43: 4946-4953.

[WHO] World Health Organization. 1976. Environmental Health Criteria I. Mercury: Geneva, Switzerland: WHO.

Willis DW, Murphy BR, Guy CS. 1993. Stock Density Indices: Development, Use, and Limitations. Reviews in Fisheries Science 1: 203-222.

Wood TS, Shelley ML. 1999. A dynamic model of bioavailability of metals in constructed wetland sediments. Ecological Engineering, 12, 231-252.

Young JF, Wosilait WD, Luecke RH. 2001. Analysis of methylmercury disposition in humans utilizing a PBPK model and animal pharmacokinetic data. J Toxicol Environ Heal A 63: 19-52. 


\section{APPENDIX A}

\section{MODEL EQUATIONS}

Biomass TL1

0 biomass of $\mathrm{fv} 1=$

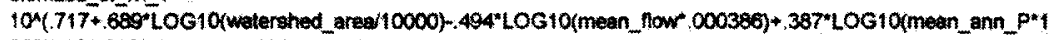

(00) y/2 21000 channe_width" channed__ength

UNITS: $\mathrm{kg}$

DOCUMENT: Uses Lambert and Steinman's regression equation to generate GPP (1997). The equation uses watershed area, diecharge and SRP to generate GPP. These 3 factors explain $70 \%$ of variation in GPP.

corversion tactors:

walershed area: comvert from m2 to hectares

how, from m3mo to L/s

from $/ y$ to $/$ ino

from $\mathrm{g}$ to $\mathrm{kg}$

Units assigned: $\mathrm{kg}$

$O$ channal_width $=5$

DOCUMENT: A mean channel width of 5 meters is chosen. In farger systems, the middie sections of the stream are deep and fast and wont support periphyton growh.

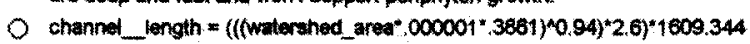

DOCUMENT: Caiculatus total channel length based on the orea of the watershed. Equation is from "A view of the river" by Leopold $1994, \mathrm{p} 222$.

Equation requires square miles, so conversion of area to square miles, and then conversion from miles (in lengtr) meters.

0 mean_fiow $=22875459.7943632$ DOCUMENT: meen annual How

$O$ watershed_area $=717600000$

UNITS: $m^{-2}$

DOCUMENT: Watershed area in m2. Input from linked Excel fle.

Degree of Retention

$O$ callbration_f $=.015$

$O$ fashiness $=(1+($ IF perturb_developed 1 THEN pertur_fr_developed ELSE

fr_developed $)^{*}$.5) Treq of high_precip

DOCUMENT: Development increases overland nunoff and quicker movement of water to the stream channel and out of the system. In order to account for this increase in flashiness, hall the traction developert of the watersted is added to one.

O ir developed $=0.078$

DOCUMENT: Portion of watershed that is developed. Input from inked Excel fite.

0 perturb_developed $=0$

$O$ perturb of developed $=1$

DOCUMENT: Allows manipuation of the portion of the watershed that is devetoped. The fraction developed is mutipliad by the value set by the user. 
0 retention $=\left(\left(\left(\left(1+\left(\text { sinuosity } / 4^{*} .5\right) \text {-flashiness/5*.5) }\right)^{*}\right.\right.\right.$ calibration_fr $\left.)\right)$

UNITS: Unitless

DOCUMENT: Reflects degree of retention of energy, debris, $\mathrm{Hg}$, etc. in the watershed. Large portion of anthropogenic management (flood control, channelization) lead to faster movernent out of the system (lower retention number) while large amounts of debris in the system stow removal (increase retention). High precip is a factor that infuences lateral connectivity-matter is deposited on/above banks.

Each factor contributes an equal amount to retention.

Includes calibration factor.

sinuosity $=1.6$

UNITS: Unitiess

DOCUMENT: Sinuosity is a standard measure of meander in a stream. A straighter stream (sinuosity closer to 1) the more like an open pipe the stream is, and the lower the retention in the stream.

Input from linked Excel file.

0 freq_of high precip $=$ GRAPH(count)

$\nabla \square(1.00,2.30),(2.00,2.00),(3.00,2.50),(4.00,5.10),(5.00,2.80),(6.00,2.90),(7.00,3.20),(8.00,2.50),(9.00$,

$\pm 1.80),(10.0,1.60),(11.0,1.90),(12.0,2.20)$

UNITS: Unitless

DOCUMENT: This is the mean of the number of days for each month with precipitation over 0.5 inches. Input from linked Excel file.

Hg Input

O count $=$ INT $($ Counter $(1,13))$

DOCUMENT: cycles through the months of the year for monthly inputs

$\mathrm{O}$ perturb_Hg_input $=0$

0 perturb_THg $=1$

UNITS: Unitless

DOCUMENT: This is connected to the slider on the interface page. It allows the user to decrease mercury entering the system at points in time.

$\mathrm{O}$ soluble_IHg_input $=(\mathrm{MIN}((\mathrm{IF}$ perturb_Hg_input $=1$ THEN perturb_THg ELSE THg_conc $), 1)+((\mathrm{IF}$ perturb_wetlands $=1$ THEN perturb_fr_wetlands ELSE fr_wetlands)" $\left.10+\mathrm{pH}_{\text {_adjust})}\right){ }^{*}$ flow"unit_conversion UNITS: $m g / m^{\wedge} 3$

DOCUMENT: This calculates the mass of soluble mercury entering the system. According to Balogh, Meyer, and Johnson (1997), Environ Sci Technol, the amount of total mercury varies widely in the system depending on suspended solids (ie, variation comes from particulate bound $\mathrm{Hg}$ ). However, the amount of soluble mercury remains stable, with a maximum of about $1 \mathrm{ng} / \mathrm{l}$. Only soluble $\mathrm{Hg}$ is available for microbial conversion, so that portion is included in this system.

$O$ unit_conversion $=.001$

DOCUMENT: conversion factor for converting ng/L to mg/m3

O flow $=$ GRAPH (count)

DIf $(1.00,3.5 e+007),(2.00,4.4 e+007),(3.00,5 e+007),(4.00,3.8 e+007),(5.00,2.9 e+007),(6.00,1.4 e+\infty 07),(7.00$,

$458.2 e+006),(8.00,6 e+006),(9.00,6.2 e+006),(10.0,4.8 e+006),(11.0,1.2 e+007),(12.0,2.7 e+007)$

UNITS: $m^{\wedge} 3$

DOCUMENT: Mean monthly flow in m3/month. Input from the linked Excel file. 
$Q \mathrm{pH}$ adjust $=\mathrm{GRAPH}(\mathrm{pH})$

$7(5.50,3.00),(5.85,2.56),(6.20,2.22),(6.55,1.44),(6.90,1.00),(7.25,0.05),(7.60,0.005),(7.95,0.00),(8.30$, $A 0.00),(8.65,0.00),(9.00,0.00)$

Q $\mathrm{THQ}$ cone $=$ GRAPH(count)

H7 $(1.00,3.13),(2.00,2.33),(3.00,1.53),(4.00,1.06),(5.00,1.16),(6.00,1.65),(7.00,1.09),(8.00,0.66),(9.00$, $\pm 0.94),(10.0,1.53),(11.0,1.29),(12.0,0.77)$

UNITS: $9-10^{\wedge}-9 n$

DOCUMENT: Mean monthly total mercury input from linked Excel file.

Index of Productivity

$O$ ir_forested $=0.688$

DOCUMENT: Fraction of the watershed that is forested. Input from the linked Excel file.

0 nutrient_level $=\left((\text { F perturb_nutrients }=1 \text { THEN perturb_nutrient_level ELSE phosphorus })^{*} 1000\right)$

UNITS: $\mathrm{mg} / \mathrm{m}^{\mathrm{n}} 3$

DOCUMENT: Presumes $P$ is limiting, as found in Lamberti and Steinman (1997).

Units of $\mathrm{mg} / \mathrm{m} 3$. Input units are $\mathrm{mg} / \mathrm{L}$ for nutrients.

0 perturb_forest $=0$

0 perturb_fr_forested $=.5$

DOCUMENT: Allows manipulation of the portion of the watershed that is forested. The fraction forested is multiplied by the value set by the user.

0 perturb_nutrients $=0$

0 perturb_nutrient_level $=.1$

DOCUMENT: Allows manipulation of the nutrient (phosphorus) level in the watershed. The monthly mean is multiplied by the value set by the user.

$Q$ productivity_index $=\left(\left((1-(16 \text {-daylength }) / 7)^{*}(1-((1 \mathrm{~F}\right.\right.$ perturb_forest=1 THEN perturb_fr_forested ELSE

fr_forested) $)^{*}\left(\text { canopy_cover) }{ }^{*} \text { perturb_fr_forested)) }\right)^{*}$ nutrient_level)/3

UNITS: $m g / m^{\wedge} 3$

DOCUMENT: generates an index of productivity based on nutrient level and light limitation.

Q. canopy_cover $=$ GRAPH(count)

(1.00,0.00), $(2.00,0.00),(3.00,0.00),(4.00,0.075),(5.00,0.845),(6.00,0.89),(7.00,0.905),(8.00,0.905),(9.00$

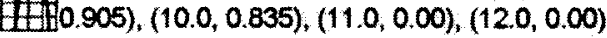

DOCUMENT: This graphical function impacts light limitation. For basins with high forested coverage, light limitation is only applied after leaf out in spring/summer.

daylength $=$ GRAPH(count)

$7(1.00,9.80),(2.00,10.9),(3.00,12.1),(4.00,13.4),(5.00,14.3),(6.00,14.9),(7.00,14.5),(8.00,13.5),(9.00$,

$4 \pm 12.4),(10.0,11,1),(11.0,10.0),(12.0,9.50)$

DOCUMENT: Graphical function giving number of daylight hours. Source: ptaff (2005)

http:/ptaff.ca/soleil/?lang=en_CA

0 phosphorus = GRAPH (count)

FTD(1.00, 0.0309), $(2.00,0.0234),(3.00,0.0159),(4.00,0.0232),(5.00,0.0205),(6.00,0.0185),(7.00,0.0193)$,

$\pm(8.00,0.0178),(9.00,0.0155),(10.0,0.0177),(11.0,0.0118),(12.0,0.0174)$

UNITS: mat

DOCUMENT: Mean monthly Phosphate phosphorus as $P$ input into the model through linked Excel file.

Mean Productivity Index 
calibr $=3.06$

DOCUMENT: calibration factor

$O$ mean_ann_P $=0.019325$

DOCUMEÑT: Mean annual phosphorus. Input from linked Excel file.

mean_daylength $=12.2$

DOCUMENT: annual mean of daytight hours. Input from linked Excel file.

mean nutrient level $=($ IF perturb nutrients $=1$ THEN perturb nutrient level ELSE mean ann $P) * 1000)$

DOCUMENT: Presumes phophorus is limiting. Mean of monthly phosphorus means. Conversion from $m g / L$ to $\mathrm{mg} / \mathrm{m} 3$ (multiply by 1000 ).

mean_productwity_index $=\left((1-(16-\text { mean_daylength }) / 7)^{*}(1-\right.$ (IF perturb_forest $=1$ THEN perturb_fr_forested ELSE

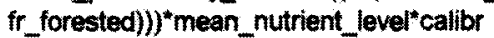
UNITS: $m g / m^{\wedge} 3$

DOCUMENT: Productivity index generated by nutrient level and light limitation. Calibration factor applied.

\section{Microbial Conversion Rate}

0 fr_wetlands $=0$

DOCUMENT: Fraction of the watershed that is wetlands: Input from the linked Excel file.

0 micro_conv_rate $=$ (MIN $($ ( (IF perturb_wetlands $=1$ THEN perturb_tr_wetlands ELSE

fr_wetiands) $\left.)^{*} 20^{*} .25\right)+($ season $* 25)+\left((9-\right.$ (If perturb_pH_input $=1$ THEN perturb_pH ELSE pH) $\left.) / 3^{*} .25\right)+$ (productivity index $\left.40^{*} .25\right)$ ), 1)*36)

DOCUMENT: Microbial conversion rate is based on the range of ratios found in Warner et al. (2005). The ratio of MeHg to $\mathrm{THg}$ typically falls between .03 and 39 .

The factors influencing this ratio have been assigned weights according to how much they influence microbial conversion (this is part of the calibration process). Weighted variables add up to 1 . This fraction is then multiplied by 0.36 , the range of values found from Warner $(0.39-0.03)$.

Weights:

$\mathrm{pH} .25$

fraction wetlands 25

season 25

productivity .25

O perturb_fr_wetlands $=.1$

DOCUMENT: Allows manipulation of the portion of the watershed that is wetlands. The fraction wetlands is multiplied by the value set by the user.

O perturb_pH $=7$

DOCUMENT: Allows manipulation of the $\mathrm{pH}$ in the stream. The value of the slider is added to the $\mathrm{pH}$.

0 perturb_pH_input $=0$

0 perturb_temp $=0$

0 perturb_water_temp $=0$

0 perturt wetlands $=0$

$0 \mathrm{pH}=$ GRAPH(count)

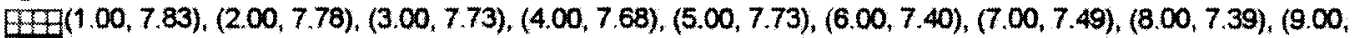
Et 7.58$),(10.0,7.48),(11.0,7.65),(12.0,7.82)$

DOCUMENT: reads mean pH from excel file for each month. 
Q season $=$ GRAPH(IF perturb_temp $=0$ THEN water_temp ELSE (water_temp+perturb_water_temp)

$6 \mathrm{f}(0.00,0.00),(2.60,0.00),(5.20,0.00),(7.80,0.005),(10.4,0.08),(13.0,0.23),(15.6,0.865),(18.2,0.94),(20.8$,

$\# 0.985),(23.4,0.99),(26.0,1.00)$

DOCUMENT: Relates the impact of water temperature on microbial activity

0 water_temp $=$ GRAPH (count)

$6 \mathrm{f}(1.00,4.00),(2.00,6.40),(3.00,8.70),(4.00,11.4),(5.00,17.8),(6.00,21.8),(7.00,23.9),(8.00,22.8),(9.00$,

A19.0), (10.0,14.6), (11.0,9.60), (12.0.5.20)

DOCUMENT: Input of mean monthly water temperature from linked Excel file.

\section{Not in a sector}

BLOOD_MeHglPopulation_Intakel $(t)=B L O O D \_$MeHglPopulation_Intake] $(t-d t)+$

(MeHg_Absorption[Population_Intake] - BI_to_Tissue_MeHg_Transfer[Population_Intake] -

Excretion_in_HairfPopulation_Intake] - Placental_Transfer[Population_Intakel -

MeHg_Defecated[Population_Intake]) ${ }^{*} \mathrm{dt}$

INIT BLOOD_Metig[Population_Intake] $=0$

\{ug MeHg\}

DOCUMENT: This stock acts as a clearinghouse for MeHg in the body. Inputs are primarily from ingestion, but can also be from tissue if the steady state between blood and tissue is disrupted. MeHg in blood moves to hair, tissue, the fetus, or is defecated.

INFLOWS:

- MeHg_Absorption[Population_Intake] = IF (TIME < 1200) THEN

(MeHg_ingestion[Population_intake]"MeHg_absorption_fraction) ELSE (0) \{ug MeHg per month)

DOCUMENT: Absorption represents the intake of mercury through fish consumption minus the MeHg that is not absorbed through the gut. The ingested MeHg is multiplied by the absorption fraction to determine the amount that is absorbed into the blood stream.

The use of the IF THEN ELSE statement was used in the development of the model to look at half-time in blood. At TIME $<1200$, the absorption flow remains on for the full run. The absorption of $\mathrm{Hg}$ can be turned off (to 0 ) during a model run by changing the 1200 to a lower number, and the response of the system to $n$ input can be observed.

OUTFLOWS:

* BI_to_Tissue_MeHg_Transfer[Population_Intake] $=(\mathrm{MeHg}$ tissue_gaplPopulation_Intake] * $\left((\overline{1} \text {-expected_ratio })^{*} \mathrm{MeHg}\right.$ Absorption[Population_Intake] $)+0^{*} \mathrm{MeHg}$ Defecated[Population_Intake] \{ug per month\}

DOCUMENT: This flow is designed to calculate the mass of $\mathrm{Hg}$ that must move from BLOOD MeHg to TISSUE MeHg (or vice versa) in order to maintain (or attain) the steady state ratio (expected ratio) that has been found in studies. In addition, the amount flowing into the BLOOD MeHg stock is considered, with the proper portion of that flow also being moved to the TISSUE MeHg stock. This addition was necessary because of the time scales involved. The time scale from which blood mercury moves into tissue is faster than the monthly time scale of the model.

The connector from MeHg Defecation flow (and muttiplication by 0 in equation) is to force the priority of the $\mathrm{Hg}$ Defecation flow to be higher than this flow. 
do Excretion_in_Hair[Population_Intake] $=$ monthly_hair_MeHg[Population_Intake] [ug MeHg per month)

DOCUMENT: Moves the amount of mercury into the HAIR stock based on the blood concentration and the literature-based ratio.

- Placental_Transfer[Population_Intake] = IF (bw=31.5) THEN (0) ELSE (IF ((MOD(TIME,60) $<9)$ THEN (needed(Population_Intakel/9) ELSE (0))

[ug MeHg per month\}

DOCUMENT: This project shows the potential exposure of a fetus based on population intake rates.

Therefore, the approach is to show exposure in snapshots. Pregnancies are generated at 5 year intervals. The fetal blood mercury amounts are derived by the ideal ratio as determined by Stern and Smith (2003).

The growth of a fetus over 9 months and subsequent time course of exposure is beyond the scope of this project. The amount of mercury needed to obtain the ideal cord blood: maternal blood ratio is calculated for the full term fetus. That quanitity is transferred to the fetus over a 9 month interval (needed/9). Birth occurs after 9 months.

If a population of children is being modeled, this pathway is turned off. The mechanics is by noting if the body weight is that of the standard child $(31.5)$, then the flow is set to 0 , otherwise the above logic applies.

* MeHg_Defecated[Population_Intake] $=B L O O D \_$MeHg|Population_Intake] ${ }^{*}$ MeHg_def_fraction \{ug MeHg per month\}

DOCUMENT: This represents the flow of MeHg that enters the gut and is defecated through the entero-hepatic shunt. It is calibrated on the basis of trying to achieve literature-based hall-times of $\mathrm{Hg}$ in the body (in combination with $1 \mathrm{Hg}$ Defecation).

FETAL_BLOOD_MeHg[Population_Intake](t) = FETAL_BLOOD_MeHg(Population_Intake](t - dt) + (Placental_Transfer[Population_Intake] - Birth[Population_Intake]) * dt

INIT FETAL_BLOOD_MeHg[Population_Intake] $=0$

\{ug MeHg\}

DOCUMENT: The stock is emptied after 9 months through the Birth flow.

INFLOWS:

- Placental_Transfer[Population_Intake] = IF (bw=31.5) THEN (0) ELSE (IF $((M O D(T I M E, 60))<9)$ THEN (needed[Population_Intake/9) ELSE (0)) fug MeHg per month) DOCUMENT: This project shows the potential exposure of a fetus based on population intake rates

Therefore, the approach is to show exposure in snapshots. Pregnancies are generated at 5 year intervals. The fetal blood mercury amounts are derived by the ideal ratio as determined by Stern and Smith (2003). The growth of a fetus over 9 months and subsequent time course of exposure is beyond the scope of this project. The amount of mercury needed to obtain the ideal cord blood: maternal blood ratio is calculated for the full term fetus. That quanitity is transferred to the fetus over a 9 month interval (needed/9). Birth occurs after 9 months.

If a population of children is being modeled, this pathway is turned off. The mechanics is by noting if the body weight is that of the standard child $(31.5)$, then the flow is set to 0 , otherwise the above logic applies.

\section{OUTFLOWS:}


d BithlPopulation_Intake] $=$ IF $(($ MOD $(T I M E, 60))>9)$ THEN (FETAL_BLOOD_MeHg[Population_Intake]

ELSE (0)

\{ug MeHg per month\}

DOCUMENT: Birth occurs after 9 months of gestation. While birth is rather abrupt in real life, this stock is emptied over a month period.

$\mathrm{IHg}$ in_1CM_HAIR[Population_Intake] $(t)=1 \mathrm{Hg}$ in_1CM_HAIR[Population_Intake]( $-\mathrm{dt})+$

(1Hg_Hair_Exc(Population_Intakel - Outgrowh_of_l $\mathrm{Hg}_{-}$in_Hair(Population_Intake) * at

INIT IHg_in_1CM_HAIR[Population_Intake] $=\overline{0}$

\{ug $\mid \mathrm{Hg}$ \}

DOCUMENT: Represents the mass of inorganic mercury in $1 \mathrm{~cm}$ hair. This is used to calculate total hair mercun concentration, one of the biomarkers of exposure.

INFLOWS:

\% $\mathrm{IHg}$ Hair_Exc[Population_Intake] = TISSUE_IHg[Population_Intake]"IHg_hair_fraction

DOCUMENT: Moves $\mathrm{IHg}$ from tissue to hair, calibrated to move the correct amount of inorganic mercury in hair to achieve the ideal ratio between total mercury in hair and blood methyimercury.

OUTFLOWS:

Outgrowth_of_IHg_in_Hair[Population_Intake] $=\mid H_{2}$ in_ $1 \mathrm{CM}$ _HAIRTPopulation_Intake

\{ug $\mathrm{IHg}$ per month\}

DOCUMENT: Moves the $\mathrm{HHg}$ out after one month to simulate a growth rate of $1 \mathrm{~cm} /$ month. This mimics the history of exposure over time as described by Cernichiari et al. (2007).

MeHg_IN_1_CM_HAIR[Population_Intake](t) $=$ MeHg_IN_1_CM_HAIR[Population_Intake] $(t-d t)+$

(Excretion_in_Hair[Population_Intake] - Outgrowth[Population_Intake]) ${ }^{*} \mathrm{dt}$

INIT MeHg IN $1 \mathrm{CM}$ HAIR[Population Intake] $=0$

\{ug MeHg\}

DOCUMENT: Hair mercury is a commonly used biomarker for $\mathrm{Hg}$ exposure. The usual process is to measure hai in $1 \mathrm{~cm}$ segments, with each segment representing a month of exposure. A stock of $1 \mathrm{~cm}$ of hair $\mathrm{MeHg}$ represents one month's exposure. A record then can be obtained for exposure over time.

The Outgrowth flow then empties the stock so that the next month's measurement is accurate.

INFLOWS:

D. Excretion_in_HairiPopulation_Intake] = monthly_hair_MeHg[Population_Intake]

[ug MeHg per month\}

DOCUMENT: Moves the amount of mercury into the HAIR stock based on the blood concentration and the literature-based ratio.

OUTFLOWS:

D. Outgrowth[Population_Intake] $=$ MeHg_IN_1_CM_HAIR[Population_Intake]

\{ug MeHg per month)

DOCUMENT: Moves the MeHg out after one month to simulate a growth rate of $1 \mathrm{~cm} / \mathrm{month}$. This mimics the history of exposure over time as described by Cernichiari et al. (2007).

MeHg_IN_DETRITUS $(t)=$ MeHg_IN_DETRITUS $(t-d)+($ Predatory_Fish_Death + LV_2_Death + LV_3_Death + LVI_1_Death - MeHg_in_Detritus_Lost_Downstream - Detrital_Uptake) ${ }^{*}$ dt INIT MeHg_IN_DETRITUS $=0$

UNITS: $m g$

DOCUMENT: This stock represents the methylmercury within dead biota in the system. The methyimercury can be eaten by detritivores or washed downstream and lost to the system. Detritivores are represented in trophic level 2.

INFLOWS: 
$\Longrightarrow$ Predatory_Fish_Death $=$ MeHg_IN_TROPHIC_LVL_4 $4^{*} .36 / 12$

UNITS: mg/mo

DOCUMENT: Rernoves MeHg from the stock that occurs from death of the fish

Current value of .36 is mean of natural montality for the predatory fish found in Kentucky streams that were used to calibrate the model.

$\approx$ LV___ Death $=$ MeHg_IN_TROPHIC_LVL_2/12

UNITS: mgimo

DOCUMENT: Assumption that primary consumers have a 1 year life span

Represents methyimercury within tropic level 2 that leaves trophic level 2 through death, not consumption.

¿. LV 3 Death $=$ MeHg IN TROPHIC LLL_3* $56 / 12$

UNITS: $\mathrm{mg} / \mathrm{mo}$

DOCUMENT: This is the natural mortality rate for bluegill, which is a representative forage fish. (TL3)

\$ LVI_1_Death $=$ MeHg_IN_TROPHIC_LVL_1"seasonal

UNITS: mg/mo

DOCUMENT: Graphical input of common pattern of death for primary producers in streams (periphyton). Mats grow rapidly in spring, and begin to die in mid-summer due to lack of oxygen (low flow and sunlight). This flow represents the movement of methyimercury from live primary producers to dead priman producers that stay within the modeled system. Mercury in periphyton mats that get lost downstream are represented in the MeHg Loss Downstream flow.

Loss of periphyton mats tends to occur seasonally, with mats dying as they get thicker and older. This dynamic is represented by the graphical function "seasonal".

\section{OUTFLOWS:}

cos MeHg_in_Detritus_Lost_Downstream $=$ MeHg_IN_DETRITUS $*(1-$ retention)

UNITS: mg/mo

DOCUMENT: Downstream loss of MeHg in detritus based on retention in the stream

$\approx$ Detrital_Uptake $=$ SMTH1 $($ MeHg_IN_DETRITUS*retention, 24)

UNITS: $\mathrm{mg} / \mathrm{mo}$

DOCUMENT: Represents the movement of methylmercury within the system from within dead biota back into trophic level 2.

The smooth function is used to dampen the wobble caused by the seasonal nature of methymercury production.

MeHg_IN_TROPHIC_LV__1 $(t)=$ MeHg_IN_TROPHIC_LVL_1 $1(t)+($ Microbial_Conversion -

Trophic_Transfer_1 - LV__1_Death - MeHg_Diffusion) * dt

INIT MeHg_IN_TROPHIC_LVL_ $1=4$

UNITS: $\mathrm{mg}$

DOCUMENT: The assumption is made that methyiation occurs in association with periphyton or biofilm, and so is associated with the lowest trophic level.

INFLOWS: 
- Microbial_Conversion $=$ SOLUBLE_IHg_in_STREAMBED'micro_conv_rate

UNITS: $\mathrm{mg} / \mathrm{mo}$

DOCUMENT: microball conversion of inorganic mercury to methymercury is assumed to occur in association with periphyton. Sunlight degrades $\mathrm{MeHg}_{1}$ and accounted for in this flow also.

OUTFLOWS:

\% Trophic_Transfer_1 $1=$ SMTH1 (gap_2,24)

UNITS; mg/mo

DOCUMENT: This flow represents the movement of methylmercury from primary producers (in this case, periphyton and biofilm) to primary consumers through consumption.

The amount of MeHg that moves through the flow is calculated based on the Predator Prey Factor 2 (PPF2). This is the ratio of the concentration of MeHg in trophic level 2 to trophic level 1. A general PPF2 is taken from the Mercury Study Report to Congress (1997). The amount is adjusted based on the nutrient status of the stream to reflect the effect of growth dilution on bioaccumulation.

The smooth function is used to dampen the wobble caused by the seasonal nature of methymercury production.

D. LV___Death $=$ MeHg_IN_TROPHIC_LVL_1 1 seasonal

UNITS: mg/mo

DOCUMENT: Graphical input of common pattern of death for primary producers in streams (periphyton). Mats grow rapidly in spring, and begin to die in mid-summer due to lack of oxygen (low flow and sunlight). This flow represents the movement of methymercury from live primary producers to dead priman producers that stay within the modeled system. Mercury in periphyton mats that get lost downstream are represented in the MeHg Loss Downstream flow.

Loss of periphyton mats tends to occur seasonally, with mats dying as they get thicker and older. This dynamic is represented by the graphical function "seasonal".

Do MeHg_Diffusion = MeHg_IN_TROPHIC_LVL_I "diffusion

UNITS: mg/mo

DOCUMENT: Very small amounts of methylmercury can be found in the water column. The assumption is that it has diffused from the biofilm or periphyton into the water column.

MeHg_IN_TROPHIC_LVL_2(t) $=$ MeHg_IN_TROPHIC_LVL_2(t - d $)+($ Trophic_Transfer_1 + Detrital_Uptake Trophic_Transfer_2 - LvI_2_Death) *dt

INIT MeHg_IN_TROPHIC_LVL_2 $=3$

UNITS: $\mathrm{mg}$

DOCUMENT: Methyimercury in primary consumers and detritivores.

INFLOWS: 
0. Trophic_Transfer_1 = SMTH1 (gap_2,24)

UNITS: $\mathrm{mg} / \mathrm{mo}$

DOCUMENT: This flow represents the movement of methylmercury from primary producers (in this case, periphyton and biofim) to primary consumers through consumption.

The amount of $\mathrm{MeHg}$ that moves through the flow is calculated based on the Predator Prey Factor 2 (PPF2). This is the ratio of the concentration of MeHg in trophic level 2 to trophic level 1. A general PPF2 is taken from the Mercury Study Report to Congress (1997). The amount is adjusted based on the nutrient status of the stream to reflect the effect of growth dilution on bioaccumulation.

The smooth function is used to dampen the wobble caused by the seasonal nature of methymercury production.

$\Rightarrow$ Detrital_Uptake = SMTH1 (MeHg_IN_DETRITUS*retention,24)

UNITS: mg/mo

DOCUMENT: Represents the movement of methylmercury within the system from within dead biota back into trophic level 2.

The smooth function is used to dampen the wobble caused by the seasonal nature of methymercury production.

OUTFLOWS:

- Trophic_Transfer_2 = SMTH1 (gap_3,24)

UNITS: mgimo

DOCUMENT: This flow represents the movement of methyimercury from primary consumers (in this case, macroinvertebrates) to secondary consumers through consumption.

The amount of MeHg that moves through the flow is calculated based on the Predator Prey Factor 3 (PPF3). This is the ratio of the concentration of MeHg in trophic level 3 to trophic level 2. A general PPF3 is taken from the Mercury Study Report to Congress (1997). The amount is adjusted based on the nutrient status of the stream to reflect the effect of growth dilution on bioaccumulation.

The smooth function is used to dampen the wobble caused by the seasonal nature of methymercury production.

$\Leftrightarrow$ LVI_2_Death $=$ MeHg_IN_TROPHIC_LVL_2/12

UNITS: $\mathrm{mg} / \mathrm{mo}$

DOCUMENT: Assumption that primary consumers have a 1 year life span.

Represents methylmercury within tropic level 2 that leaves trophic level 2 through death, not consumption.

MeHg_IN_TROPHIC_LVL_3(t) $=$ MeHg_IN_TROPHIC_LVL_3 $(t-d t)+($ Trophic_Transter_2-

Trophic Transfer $3-$ LV 3 Death) * dt

INIT MeHg_IN_TROPHIC_LV_3 $=2$

UNITS: $\mathrm{mg}$

DOCUMENT: Methylmercury in forage fish

INFLOWS: 
๘. Trophic_Transfer_2 $=$ SMTH1 (gap_3,24)

UNITS: mgimo

DOCUMENT: This flow represents the movement of methyimercury from primary consumers (in this case, macroinvertebrates) to secondary consumers through consumption.

The amount of MeHg that moves through the flow is calculated based on the Predator Prey Factor 3 (PPF3). This is the ratio of the concentration of MeHg in trophic level 3 to trophic level 2 . A general PPF3 is taken from the Mercury Study Report to Congress (1997). The amount is adjusted based on the nutrient status of the stream to reflect the effect of growth dilution on bioaccumulation.

The smooth function is used to dampen the wobble caused by the seasonal nature of methymercury production.

OUTFLOWS:

Do Trophic_Transfer_3 $=$ SMTH1(gap_4,24)

UNITS: mg/mo

DOCUMENT: This flow represents the movement of methyimercury from forage fish to piscivorous fish through consumption.

The amount of MeHg that moves through the flow is calculated based on the Predator Prey Factor 4 (PPF4). This is the ratio of the concentration of MeHg in trophic level 4 to trophic level 3. A general PPF4 is taken from the Mercury Study Report to Congress (1997). The amount is adjusted based on the nutrient status of the stream to refect the effect of growth dilution on bicaccumulation.

The smooth function is used to dampen the wobble caused by the seasonal nature of methymercury production.

$\Rightarrow$ LV_3_Death $=$ MeHg_IN_TROPHIC_LV__3*.56/12

UNITS: mgimo

DOCUMENT: This is the natural mortality rate for bluegill, which is a representative forage fish. (TL3)

MeHg_IN_TROPHIC_LVL_4t $)=$ MeHg_IN_TROPHIC_LVL_4(t - dt) $+($ Trophic_Transfer_3

Predatory_Fish_Death)* dt

INIT MeHg_IN_TROPHIC_LVL_4 =1

UNITS: $\mathrm{mg}$

DOCUMENT: Methyimercury in piscivorous fish.

\section{INFLOWS:}

D. Trophic_Transfer_3 $=$ SMTH1 (gap_4,24)

UNITS: mgimo

DOCUMENT: This flow represents the movernent of methylmencury from forage fish to piscivorous fish through consumption.

The amount of MeHg that moves through the flow is calculated based on the Predator Prey Factor 4 (PPF4). This is the ratio of the concentration of MeHg in trophic level 4 to trophic level 3. A general PPF4 is taken from the Mercury Study Report to Congress (1997). The amount is adjusted based on the nutrient status of the stream to reflect the effect of growth dilution on bioaccumulation.

The smooth function is used to dampen the wobble caused by the seasonal nature of methymercury production. 


\section{OUTFLOWS:}

- Predatory_fish_Death $=$ MeHg_IN_TROPHIC_LVL_4 $4^{*} \cdot 36 / 12$

UNITS: $m g / m o$

DOCUMENT: Removes MeHg from the stock that occurs from death of the fish.

Current value of .36 is mean of natural mortality for the predatory fish found in Kentucky streams that were used to calibrate the model.

MeHg_IN_WATER $(t)=$ MeHg_IN_WATER(t $-d t)+($ MeHg_Diffusion - MeHg_LOSS_Downstream $) * d t$

INIT MEHg_IN_WATER $=1$

UNITS: $\mathrm{mg}$

DOCUMENT: This stock represents the methylmercury found in the water colurnn.

INFLOWS:

- $\rightarrow$ MeHg_Diffusion $=$ MeHg_IN_TROPHIC_LVL_1 diffusion

UNITS: mgimo

DOCUMENT: Very small amounts of methymercury can be found in the water column. The assumption is that it has diffused from the biofim or periphyton into the water column.

OUTFLOWS:

0. MeHg_Loss_Downstream $=$ MeHg_IN_WATER*(1-retention)

UNITS: mgimo

DOCUMENT: The methylmercury is frequently produced in periphyton mats and other areas associated with productivity, and therefore is subject to high uptakes rates into the food web. However, high flow events can wash $\mathrm{MeHg}$ and even whole periphyton mats, with the associated MeHg downstream out of the system.

SOLUBLE_IHg in_STREAMBED $(t)=$ SOLUBLE_IHg_in_STREAMBED $(t-a t)+($ Deposition -

Microbial_Conversion) * at

INIT SOLUBLE_IHg in_STREAMBED $=2$

UNITS: $\mathrm{mg}$

DOCUMENT: This stock represents the soluble inorganic mercury that is retained in the system. It may be particulate-bound inorganic mercury that deposits in a pool and subsequently enters solution, or it may be soluble $\mathrm{Hg}$ that, as it moves through a periphyton mat, is sorbed by biofim.

INFLOWS:

Deposition = SOLUBLE_IHg_IN_WATER*retention

UNITS: mgimo

DOCUMENT: Represents the amount of inorganic mercury that remains in the system each month. It ma! be particulate-bound $\mathrm{Hg}$ that is deposited to the streambed in a slow-moving pool and subsequently dissolves, or it might be soluble $\mathrm{IHg}$ that is taken up by biofilm.

The majority of $\mathrm{IHg}$ in the system moves out of the system by being carried downstream. Only the amount retained is available for conversion to methylmercury.

OUTFLOWS:

20. Microbial_Conversion $=$ SOLUBLE_IHg_in_STREAMBED*micro_conv_rate

UNITS: mgimo

DOCUMENT: microbail conversion of inorganic mercury to methylmercury is assumed to occur in association with periphyton. Sunlight degrades $\mathrm{MeHg}$, and accounted for in this flow also. 
SOLUBLE_IHg_IN_WATER $(t)=$ SOLUBLE_IHg_IN_WATER $(t-d t)+($ Soluble_IHg_Inflow -

IHg_Loss_Downstream - Deposition) * dt

INIT SOLUBLE_IHg_IN_WATER $=50$

UNITS: $m g$

INFLOWS:

\$. Soluble_Hg_Inflow $=$ soluble_ $\mathrm{H} H \mathrm{Hg}_{\text {input }}$

UNITS: mgimo

DOCUMENT: The amount of soluble $\mathrm{Hg}$ entering the system as determined by the $\mathrm{Hg}$ Input sector.

OUTFLOWS:

$\Rightarrow 1 \mathrm{Hg}$ Loss Downstream $=$ SOLUBLE_IHg_IN_WATER ${ }^{*}$ (1-retention)

UNITS: mg/mo

DOCUMENT: The vast majority of inorganic mercury in the system is associated with suspended

particulate matter and is lost downstream. The $\mathrm{IHg}$ is not avallable for conversion to melhyimercury.

$\%$ Deposition $=$ SOLUBLE_IHg_IN_WATER*retention

UNITS: mg/mo

DOCUMENT: Represents the amount of inorganic mercury that remains in the system each month. It may be particulate-bound $\mathrm{IHg}$ that is deposited to the streambed in a slow-moving pool and subsequently dissolves, or it might be soluble $\mathrm{IHg}$ that is taken up by biofilm.

The majority of $\mathrm{IHg}$ in the system moves out of the system by being carried downstream. Only the amount retained is available for conversion to methylmercury.

TISSUE_IHg[Population_Intake](t) = TISSUE_IHgIPopulation_Intake] $(\mathrm{t}-\mathrm{dt})+$

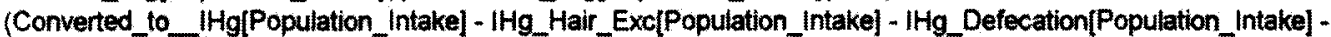
Urine_IHg_Loss[Population_Intake]) * dt

INIT TISSUE_ IHg[Population_Intake] $=0$

fug $\mathrm{IHg}$ \}

DOCUMENT: MeHg can be converted to $\mathrm{IHg}$ in the tissue. This stock represents $\mathrm{IHg}$ in tissue. Different organs may have varying concentrations of $\mathrm{IHg}$, but this stock represents all in the body.

INFLOWS:

os Converted_to $I \mathrm{Hg}[$ Population_Intake] $=$

TISSUE_MeHg[Population_Intakel"rate_constant_convert_to_lHg \{ug $\mathrm{IHg}$ per month\}

DOCUMENT: This flow represents the rate of conversion of $\mathrm{MeHg}$ to $\mathrm{Hg}$ within the tissue, and was calibrate to optimize the $\mathrm{MeHg}$ blood concentration; tissue MeHg ratio and time to steady state. The addition of Disposition " $O$ is to give the flow the correct outllow priority.

OUTFLOWS:

- $1 \mathrm{Hg}$ Hair Exc[Population Intake] = TISSUE IHg[Population Intake ${ }^{*} \mathrm{Hg}$ hair fraction DOCUMENT: Moves $\mathrm{Hg}$ from tissue to hair, calibrated to move the correct amount of inorganic mercury in hair to achieve the ideal ratio between total mercury in hair and blood methylmercury.

$\Leftrightarrow I \mathrm{Hg}$ Defecation $[$ Population_Intake] $=$ TISSUE_IHg[Population_Intake]* $1 \mathrm{Hg}$ def_rate (ug per month)

DOCUMENT: It is believed that some $\mathrm{Hg}$ loss to the system occurs through removal of $\mathrm{IHg}$ from the bloox by the liver and excretion into the gut by bile, or direct excretion across the lumnial tract (Clarkson et al. 2007). It is calibrated on the basis of trying to achieve literature-based half-times of $\mathrm{Hg}$ in the body (in combination with MeHg Defecation). 
-O. Urine_IHg_Loss[Population_Intake] = TISSUE_IHg|Population_Intake]"tissue_to_urine_transfer_rate \{ug per month)

DOCUMENT: Calibrated to balance defecation loss and half-times in body.

TISSUE_MeHg[Population_Intake] $(t)=$ TISSUE_MeHg[Population_intake] $(t-d t)$ * (B!_to_Tissue_MeHg_Transfer[Population_Intake] - Converted_to_IHg[Population_Intake]) * dt INITT TISSUE_MeHglPopulation_Intake] $=100$ fug $\mathrm{MeHg}$ \}

DOCUMENT: At steady state, tissue $\mathrm{MeHg}$ and blood MeHg have a desired ratio of 7.5:1. Movement from tissue can occur back to blood or can be to $\mathrm{Hg}$ in tissue (representing demethylation in tissue).

INFLOWS:

* BI_to_Tissue_MeHg_Transfer[Population_Intake $=($ MeHg_tissue_gap[Population_Intake $)+$ $\left(\left(1\right.\right.$-expected_ratio) ${ }^{*} \mathrm{MeHg}$ Absorption(Population_Intake]) ${ }^{*} \mathrm{O}^{*} \mathrm{MeHg}$ Defecated[Population_Intake] (ug per month) DOCUMENT: This flow is designed to calculate the mass of $\mathrm{Hg}$ that must move from BLOOD MeHg to TISSUE MeHg (or vice versa) in order to maintain (or attain) the steady state ratio (expected ratio) that has been found in studies. In addition, the amount flowing into the BLOOD MeHg stock is considered, with the proper portion of that how also being moved to the TISSUE MeHg stock. This addition was necessary because of the time scales involved. The time scale from which blood mercury moves into tissue is faster than the monthly time scale of the model.

The connector from MeHg Defecation flow (and multiplication by 0 in equation) is to force the priority of the Hg Defecation flow to be higher than this flow.

OUTFLOWS:

Converted_to_IHgIPopulation_Intake] =

TISSUE_MeHglPopulation_Intake]"rate_constant_convert_to_IHg

\{ug $\mathrm{IHg}$ per month\}

DOCUMENT: This flow represents the rate of conversion of $\mathrm{MeHg}$ to $\mathrm{IHg}$ within the tissue, and was calibrate to optimize the $\mathrm{MeHg}$ blocd concentration: tissue $\mathrm{MeHg}$ ratio and time to steady state. The addition of Disposition" 0 is to give the flow the correct outflow priority.

0 anglers_ $1=1$

DOCUMENT: This converter is a switch. When this population is chosen, it takes on a value of " 1 ". When not chosen, it has a value of " 0 ".

0 anglers $2=0$

DOCUMENT: This converter is a switch. When this population is chosen, it takes on a value of "1". When not chosen, it has a value of " 0 ".

$O$ biomass_of_IVI_2 = biomass_of_M_1*.1

UNITS: $\mathrm{kg}$

DOCUMENT: Biomass of each level is set to $10 \%$ of biomass of the level below

$O$ biomass_of $I M L 3=$ biomass_of_IM_2*.1

UNITS: $\mathrm{kg}$

DOCUMENT: biomass of each level is set to $10 \%$ of level below

0 biomass_of_IVI $4=$ biomass_of_M_ $3^{*} .1$

UNITS: $\mathrm{kg}$

DOCUMENT: biomass of each level is set to $10 \%$ of level below 
O blood_vol = IF (bw=31.5) THEN (2.4) ELSE (5)

\{L blood\}

DOCUMENT: Blood volume is $5 \mathrm{~L}$ for adults (IRIS). For children, if was found to average $75.4 \mathrm{ml} / \mathrm{kg}$ (so $31.5 \mathrm{~kg}$ multiplied by .0754 gives $2.4 \mathrm{~L}$ ). Source for formula for children: Graham, G.(1963); Blood volume in children. Annals R Coll Surg Engi. 33(3): 149-158.

$O$ body_burden_IHg[Population_Intake] $=$ TISSUE_IHg[Population_Intake] \{ug IHg\} DOCUMENT: used in calculating total body burden $\mathrm{Hg}$

$\bigcirc$ body_burden_MeHg[Population_Intake] $=$ BLOOD_MeHg[Population_Intake]+TiSSUE_MeHg[Population_Intake] \{ug MeHg\}

DOCUMENT: used in calculating total body burden $\mathrm{Hg}$

O $\quad$ W $=$ IF (child__14+childr_14_cons>0) THEN (31.5) ELSE (67)

$\{\mathrm{kg}\}$

DOCUMENT: Body weight is that used by the EPA for the pregnant woman. Found in the IRIS documentation on $\mathrm{MeHg}$ exposure $\mathrm{pg} 6$. If the population being modeled is of a child, then the bocty weight is 31.5 , which is the mean body weight for 9 year old boys and girls given in Table 3 of Chapter 7 of the Exposure Factors Handbook. This population represents children from age 0 to 14 and so it has a highly varied body weight. The weight of a Q-year-old was arbitrarily chosen to represent the group.

childr $14=1$

DOCUMENT: This converter is a switch. When this population is chosen, it takes on a value of " 1 ". When not chosen, it has a value of " 0 ".

0 childr_14_cons $=1$

DOCUMENT: This converter is a switch. When this population is chosen, it takes on a value of "1". When not chosen, it has a value of " 0 ".

$O$ conc_in_W__ $=$ MeHg_IN_TROPHIC_LVL_t/biomass_of_IV_1

UNITS: $\mathrm{mg} / \mathrm{kg}$

DOCUMENT: The mass of MeHg in TLI divided by the biomass in TL1. This value is used to determine the amount of MeHg that needs to move to TL2.

$O$ cono_in_M_2 $=$ MeHg_IN_TROPHIC_LVL_2biomass_of_IW_2 UNITS: $\mathrm{mg} / \mathrm{kg}$

DOCUMENT: Mass of MeHg in TL2 divided by the biomass in TL2. This is used to determine the mass of MeHg that needs to move to TL.3.

$O$ conc_in_IV_3 $=$ MeHg_IN_TROPHIC_LVL_3/biomass_of_IM_3

UNITS: $m g / k g$

DOCUMENT: Mass of MeHg in TL3 divided by the biomass of TL3. This is used to determine the mass of MeHg that needs to move to TL4. It is also the output for fish tissue concentration for TL3 (panfish).

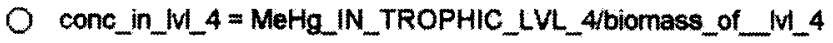

UNITS: $\mathrm{mg} / \mathrm{kg}$

DOCUMENT: MeHg in TL4 divided by the biomass of TL4. This is the model output for fish tissue concentration for TL4 (piscivorous fish).

$\mathrm{O}$ consumers $=1$ DOCUMENT: This converter is a switch. When this population is chosen, it takes on a value of " 1 ". When not chosen, it has a value of " 0 ".

$\bigcirc$ convert_units $=100$

DOCUMENT: convert mgikg to ng/kg 
$O$ cord_conc(Population_Intake] = IF ((MOD $(T I M E, 60)>0)$ AND $($ MOD $(T I M E, 60)<9))$ THEN

(FETAL_BLOOD_MëHglPopulation_Intake](fetal_bl_vol*(MOD(TIME,60)/9))) EL.SE (0)

\{ug MeHg per L blood\}

DOCUMENT: As with the flow of MeHg through the placenta, the total blood volume for a full term intant is evenly divided over a 9 month period. The dynamics of fetal growth is beyond the scope of this project. By spreading the volume over the entire 9 months of gestation, it gives a more accurate portrayal of what fetal blood concentrations are, again, allowing some adjustments in maternal compensation.

The MOD statement keeps track of when a pregnancy is occuring (every 5 years), and returns the month of the pregnancy. By multiplying the fetal blood volume by the month and dividing by the total months of pregnancy, the blood volume is a fraction of the pregnancy. (So if it is month 2 , the total fetal blood volume is multiplied by 29). The MOD>0 staternent is necessary to prevent a divide by 0 error.

EPA fish criterion $=3$

DOCUMENT: Fish tissue concentration set by EPA as water quality criterion for methylmercury in fish.

O EPA_safe_exposure_level $=5.8$

\{ug MeHg per L blood\})

DOCUMENT: Maternal blood concentration which EPA has determined to be protective of the developing fetus

EPA 2009a. Mercury: Human exposure. (03/17/2010 2010; http://www.epa gov/mercury/exposure htm)

0 expected_ratio $=1 / 7.5$

[no units\}

DOCUMENT: According to Cernichiari et al. (2007) The biological monitoring of prenatal exposure, the ratio of brain to whole blood methylmercury ranges from 5:1 to 10:1. The mean was used.

0 fetal_bl_vol = fetal_bw .085

\{L blocod

DOCUMENT: The fetal bl vol was derived from the American Academy of Pediatrics website (American Academy of Pediatrics 2010). It reports fetal blood volume averages $78-86 \mathrm{ml} / \mathrm{kg}$ for the term infant. An upper-end number $(085 \mathrm{~L} / \mathrm{kg}$ ) was chosen because there will be pulling into the tissue from the blood.

fetal_bw $=3.25$

(kg)

DOCUMENT: The fetal body weight was the mean of male and female full-term infants taken from Chapter 7 (Body Weight Studies) of the Exposure Factors Handbook (EPA, 1997).

O fish_intake_rate[50 $]=$

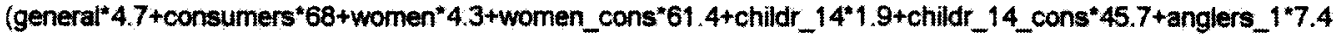
+anglers_2*4.9+sub_fisher_1*53.3+sub_fisher_2*58.7)/1000*30

DOCUMENT: The input of the intake rate of the population of concern is controlled by the chained switch on the interface. Only one population can be "on". This switch receives a value of " 1 " while all others receive a " 0 ". The proper intake rates are then input in the model by multiplying the switch value $(0$ or 1$)$ for each possibie, and addin them together. For all populations that are "off", the value will be 0 , while the population that is chosen will be given the appropriate intake rate. This value is then divided by 1000 to convert from grams to kilograms, and multiplied b 30 to give per month instead of per day. 
0 fish_intake_rate $[90]=$ (general $12.6+$ consumers"170.8+women*10.9+women_cons*148.8+childr_14*1.3+childr_14_cons*108.4+angler s_1*20.6+anglers_2*13.2+sub_fisher_1*203+sub_fisher_2*110)/1000*30

DOCUMENT: The input of the intake rate of the population of concern is controlled by the chained switch on the interface. Only one population can be "on". This switch receives a value of " 1 " while all others receive a " 0 ". The proper intake rates are then input in the model by multiplying the switch value $(0$ or 1$)$ for each possible, and addiny them together. For all populations that are "ofr", the value will be 0 , while the population that is chosen will be given the appropriate intake rate. This value is then divided by 1000 to convert from grams to kilograms, and multiplied b. 30 to give per month instead of per day.

0 fish_intake_rate[95] $=$

(general" $32.2+$ consumers*224.8+women"28.8+women_cons* $185.9+$ childr_14*13.9+childr_14_cons"136.2+angle rs_1*24.6+anglers_2*17.9+sub_fisher_1*216.7+sub_fisher_2*170)/1000* $\overline{30}$

DOCUMENT: The input of the intake rate of the population of concem is controlled by the chained switch on the interlace. Only one population can be "on". This switch receives a value of " 1 " while all others receive a " 0 ". The proper intake rates are then input in the model by multiplying the switch value $(0$ or 1) for each possible, and adding them together. For all populations that are "off", the value will be 0 , while the population that is chosen will be given the appropriate intake rate. This value is then divided by 1000 to convert from grams to kilograms, and multiplied b. 30 to give per month instead of per day.

fish_intake_rate $\{99]=$ (general*82.5+consumers" $374.7+$ women*70.9+women_cons*363.6+childr_14*40.8+childr_14_cons"214.6+angle rs_. $1 * 82.2$ +anglers_2*39.8*sub_fisher_1*240+sub_fisher_2*389)/1000*30 $\{\mathrm{kg}$ fish per month\}

DOCUMENT: The input of the intake rate of the population of concern is controlled by the chained switch on the interface. Only one population can be "on". This switch receives a value of " 1 " while all others receive a " 0 ". The proper intake rates are then input in the model by multiplying the switch value $(0$ or 1) for each possible, and adding them together. For all populations that are "off", the value will be 0 , while the population that is chosen will be given the appropriate intake rate. This value is then divided by 1000 to convert from grams to kilograms, and multiplied b: 30 to give per month instead of per day.

0 gap_2 $=$ needed_IML2-MeHg_IN_TROPHIC_LVL_2

UNITS: $m g$

DOCUMENT: Difference between the mass needed to achieve target concentration and mass already resident in the stock.

0 gap_3 $=$ needed_IM_3-MeHg_IN_TROPHIC_LVL_3

UNITS: $\mathrm{mg}$

DOCUMENT: Difference between the mass needed to achieve target concentration and mass already resident in the stock.

O gap_4 = needed_M_4MeHg_IN_TROPHIC_LVL_4

UNITS: $\mathrm{mg}$

DOCUMENT: Difference between the mass needed to achieve target concentration and mass already resident in the stock.

general $=1$

DOCUMENT: This converter is a switch. When this population is chosen, it takes on a value of " 1 ". When not chosen, it has a value of " 0 ". 
0 hair_to blood_ratio $=250$

\{no units\}

DOCUMENT: Clarkson el al. 2007 reports a central tendency of total hair mercury to blood methylmercury of 250:1. This is further broken into $80 \% \mathrm{MeHg}$ and $20 \% \mathrm{IHg}$ as reported by Phelps, Clarkson, Kershaw, Wheatiey (1980) Archives of Environmental Health. Vol 35 (3): pp 161 168).

$O$ ideal_cord:__maternal_ratio $=1.9$

DOCUMENT: Stern \& Smith (2003) found a central tendency ratio of 1.9 for cord blood to maternal blood methyimercury in a meta-analysis of studies. (This is the ratio found for the meta-analysis that included studies that reported methylmercury concentrations only.)

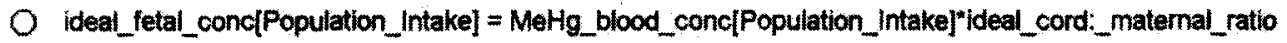
\{ug per L $\mathrm{\}}$

$O$ ideal $M I_{2}$ _conc $=$ conc_in_WL_t*PPF2 UNITS: $m g / m^{\wedge} 3$

DOCUMENT: Based on the predator prey factor and the concentration of methylmercury in trophic level 1, this is the target concentration for trophic level 2.

0 ideal_M_3_conc $=$ conc_in_W_2ZPPF3 UNITS: $m g / m^{\wedge} 3$

DOCUMENT: Based on the predator prey factor and the concentration of methymercury in trophic level 2, this is the target concentration for trophic level 3.

0 ideal_IW_4_conc $=$ conc_in_IVI_3*PPF4

UNITS: $m g / m^{\wedge} 3$

DOCUMENT: Based on the predator prey factor and the concentration of methylmercury in trophic level 3 , this is the target concentration for trophic level 4.

$O$ ideal_tissue_MeHgl50] = body_burden_MeHg[50y(1+(blood_vol*expected_ratio/bw))

DOCUMENT: Ideal tissue MeHg is the calculated mass of MeHg that should be in TISSUE MeHg in order to attain the expected ratio. It is calculated from the body burden $\mathrm{MeHg}$, expected ratio, bw, and blood vol. The two. equations: Body burden $\mathrm{MeH} \mathrm{Hg}=$ ideal Blood $\mathrm{MeHg}+$ ideal tissue MeHg and expected ratio $=$ (BLOOD MeHg/blood vol)/(TISsuE MeHg/bw) are solved for ideal tissue $\mathrm{MeHg}$, to become:ideal tissue $\mathrm{MeHg}=$ body burden MeHg/(1+(blood_vol*expected_ratio/bw)).

0 ideal_tissue_MeHg[S0] = body_burden_MeHg[900/(1+(blood_yol"expected_ratio/bw)) DOCUMENT: Ideal tissue MeHg is the calculated mass of MeHg that should be in TISSUE MeHg in order to aftain the expected ratio. It is calculated from the body burden MeHg, expected ratio, bw, and blood vol. The two equations: Body burden $\mathrm{MeHg}=$ ideal Blood $\mathrm{MeHg}+$ ideal tissue $\mathrm{MeHg}$ and expected ratio $=(\mathrm{BLOOD}$ MeHg/blood vol)/(TISSUE MeHg/bw) are solved for ideal tissue $\mathrm{MeHg}$, to become:ideal tissue $\mathrm{MeHg}=$ body burden MeHg/(1+(blood_vol*expected_ratiofbw)).

0 ideal tissue MeHg[95] = body_burden_MeHg[95] $\left(1+\left(\right.\right.$ blood_vol ${ }^{*}$ expected_ratio/bw) $)$ DOCUMENT: Ideal tissue MeHg is the calculated mass of MeHg that should be in TISSUE MeHg in order to attain the expected ratio. It is calculated from the body burden $\mathrm{MeHg}$, expected ratio, bw, and blood vol. The two equations: Body burden $\mathrm{MeHg}=$ ideal Blood MeHg + ideal tissue $\mathrm{MeHg}$ and expected ratio $=(B \mathrm{LOOD}$ MeHg/blood vol)/(TISSUE MeHg/bw) are solved for ideal tissue MeHg, to become:ideal tissue $\mathrm{MeHg}=$ body burden $\mathrm{MeH} /(1+(\mathrm{blood}$ _vol*expected_ratio/bw) $)$. 
0 ideal_tissue_MeHg[99] = body_burden_MeHg[99j/(1+(blood_vol"expected_ratio/bw))

\{ug\}

DOCUMENT: Ideal tissue MeHg is the calculated mass of MeHg that should be in TISSUE MeHg in order to attain the expected ratio. It is calculated from the body burden MeHg, expected ratio, bW, and blood vol. The two equations: Body burden $\mathrm{MeHg}=$ ideal Blood $\mathrm{MeHg}+$ ideal tissue $\mathrm{MeHg}$ and expected ratio $=(B \mathrm{LOOD}$

MeHg/blood vol)/(TISSUE MeHg/bw) are solved for ideal tissue MeHg, to become:ideal tissue $\mathrm{MeHg}=$ body burden MeHg/(1+(blood_vol"expected_ratio/bw)) .

$O \mathrm{Hg}$ conc_in_hairtPopulation_Intake $=1 \mathrm{Hg}$ in_1 $1 \mathrm{CM}$ HAIRIPopulation_Intakel/mass_of_1_cm_hair \{ug $1 \mathrm{Hg}$ per $\mathrm{kg}$ hair\}

DOCUMENT: ug $\mathrm{IHg}$ per $\mathrm{kg}$ of hair. Used in calculation of total hair mercury.

0 IHg_def_rate $=9$

[no units\}

DOCUMENT: Set to help achieve a $80-90 \%$ loss through the defecation pathways (both MeHg and $\mathrm{HHg}$ together).

$0 \mathrm{Hg}$ hair_fraction $=.0296$

DOCUMENT: Fraction was determined by back-calculating the fraction of TISSUE IHg needed to generate the correct amount of inorganic mercury in hair to achieve the ideal ratio between total mercury in hair and blood methylmercury.

0 intake_conc $=($ conc_in_M_3troph_IM_3_intake+conc_in_M_4ttroph_M_4_intake $) / 100$

UNITS: $\mathrm{mg} / \mathrm{kg}$

DOCUMENT: Feeds into human disposition sector. Allows user to define proportion of diet for a population that comes from trophic levels 3 and 4.

This can be used in two ways:

As written, a population, on average, may consume a certain proportion of its fish intake at trophic level 3 , and the rest at trophic level 4. The sliders are set to reflect the proportion of each trophic level consumed.

If interested in the impact of consumption of a particular fish species whose trophic level falls between 3 and 4, the sliders can be sel to equal that trophic level (eg. troph IVI 3 intake slider set at 60\% and troph Ivi 4 intake set at $40 \%$ is equivalent to intake of a species at trophic level 3.4 .

0 mass_of_1_cm_hair $=0173$

$\{\mathrm{kg}$ hair $\}$

DOCUMENT: According to Omega Laboratories

(http://www.omegalabs net/abouthairtesting/hairtestinglaq/hairtestingfaq.aspx) about 90 to 120 strands of hair (1.5 inches long) make up a $60 \mathrm{mg}$ sample. With estimates of 100,000 to 150,000 strands of hair per head (for those who are not bald), I calculated (using 105 strands for $60 \mathrm{mg}$ and 100,000 strands per head) that the average head would have $18.7 \mathrm{~g}$ hair for the first centimeter of growth. this is $0.0173 \mathrm{~kg}$.

$\mathrm{O}$ MeHg_absorption_fraction $=95$

DOCUMENT: According to Mlettinen et al (1971), approximately $95 \%$ of ingested $\mathrm{MeHg}$ is absorbed.

0 MeHg_blood_conciPopulation_Intake] $=$ BLOOD_MeHg[Population_Intake/lblood_vol (ug MeHg per L blood)

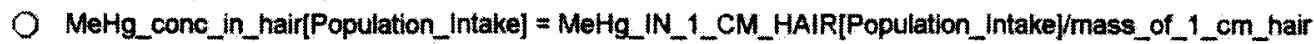
[ug MeHg per $\mathrm{kg}$ hair)

DOCUMENT: Mass of MeHg in $1 \mathrm{~cm}$ hair. 
O MeHg_def_fraction $=.4$

\{unitless\}

DOCUMENT: Set to help achieve a $80-90 \%$ loss through the defecation pathways (both MeHg and $\mathrm{Hg}$ together).

O MeHg_ingestion|Population_Intake] $=$ fish_intake_rate[Population_Intake]*intake_conc*convert_units (ug MeHg per month)

DOCUMENT: Calculates the MeHg ingested based on the $\mathrm{kg}$ fish intake for the population multiptied by the fish tissue concentration.

$\mathrm{kg}$ fish per month $\mathrm{X}$ ug MeHg per $\mathrm{kg}$ fish gives units of ug MeHg per month.

O MeHg_tissue_conclPopulation_Intake] = TISSUE_MeHg[Population_Intakelbw \{ug per $\mathrm{kg}$ \} DOCUMENT: Gives ug methymercury per $\mathrm{kg}$ tissue. Used in calibration process to determine if the model was achieving the desired ratio between blood and tissue.

O MeHg_tissue_gap[Population_intake] = ideal tissue_MeHg[Population_Intake\}-TISSUE_MeHg[Population_Intake] \{ug $\overline{\mathrm{MeH}} \mathrm{g}$ \}

DOCUMENT: MeHg tissue gap is the difference between TISSUE MeHg and ideal tissue MeHg. This converter informs the B1 to Tissue MeHg Transfer flow (in addition to the MeHg Absorption flow). If the number is positive, it is the amount needed to move from BLOOD MeHg to TISSUE MeHg to attain the expected ratio. If it is negative, it is the amount needed to move from TISSUE MeHg to BLOOD MeHg to attain the ratio.

9 monthly_hair_MeHg[Population_Intake] $=$ MeHg_blood_conclPopulation_Intakel"hair_to_blood_ratio*mass_of_1_cm_hair*.8 [ug] DOCUMENT: Calculates amount of mercury in $1 \mathrm{~cm}$ of hair (from entire scalp) based on the ratio of hair concentration to blood concentration (250:1). This is multiplied by .8 because a portion of the hair mercury is inorganic, and is calculated separately through the inorganic flow. Total hair mercury is then calculated by adding $\mathrm{MeHg}$ and $\mathrm{IHg}$ in hair. (80\% is the estimated content of MeHg in hair, Phelps, Clarkson, Kershaw, Wheatley. (1980) Archives of Environmental Health. Vol 35 (3): pp 161-168).

0 needed[Population_intake] $=$ ideal_fetal_conc[Population_Intake|"fetal_bI_vol \{ug $\mathrm{MeHg}$ \} DOCUMENT: Calculates the mass of methyimercury needed to achieve the ideal ratio between cord blood and maternal blood:

$O$ needed_IM_3 = biomass_of_M_ $3^{*}$ ideal_IV_3_conc

UNITS: $\mathrm{mg}$

DOCUMENT: The mass of methylmercury needed in the trophic level 3 stock based on the target concentration and the biomass of trophic level 3.

0 needed_M_4 = blomass_of_IM_4*ideal_MI4_conc

UNITS: $m g$

DOCUMENT: The mass of methylmercury needed in the trophic level 4 stock based on the target concentration and the biomass of trophic level 4 .

0 needed_IV_2 =ideal_IVI2_conc*biomass_of IML2 UNITS: $\mathrm{mg}$ DOCUMENT: The mass of methylmercury needed in the trophic level 2 stock based on the target concentration and the biomass of trophic level 2 . 
0 PPF2 $=7+$ bloom_growth_dilution

UNITS: Unitless

DOCUMENT: PPF is the predator prey factor. It is the "unitless factor by which methyimercury concentrations in trophic level [2] organisms exceed those in the trophic level [1] organisms upon which they prey". $\mathrm{Hg}$ Study Report to Congress Vol VII, p 6-5.

Detailed analysis of the derivation of PPF can be found in $\mathrm{Hg}$ Study Report to Congress Vol III, Appendix D. (pg D-6 for PPF2). The suggested value of 6.3 was adjusted to 7 to increase model fit.

The bloom growth dilution factor adjusts the PPF to simulate the effects of nutrient status on bioaccumulation.

P PPF3 $=7+$ bloom growth dilution

UNITS: Unitless

DOCUMENT: PPF4 is the predator prey factor. It is the "unitless factor by which methyimercury concentrations in trophic level 4 organisms exceed those in the trophic level 3 organisms upon which they prey". Hg Study Report to Congress Vol VII, $p$ 6-5.

PPF3 is the ratio of methymercury concentration of trophic level 3 over trophic level 2. These values are derived from several studies and represent a mean value.

Detailed analysis of the derivation of PPF can be found in Hg Study Report to Congress Vol III, Appendix D. (Pg D-7 for PPF3).

A PPF3 of 6.3, the suggested average in the Study Report was begun with. This value was adjusted to reduce mean error for all sites. The final adjusted value was 7.0. (Range from cited studies: 2.6-15.5.)

The bloom growth dilution factor adjusts the PPF to simulate the effects of nutrient status on bioaccumulation.

0 PPF $4=4.5+$ bloom_growth_ditution

UNITS: Unitless

DOCUMENT: PPF is the predator prey factor. It is the "Unitless factor by which methylmercury concentrations in trophic level 4 organisms exceed those in the trophic level 3 organisms upon which they prey". Hg Study Report to Congress Vol vil, p 6.5 .

Detailed analysis of the derivation of PPF can be found in $\mathrm{Hg}$ Study Report to Congress Vol III, Appendix D. (pg D-8 for PPF4)

The suggested PPF of 5 was adjusted to 4.5 for better model fit.

The bloom growth dilution factor adjusts the PPF to simulate the effects of nutrient status on bioaccumulation.

0 rate_constant_convert_to_ $\mathrm{Hg}=0.00155 * 30$

\{no units\}

DOCUMENT: This rate was calibrated by adjusting so that the half-ime in the body and the ratio between blood and tissue methylmercury came closest to matching literature values.

Sub_fisher_ $1=1$

DOCUMENTT: This converter is a switch. When this population is chosen, it takes on a value of " 1 ". When not chosen, it has a value of " 0 ". 
Sub_fisher_2 $2=0$

DOCUMENT: This converter is a switch. When this population is chosen, it takes on a value of " 1 ". When not chosen, it has a value of " 0 ".

0 tissue to_urine_transfer_rate $=.001 * 30$ \{no units\}

DOCUMENT: This rate was set to help achieve the goal of having an $80-90 \%$ loss through the defecation pathways $(\mathrm{MeHg}+\mathrm{IHg})$.

0 total_body_burden[Population_intake] $=$ body_burden_IHglPopulation_Intake]+body_burden_MeHglPopulation_Intake] \{ug Hg\}

DOCUMENT: This converter was used in evaluating the half-time of $\mathrm{Hg}$ in the body, It includes all the stocks except $\mathrm{Hg}$ in HAIR and FETAL BLOOO.

$O$ total_conc_in_hair[Population_Intake] =

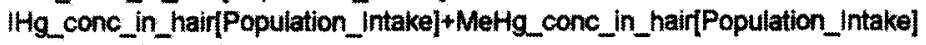
\{ug $\mathrm{Hg}$ per $\mathrm{kg}$ hain\}

0 troph_IN_3 intake $=0$

DOCUMENT: Links to slider on interface page. User inputs the proportion of the diet of the target population that is TL3.

0 troph $M$ L intake $=100$

DOCUMENT: Links to slider on interface page. User inputs the proportion of the diet of the target population that is TL4.

$O$ weighted_TL $=\left(3^{*}\right.$ troph_IM_3_intake+4*troph_IV__ 4 intake $) / 100$

women $=1$ DOCUMENT: This converter is a switch. When this population is chosen, it takes on a value of "1". When not chosen, it has a value of " 0 ".

0 women_cons $=1$

DOCUMENT: This converter is a switch. When this population is chosen, it takes on a value of "1". When not chosen, it has a value of " 0 ".

0 bloom_growth_dilution = GRAPH(mean_productivity_index)

HD $10.00,2.00),(18.4,1.88),(36.8,0.245),(55.3,0.155),(73.7,0.065),(92.1,0.00),(111,0.005),(129,0.00),(147$, $40.00),(166,0.00),(184,0.00),(203,0.00),(221,0.00),(239,0.00),(258,0.00),(276,0.00),(295,-0.025),(313$, $-0.075),(332,-0.15),(350,-0.175)$

DOCUMENT: This converter represents the effects of nutrients on bioaccumulation. In eutrophic systems, the methyimercury is spread through a larger number of algal cells. This effect is called bloom dilution (Chen \& folt, 2005). Primary consumers then intake less methyimercury per unit algae consumed than in more oligotrophic systems. in addition, the algae in high-nutrient systems tend to produce more biomass per unit consumed than in nutrient-poor systems (Karimi et al, 2007), so consumers in eutrophic systems consume less for a given amount of biomass produced. This effect is called growth dilution. These two factors lead to eutrophic systems having lower predator prey factors than oligotrophic systems. This graphical function is used to adjust the predator prey factor to reflect this.

0 diffusion $=$ GRAPH(water_temp)

$00(0.00,0.3),(3.00,0.345),(6.00,0.41),(9.00,0.48),(12.0,0.565),(15.0,0.635),(18.0,0.73),(21.0,0.795),(24.0$, 110.845), $(27.0,0.895),(30.0,0.935)$

seasonal $=$ GRAPH (count)

GD(1.00,0.395), $(2.10,0.4),(3.20,0.4),(4.30,0.4),(5.40,0.335),(6.50,0.215),(7.60,0.255),(8.70,0.8),(9.80,0.8)$ $E(10.9,0.8),(12.0,0.405)$

DOCUMENT: Simulates the seasonal pattern of decline, death, and sloughing of periphyton mats 


\section{Appendix B}

\section{DATA SOURCES}

\section{References for Table 2}

Tennessee spatial data server. http://www.tngis.org/data.html. Accessed: 8/15/2011.

Georgia Spatial Data Infrastructure. 2009. Georgia GIS clearinghouse.

http://data.georgiaspatial.org/login.asp. Accessed: 8/15/2011.

Homer, Huang C, Yang L, Wylie B, Coan M. 2004. Development of a 2001 National

Landcover Database for the United States. Photogramm Eng Rem S 70: 829-840.

Kentucky Geological Survey. State hydrology series.

http://www.uky.edu/KGS/gis/hydro.htm. Accessed 08/15/2010.

National Climatic Data Center. 2010. Climate-radar data inventories.

http://www.ncdc.noaa.gov/oa/climate/stationlocator.html. Accessed: 3/30/3011.

ptaff. 2005. Sunrise, sunset, daylight in a graph. http://ptaff.ca/soleil/?lang=en_CA.

Accessed: 10/10/2010.

University Information Technology Services. 2011. Indiana spatial data portal.

http://gis.iu.edu/. Accessed: 8/15/2011

US Geological Survey. 2011. USGS Water Data for USA.

http://waterdata.usgs.gov/nwis. Accessed 9/23/2011

[USEPA] US Environmental Protection Agency. 2011. STORET/WQX: STORET

database access. http://epa.gov/storet/dbtop.html. Accessed: 10/26/2010.

[USEPA] US Environmental Protection Agency Region 4. 2003. Total Maximum Daily

Load (TMDL) for total mercury in fish tissue residue in Spring Creek (HUC 03150104) including listed segment. 
[USEPA] US Environmental Protection Agency Region 4. 2003. Total Maximum Daily Load (TMDL) for total mercury in fish tissue residue in Talking Rock Creek (HUC 03150102) including listed segment.

West Virginia Department of Health and Human Resources. 2010. West Virginia fish consumption advisories: Advisory database. http://www.wvdhhr.org/fish/Data/Data_for_2010_Advisory-waterbody.pdf. Accessed: 9/25/2011.

West Virginia GIS Technical Center. 2011. WV State GIS data Clearinghouse. http://wvgis.wvu.edu/data/data.php. Accessed: 8/15/2011. 


\section{Fish Tissue Data}

\begin{tabular}{|c|c|c|c|c|c|c|c|}
\hline Calibration Sitest & $\pi$ & species & year & $\begin{array}{c}\mathrm{QL} \\
\mathbf{m m}\end{array}$ & $\begin{array}{c}\text { length } \\
\text { mm }\end{array}$ & $\begin{array}{c}\text { sample } \\
\mathrm{Hg}\end{array}$ & $\begin{array}{l}\text { sample } \\
\text { mean** }\end{array}$ \\
\hline \multirow[t]{4}{*}{ Floyds Fork } & \multirow{3}{*}{3.5} & spotted bass & 1999 & 280 & 289 & 0.164 & \multirow{3}{*}{0.179} \\
\hline & & rock bass & 2004 & 180 & 191 & 0.194 & \\
\hline & & * channel catfish & 1999 & 410 & 216 & 0.053 & \\
\hline & 3 & black redhorse & 2004 & & 349 & 0.138 & 0.138 \\
\hline Tygarts Creek & 4 & sauger & 2002 & 300 & 432 & 1.140 & 1.140 \\
\hline \multirow[t]{14}{*}{ Mud River } & 4 & LMB & 2004 & 300 & 358 & 0.366 & 0.366 \\
\hline & \multirow{7}{*}{3.5} & channel catfish & 2004 & 410 & 444 & 0.122 & \multirow{7}{*}{0.201} \\
\hline & & channel catiish & 2005 & 410 & 513 & 0.160 & \\
\hline & & channel catfish & 2005 & 410 & 513 & 0.179 & \\
\hline & & freshwater drum & 2002 & 300 & 358 & 0.243 & \\
\hline & & *black crappie & 2005 & 200 & 267 & 0.303 & \\
\hline & & ${ }^{*}$ flathead catfish & 1999 & 510 & 305 & 0.166 & \\
\hline & & black crappie & 2005 & 200 & 263 & 0.303 & \\
\hline & \multirow{6}{*}{3} & bhuegill & 1999 & 150 & 196 & 0.091 & \multirow{6}{*}{0.085} \\
\hline & & longear sunfish & 1999 & 150 & 140 & 0.180 & \\
\hline & & black rechorse & 2002 & & 376 & 0.057 & \\
\hline & & black redhorse & 2002 & & 368 & 0.076 & \\
\hline & & *smallmouth buffalo & 2002 & & 450 & 0.039 & \\
\hline & & bhegill & 2004 & 150 & 184 & 0.068 & \\
\hline Mayfield Creek & 3.5 & chamnel catfish & 2000 & 410 & 419 & 0.247 & 0.247 \\
\hline \multirow[t]{4}{*}{ Salt River } & \multirow{3}{*}{3.5} & spotted bass & 1999 & 280 & 330 & 0.277 & \multirow{3}{*}{0.179} \\
\hline & & northem hogsucker & 1999 & & 275 & 0.131 & \\
\hline & & freshwater drum & 1999 & 300 & 279 & 0.129 & \\
\hline & 3 & longear sunfish & 1999 & 150 & 121 & 0.073 & 0.073 \\
\hline Nolin River & 3.5 & rock bass & 2001 & 180 & 190 & 0.170 & 0.170 \\
\hline Slate Creek & 4 & SMB & 2004 & 280 & 310 & 0.190 & 0.190 \\
\hline
\end{tabular}

*utlier

** exchuding outliers

Tall calibration sites are in

Kentucky
Abbreviations: TL - trophic level; QL - Quality Length; $\mathrm{Hg}$ - mercury Mercury measurements in mg/kg 


\begin{tabular}{|c|c|c|c|c|c|c|c|}
\hline Evaluation Sites & $\pi$ & species & year & $\begin{array}{l}\mathrm{QL} \\
\mathbf{m m}\end{array}$ & $\begin{array}{c}\text { length } \\
\mathrm{mm}\end{array}$ & $\begin{array}{c}\text { sample } \\
\mathrm{Hg}\end{array}$ & $\begin{array}{l}\text { sample } \\
\text { mean }^{* *}\end{array}$ \\
\hline Spring Creek & & redeye bass & 2002 & & 260 & 0.380 & \multirow{5}{*}{0.262} \\
\hline \multirow[t]{8}{*}{ Georgia } & \multirow{4}{*}{3.5} & redeye bass & 2002 & & 260 & 0.300 & \\
\hline & & spotted bass & 2002 & 280 & 225 & 0.320 & \\
\hline & & spotted bass & 2002 & 280 & 215 & 0.150 & \\
\hline & & shadow bass & 2002 & & 190 & 0.160 & \\
\hline & \multirow{4}{*}{3} & bluegill & 2002 & 150 & 180 & 0.310 & \multirow{4}{*}{0.12} \\
\hline & & green sunfish & 2002 & 150 & 146 & 0.080 & \\
\hline & & green sunfish & 2002 & 150 & 150 & 0.050 & \\
\hline & & green sunfish & 2002 & 150 & 130 & 0.050 & \\
\hline Talking Rock Creek & 4 & striped bass* & 2002 & 510 & 450 & 0.130 & \\
\hline \multirow{16}{*}{ Georgia } & & striped bass* & 2002 & 510 & 405 & 0.060 & \\
\hline & \multirow{9}{*}{3.5} & redeye bass & 2002 & & 235 & 0.500 & \multirow{9}{*}{0.271} \\
\hline & & redeye bass & 2002 & & 224 & 0.150 & \\
\hline & & redeye bass & 2002 & & 233 & 0.420 & \\
\hline & & spotted bass & 2002 & 280 & 330 & 0.660 & \\
\hline & & spotted bass & 2002 & 280 & 285 & 0.260 & \\
\hline & & spotted bass & 2002 & 280 & 335 & 0.150 & \\
\hline & & spotted bass & 2002 & 280 & 275 & 0.120 & \\
\hline & & chamnel catfish & 2002 & 410 & 445 & 0.030 & \\
\hline & & shadow bass & 2002 & & 159 & 0.150 & \\
\hline & \multirow{6}{*}{3} & bluegill & 2002 & 150 & 166 & 0.080 & \multirow{6}{*}{0.065} \\
\hline & & bluegill & 2002 & 150 & 184 & 0.100 & \\
\hline & & bluegill & 2002 & 150 & 185 & 0.070 & \\
\hline & & redbreast sunfish & 2002 & & 165 & 0.050 & \\
\hline & & redbreast sunfish & 2002 & & 164 & 0.050 & \\
\hline & & redbreast sunfish & 2002 & & 175 & 0.040 & \\
\hline
\end{tabular}

*outlier

**excluding ourliers

Abbreviations: TL - trophic level; QL - Quality Length; Hg mercury

Mercury measurements in $\mathrm{mg} / \mathrm{kg}$ 


\begin{tabular}{|c|c|c|c|c|c|c|c|}
\hline Evahuation Sites & IL & species & year & $\underset{\mathbf{m m}}{\mathrm{QL}}$ & $\begin{array}{l}\text { length } \\
\text { mm }\end{array}$ & $\begin{array}{c}\text { sample } \\
\mathrm{Hg}\end{array}$ & $\begin{array}{l}\text { sample } \\
\text { mean }^{* *}\end{array}$ \\
\hline \multirow{3}{*}{$\begin{array}{l}\text { Big Creek } \\
\text { Indiana }\end{array}$} & 3.5 & channel catfish & 2002 & 410 & 495 & 0.260 & 0.260 \\
\hline & 3 & longear sunfish & 2002 & 150 & 142 & 0.120 & \multirow{2}{*}{0.12} \\
\hline & & longear sunfish & 2002 & 150 & 143 & 0.120 & \\
\hline \multirow{4}{*}{$\begin{array}{l}\text { Muscatatuck River } \\
\text { Indiana }\end{array}$} & 3.5 & spotted bass & 2002 & 280 & 279 & 0.330 & 0.330 \\
\hline & \multirow{3}{*}{3} & longear sunfish & 2002 & 150 & 132 & 0.085 & \multirow{3}{*}{0.097} \\
\hline & & longear sunfish & 2002 & 150 & 143 & 0.076 & \\
\hline & & redear sunfish & 2002 & 150 & 180 & 0.130 & \\
\hline North Fork Forked & & largemouth bass & 2007 & 300 & 338 & 0.361 & \multirow{3}{*}{0.426} \\
\hline Deer River & 4 & largemouth bass* & 1998 & 300 & 493 & 0.520 & \\
\hline \multirow{4}{*}{ Tennessee } & & largemouth bass & 1998 & 300 & 371 & 0.490 & \\
\hline & \multirow{3}{*}{3.5} & channel catfish* & 1998 & 410 & 566 & 0.360 & \multirow{3}{*}{0.162} \\
\hline & & channel catfish & 2007 & 410 & 437 & 0.144 & \\
\hline & & spotted bass & 2007 & 280 & 318 & 0.180 & \\
\hline Little Kanawha & \multirow{6}{*}{3.5} & spotted bass & 2002 & 280 & 257 & 0.368 & \multirow{6}{*}{0.174} \\
\hline \multirow[t]{7}{*}{ West Virginia } & & channel catfish & 2008 & 410 & 372 & 0.041 & \\
\hline & & channel catfish & 2002 & 410 & 441 & 0.138 & \\
\hline & & channel catfish & 2002 & 410 & 387 & 0.193 & \\
\hline & & channel catfish & 2008 & 410 & 313 & 0.079 & \\
\hline & & channel catfish & 2002 & 410 & 492 & 0.225 & \\
\hline & \multirow[t]{2}{*}{3} & bhuegill & 2002 & 150 & 152 & 0.018 & 0.018 \\
\hline & & channel catfish & 2002 & 410 & 437 & 0.148 & \multirow{3}{*}{0.179} \\
\hline Middle Island Creek & 3.5 & channel catfish & 2002 & 410 & 374 & 0.200 & \\
\hline West Virginia & & chamnel catfish & 2002 & 410 & 499 & 0.188 & \\
\hline
\end{tabular}

*outlier

***xcluding outliers
Abbreviations: TL - trophic level; QL - Quality Length; Hg - mercury Mercury measurements in $\mathrm{mg} / \mathrm{kg}$ 


\section{Appendix C}

\section{Legend}

Fish Sampling Station

Water Sampling Station

Streams

Land Cover

Open Water

Developed, Open Space

Developed, Low Intensity

Developed, Medium Intensity

Developed, High Intensity

Barren Land

Deciduous Forest

Evergreen Forest

Mixed Forest

Shrub/Scrub

Grassland/Herbaceous

Pasture Hay

Cultivated Crops

Woody Wetlands

Emergent Herbaceous Wetlands 


\section{LAND COVER MAPS FOR CALIBRATION AND EVALUATION}

BASINS.

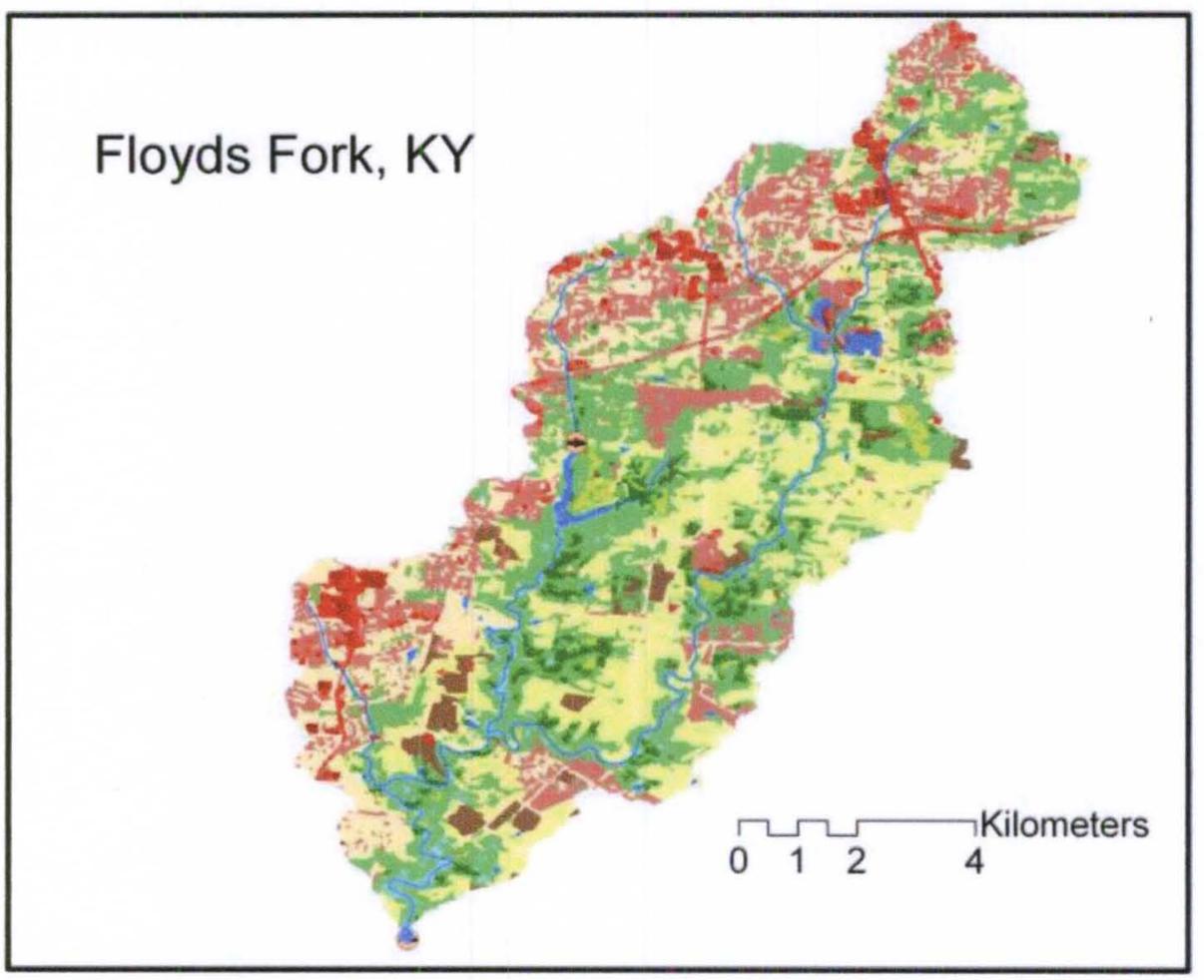



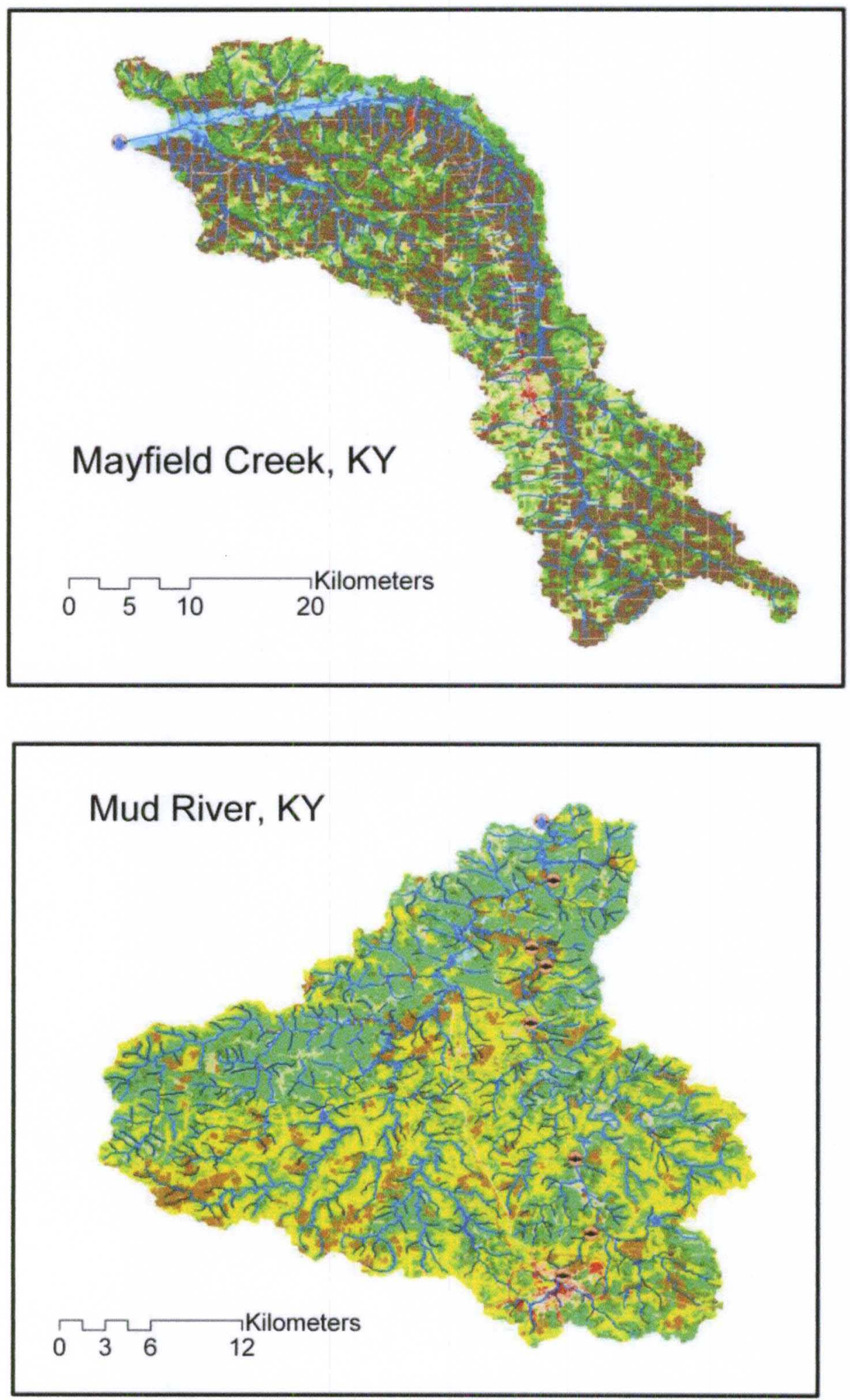

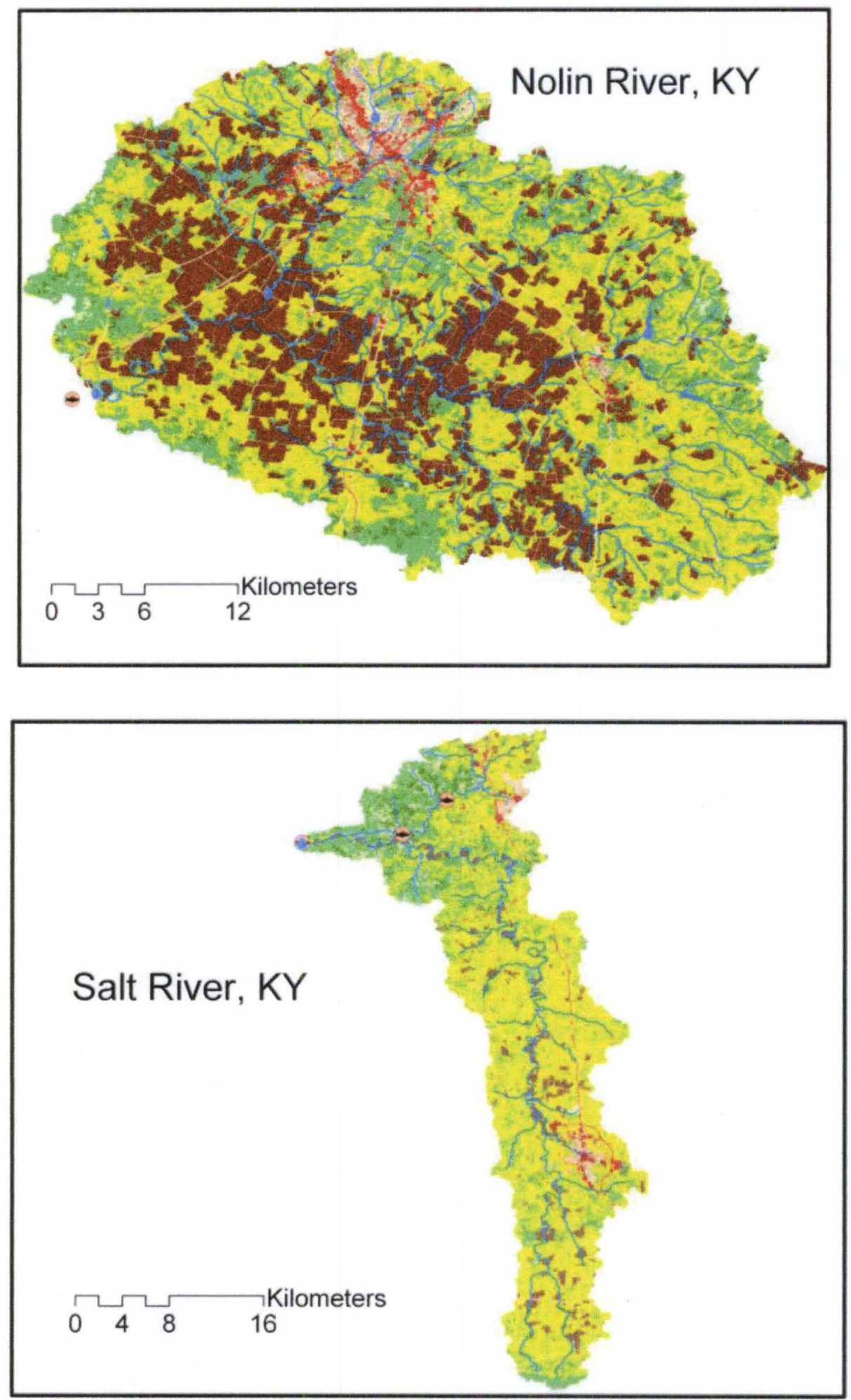



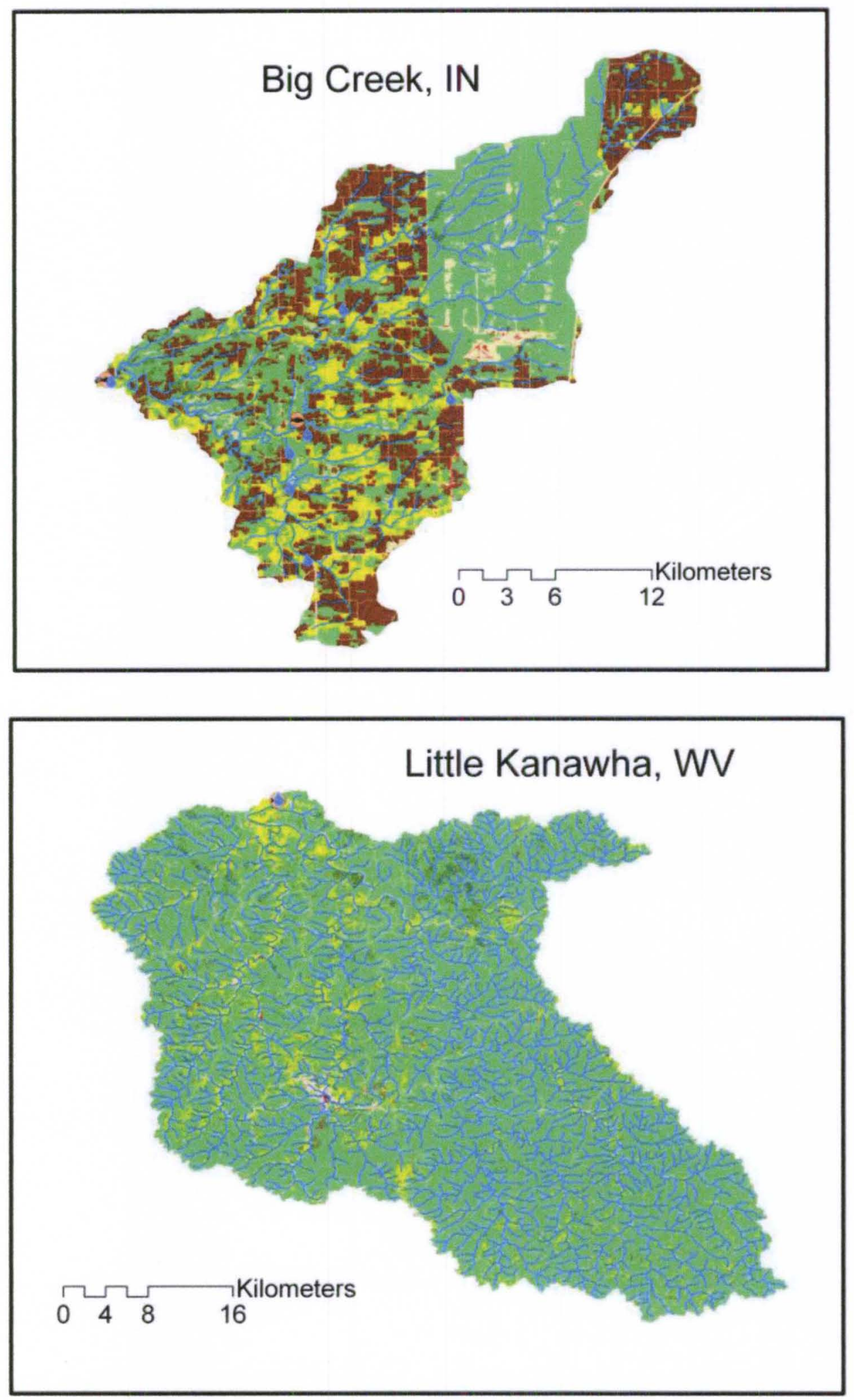



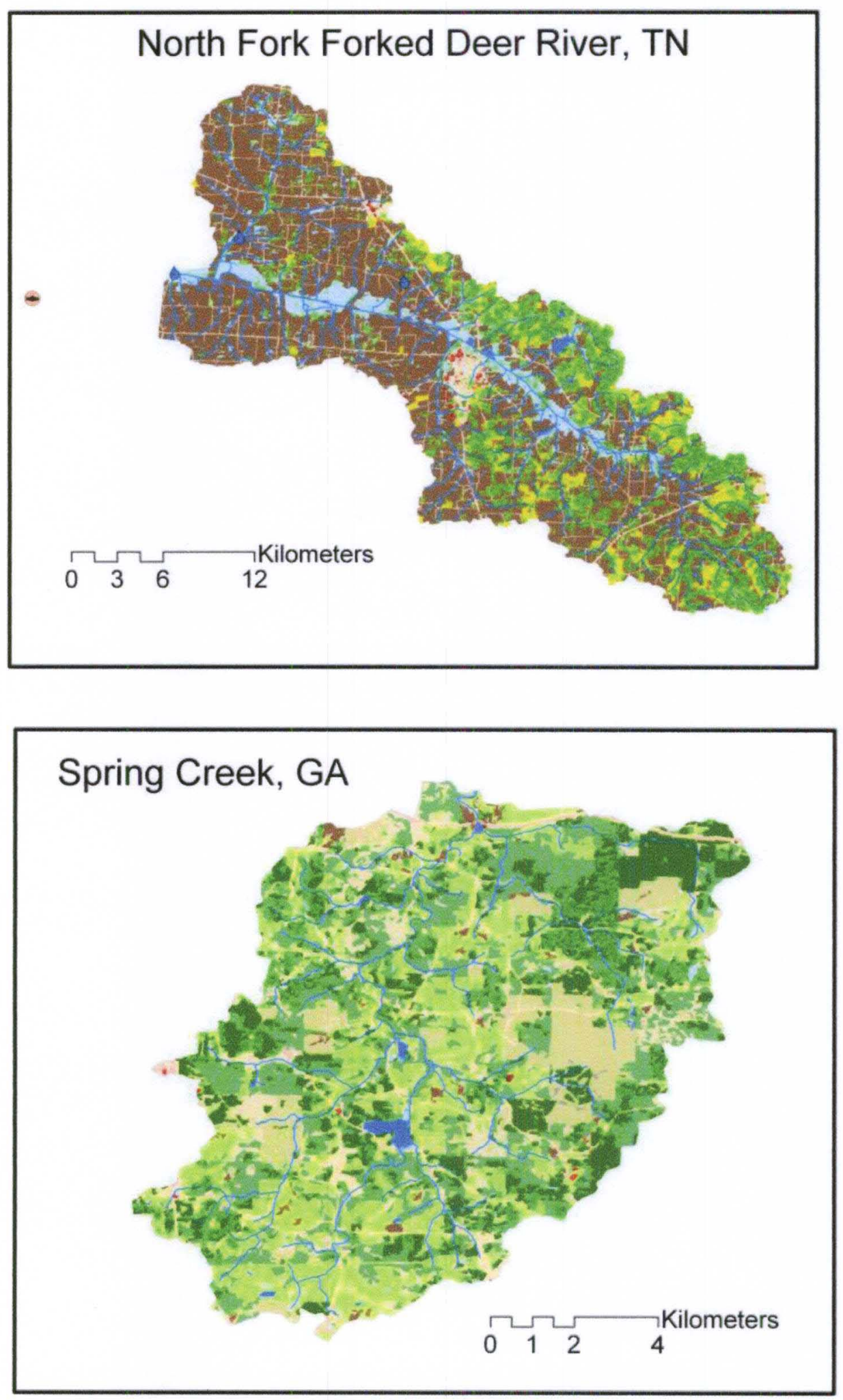
Talking Rock Creek, GA *

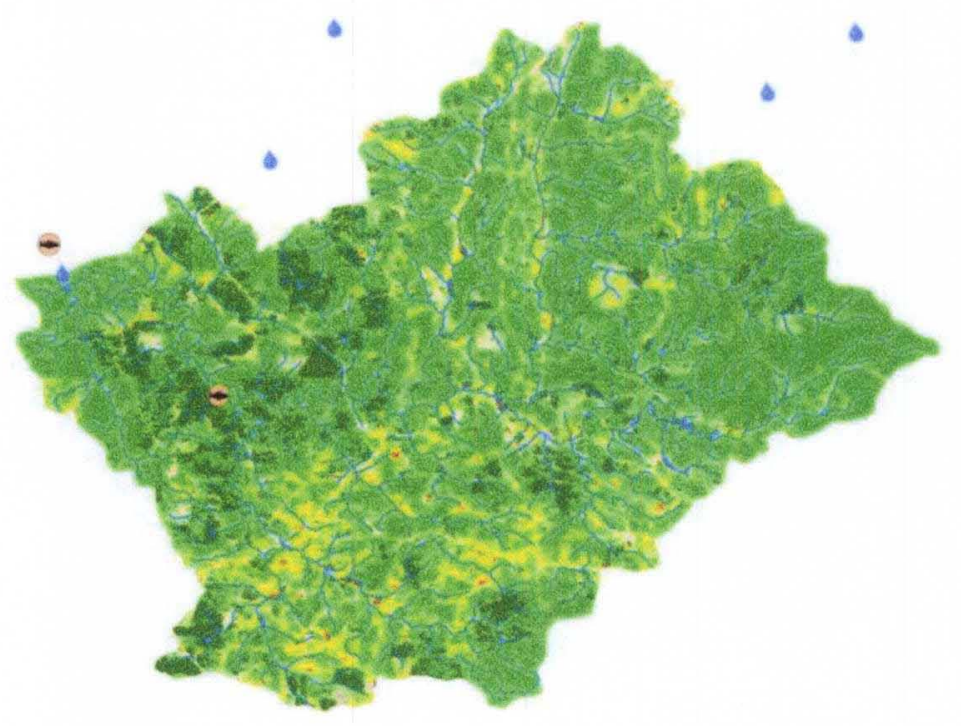

$\sqrt{3} \sqrt{6}$ Kilometers $^{\text {Kilom }}$ 


\section{Appendix D}

\section{PERMISSIONS}

In regards to the following papers:

Chan C, Heinbokel JF, Myers JA, Jacobs RR. 2011. Development and evaluation of a dynamic model that projects population biomarkers of methylmercury exposure from local fish consumption. Integr Environ Assess Manag 7: 624-635.

Chan C, Heinbokel JF, Myers GJ, Jacobs RR. 2012. A dynamic model using monitoring data and watershed characteristics to project fish tissue mercury concentrations in stream systems. Integr Environ Assess Manag (DOI: 10.1002/ieam.1302).

Permission is granted for you to use the material requested for your thesis/dissertation subject to the usual acknowledgements and on the understanding that you will reapply for permission if you wish to distribute or publish your thesis/dissertation commercially.

Permission is granted solely for use in conjunction with the thesis, and the article may not be posted online separately.

Any third party material is expressly excluded from this permission. If any material appears within the article with credit to another source, authorisation from that source must be obtained.

John Wiley \& Sons Ltd. 


\title{
CURRICULUM VITAE
}

\author{
Caroline Biagi Chan \\ 804 Edenwood Circle \\ Louisville, KY 40243
}

\section{Education}

Doctorate of Philosophy in Public Health Sciences - Environmental Health, May 2012

University of Louisville

Master of Public Health, May 2007

University of Louisville

Bachelor of Science: Biology, May 1984

University of Notre Dame

\section{Fellowships}

STAR Fellowship

United States Environmental Protection Agency, 2010-2012

Science to Achieve Results Fellowship, number FP-91711701-0.

Pre-doctoral Trainee

National Institute of Environmental Health Sciences, University of Louisville, 2009-2010

National Institute of Health Sciences-funded Training Program in Environmental Health Sciences, grant number T32-ES011564.

\section{Teaching and Research Experience}

Instructor

University of Louisville, Spring 2011

PHEH 500: Introduction to Environmental and Occupational Health

Teaching Assistantship

University of Louisville, Fall 2010

PHEH 610: Occupational Safety and Health. 
Graduate Teaching Academy

University of Louisville $2010-2011$

Research Assistantship

University of Louisville, 2007-2009

Assisting in a study to determine standardized mortality ratios for an occupational cohort.

Duties include data analysis and manuscript preparation.

Computer Programmer

University of Notre Dame, 1982-1984

Teaching Assistantship

University of Notre Dame, Summer 1983

\section{Honors and Awards}

First Place, Graduate Public Health Student Poster. Research! Louisville. October 2010

Dean's Award (University of Louisville School of Public Health and Information

Sciences), May 2007

Delta Omega, Honorary Society in Public Health, 2008

\section{Membership in Professional Societies}

American Public Health Association, 2007 - present

Society of Environmental Toxicology and Chemistry, 2008 - present

Certification in Public Health by the National Board of Public Health Examiners, 2008

\section{Publications}

Chan C, Heinbokel JF, Myers JA, Jacobs RR. 2012. A dynamic model using monitoring data and watershed characteristics to project fish tissue mercury concentrations in stream systems. Integr Environ Assess Manag in press.

Chan C, Heinbokel JF, Myers JA, Jacobs RR. 2011. Development and evaluation of a dynamic model that projects population biomarkers of methylmercury exposure from local fish consumption. Integr Environ Assess Manag 7: 624-635.

Chan C, Hughes T, Muldoon S, Aldrich T, Rice C, Hornung R, Brion G, Tollerud D. 2010. Mortality patterns among Paducah Gaseous Diffusion Plant Workers. J Occup Environ Med 52: 725-732. 


\section{Presentations}

Oral Presentations

"Creation of a Catalog of Environmental Mercury Databases in Kentucky", Department of Environmental Protection, Frankfort, Kentucky, June 2007

"Creation of a Catalog of Environmental Mercury Databases in Kentucky", Kentucky Water Resources Research Institute Annual Symposium, Lexington, Kentucky, March 2008.

"Water Quality in Public Health", Area Health Education Centers Summer Conference, Mt Vernon, Kentucky, June 2008.

\section{Poster Presentations}

Chan, C., Heinbokel, J., Myers, J., \& Jacobs, J. Calibration and evaluation of a dynamic model that projects population outcomes from methylmercury exposure from local fish consumption, Research! Louisville; October 12, 2010 and American Public Health Association: Social Justice: November 8, 2010.

Chan, C., Hughes, T., Muldoon, S., Aldrich, T., Rice, C., Hornung, R., \& Tollerud, D. Paducah Gaseous Diffusion Plant mortality study: Job title analysis, American Public Health Association: Water and Public Health: the $21^{\text {st }}$ Century Challenge. November 2009.

Chan, C., Jacobs, R., Heinbokel, J., \& Tollerud, D. Building a Dynamic Model Linking Human Exposure to Mercury Emission Regulations, in Environmental Health Sciences Regional Showcase of Fellows. September 2009 and American Public Health Association: Social Justice: November 2010.

Fell, B., Chan, C., Gehrke, T., Heinbokel, J., \& Potash, J. Optimization of Interventions for the Reduction of Morbidity and Mortality from Malaria in Children under Five in Ghana. In Research! Louisville. October 2008.

Chan, C., Muldoon, S., Hughes, T., Aldrich, T., \& Tollerud, D. The Paducah Gaseous Diffusion Plant Occupational Cohort Study: Analysis of Mortality Patterns Associated with Grouped Job Titles. In Research! Louisville. October 2008.

Chan, C., Jacobs, R., Van Arsdall, T., \& Keatley, A. Creation of a Catalog of Environmental Mercury Databases in Kentucky. In American Public Health Association: Public Health Without Borders. October 2008. 